\title{
REGIONAL
}

\section{HEALTH FORUM}

\section{WHO South-East Asia Region}

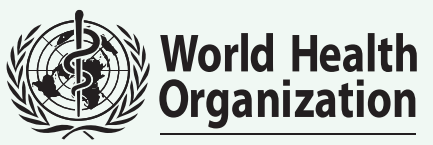

Regional Office for South-East Asia 

Special Issue on World Health Day 2008 theme:

Protecting Health from Climate Change

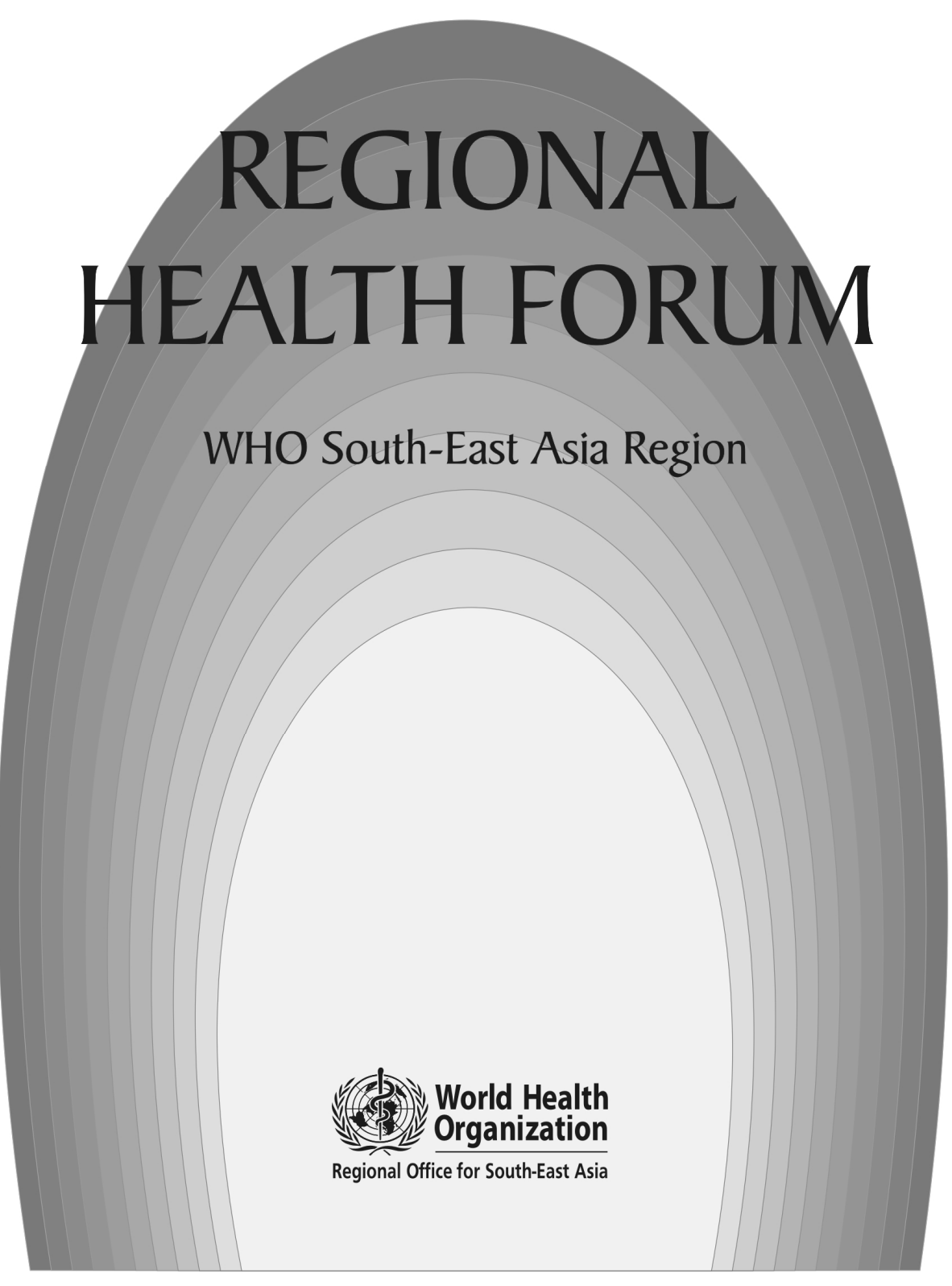


ISSN 10204237

(c) World Health Organization 2008

Publications of the World Health Organization enjoy copyright protection in accordance with the provisions of Protocol 2 of the Universal Copyright Convention. For rights of reproduction or translation, in part or in toto, of publications issued by the WHO Regional Office for SouthEast Asia, application should be made to the Regional Office for South-East Asia, World Health House, Indraprastha Estate, New Delhi 110002 , India.

The designations employed and the presentation of the material in this publication do not imply the expression of any opinion whatsoever on the part of the Secretariat of the World Health Organization concerning the legal status of any country, territory, city or area or of its authorities, or concerning the delimitation of its frontiers or boundaries.

The views expressed in this publication are those of the author(s) and do not necessarily reflect the decisions or stated policy of the World Health Organization; however they focus on issues that have been recognized by the Organization and Member States as being of high priority.

Printed in India 


\section{Editorial}

The most recent report of the 2007 Nobel Peace Prize winner, the "Intergovernmental Panel on Climate Change (IPCC)," says it very clearly: "the global warming-induced climate change is happening, and it is man-made." The challenges posed by climate change are probably the greatest mankind has had to confront. Indeed, all climatic changes projected by the IPCC will impact heavily on natural resources and ecosystems, with grave (direct and indirect) adverse effects on human health. The first article in this Special Issue of the Regional Health Forum (RHF) details the key findings of the IPCC on how climate change will affect the South-East Asia Region. Both authors work with The Energy and Resources Institute, New Delhi, the Director-General of which, Dr Pachauri, is also the Chairman of the IPCC.

Among the most vulnerable people in the context of climate change are those who live in remote places and whose livelihood depends on the natural ecosystems. Such people are the mountain communities living in the Hindu Kush-Himalaya region. The second article focuses on the climate change impacts that are already forcing these populations to abandon their traditional ways of life, thereby driving them into an uncertain future. The authors are senior staff members of the International Centre for Integrated Mountain Development (ICIMOD), which has its headquarters in Kathmandu, Nepal.

Dr Atiq Rahman, one of the United Nations Environment Programme (UNEP) 2007 "Champion of the Earth" award winners for his lifelong work as an environmentalist in Bangladesh, has authored the third article in this RHF issue. His contribution reviews the special vulnerability of Bangladesh, emphasizing the measures that the government and other players have already initiated to adapt to climate change in order to mitigate its adverse health effects.

Three senior scientists of the National Institute of Malaria Research, India present their findings in the fourth article, on how the lifecycle and behaviour of malaria vectors are influenced by changes in climatic determinants. The fifth article also points out significant possible linkages between temperature, humidity and rainfall and the incidence of malaria and kala-azar, but this time in Nepal. Both articles stress the existence of important uncertainties in the capacity to accurately project how climate change will impact on communicable diseases. At the same time, authors of both articles agree that we urgently need to act.

Climate change will have enormous economic and social effects. In the sixth article, the scientists of the National Environmental Engineering Research Institute, Mumbai, India show this by presenting a case study on how climate change will affect the city of Mumbai.

An important health impact from climate change will be its influence on mental health of the affected populations. Indeed, more frequent and more intense extreme-weather events would trigger migration processes that could lead to loss of livelihoods and create tensions, with major psychosocial consequences. This issue is discussed in the seventh article.

Maldives is one of the most vulnerable countries of our Region: it is threatened by sealevel rise and by the loss of drinking water reserves and food sources. The last article in this Special Issue presents the views of the Ministry of Health, Maldives on how the country is getting ready to address these major challenges. 



\section{Contents}

\section{Climate change and human health}

Protecting human health from climate change - some key findings from the Fourth Assessment Report of the Intergovernmental Panel on Climate Change

Andy Reisinger and Nitish K. Dogra

How does climate change affect human health in the Hindu Kush-Himalaya region?

Mats Eriksson, Jing Fang and Julie Dekens

Climate change and its impact on health in Bangladesh

Atiq Rahman

Climate change and malaria in India: Interplay between

temperatures and mosquitoes

Ramesh C. Dhiman, Sharmila Pahwa and Aditya P. Dash

Climatic determinants of malaria and kala-azar in Nepal

Sagar Dahal

Economic impact of climate change on Mumbai, India

Rakesh Kumar, Parag Jawale and Shalini Tandon

Climate change and mental health

Prabhat Kumar Chand and Pratima Murthy

Adaptation measures for human health in response to climate change in Maldives

Dr Sheena Moosa

\section{Opinion}

Indonesia's vulnerability to climate change: An increasing trend

Tom Staringa

\section{Comment}

Notes and news

Publications corner 



\title{
Climate change and human health
}

\section{Protecting human health from climate change - some key findings from the Fourth Assessment Report of the Intergovernmental Panel on Climate Change}

\author{
Andy Reisinger* and Nitish K. Dogra*十
}

\begin{abstract}
This paper summarizes some of the main findings arising from the Fourth Assessment Report of the Intergovernmental Panel on Climate Change (IPCC) related to the protection of human health in a changing climate. The paper first discusses observed and projected changes in climate and their likely impacts on human health with the focus on South and South-East Asia, followed by a summary of key issues for adaptation, including field experiences of conducting climate-related health research. It also gives a brief overview of options to reduce greenhouse gas emissions; adaptation and mitigation measures to protect human health from climate change; and linkages of these measures with broader sustainable development objectives.
\end{abstract}

\section{Introduction}

The IPCC carries out regular assessments of the scientific knowledge of the causes, observations and projections of climate change and its likely impacts, and of options to adapt to those changes and to reduce greenhouse gas (GHG) emissions. The Fourth Assessment Report (AR4) was completed in 2007 and represents the most comprehensive report of current knowledge.

The findings from the AR4 are of particular relevance to public health researchers and policy-makers as they represent increased knowledge about the potential impacts of climate change on human health, as well as improved understanding of the broader linkages between climate change and development issues. References in this article exclusively

*The Energy and Resources Institute, New Delhi, India

†E-mail: nitish@teri.res.in point to specific chapters and summaries from the IPCC AR4; additional primary literature references may be found in relevant chapters of the cited IPCC reports.'

\section{Observed changes in climate, their causes and effects}

The recent IPCC assessment (IPCC, 2007) concludes that evidence on warming of the climate system is unequivocal. This strong finding is based on multiple strands of evidence such as increases in global average surface temperature (about $0.74{ }^{\circ} \mathrm{C}$ over the past 100 years), rising global average sea level from thermal expansion of the oceans and melting of ice and snow, and concurrent decreases in the Northern Hemisphere snow cover. These observations are summarized in

\footnotetext{
1 The entire IPCC AR4 is available on the Internet at www.ipcc.ch.
} 
Figure 1. Precipitation patterns have also changed, with increases in many high-latitude regions including parts of Central Asia, and decreases in many already dry mid-latitude and subtropical land regions, including parts of South Asia.

Significant changes have been observed in the frequency and/or intensity of some weather and climate extremes, including a very likely ${ }^{2}$ increase in the number and severity of hot days and heat waves and decrease in cold days, and a likely global increase in the area affected by drought, but also a concurrent increase in the frequency of heavy rainfall. There is evidence of increase in intense tropical cyclone activity in the North Atlantic since 1970, and possibly in some other regions where concerns about data quality are greater, but no increase in the overall global number of tropical cyclones (IPCC, 2007).

These observed climate changes have already affected many natural systems on all continents and most oceans (IPCC, 2007). Examples include ground instability from melting ice, enlargement of glacial lakes linked with recession of glaciers, and earlier spring peak discharge in many glacier- and snow-fed rivers. Higher temperatures have affected many marine and terrestrial ecosystems, including changes in bird migration and timing of spring events. In more than $89 \%$ cases, the observed effects are consistent with the effect expected from rising temperatures. However, there is a notable lack of balance in the literature on observed effects. Most studies come from Europe with far fewer studies from developing countries, including those in the South and South-East Asia regions.

\footnotetext{
${ }^{2}$ Consistent with their use in the IPCC, the expressions "likely" and "very likely" represent calibrated expressions of uncertainty. "Very likely" indicates an assessed probability of $90 \%$ or greater of a statement being true, while "likely" indicates a probability of $66 \%$ or greater of being true. These probability estimates are based on statistical analyses of data along with expert judgements of the completeness and robustness of data and model results.
}

Figure 1: Observed changes in (a) global average surface temperature; (b) global average sea level from tide gauge (blue) and satellite (red) data and (c) Northern Hemisphere snow cover for March-April

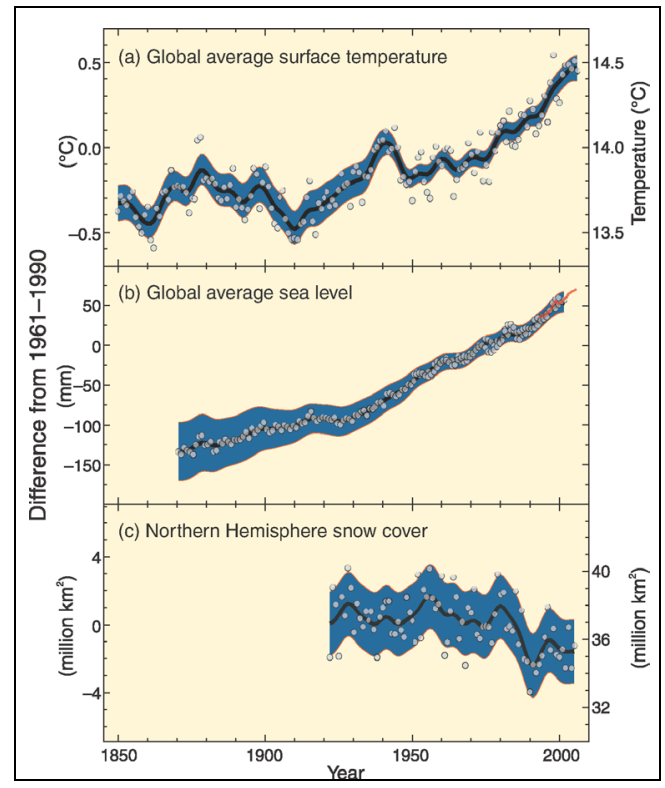

[All differences are relative to corresponding averages for the period 1961-1990. Smoothed curves represent decadal averaged values while circles show yearly values. The shaded areas are the uncertainty intervals estimated from a comprehensive analysis of known uncertainties ( $a$ ) and (b) and from the time series (c). (Source: IPCC, 2007)]

The effects of recent climate change on human systems are also emerging, but are more difficult to detect due to adaptation and non-climatic drivers. Documented effects on human health include excess heat-related mortality in Europe, changes in infectious disease vectors in parts of Europe, and earlier onset of and increases in seasonal production of allergenic pollen in Northern Hemisphere's high and mid-latitudes (IPCC, 2007). Lack of consistent long-term datasets related to human health and climate and rapid socioeconomic changes make it more difficult to draw quantitative conclusions on the effects of recent climate changes on human health in developing countries, but some relevant data exist e.g. on the effect of heat waves on mortality in the Indian subcontinent (Confalonieri et al., 2007). 
Improved understanding of the climate system allows the conclusion that most of the observed increase in global average temperature over the past 50 years is very likely due to the increase in GHG concentrations. GHG emissions from human activities have risen significantly since preindustrial times, with an increase of as much as $70 \%$ in the period from 1970 to 2004 alone. The concentration of the most important greenhouse gas - carbon dioxide $\left(\mathrm{CO}_{2}\right)$ - is now higher than at any time during the past 650000 years, mostly due to fossil fuel burning and, to a lesser but also significant extent, deforestation (IPCC, 2007).

However, not all of the recently observed climate and weather extremes can necessarily be attributed to human-induced global climate change. At regional and local scales, natural climate variability is relatively larger than at the global scale (IPCC, 2007) and may for a limited time either enhance or counterbalance the long-term warming trend. For example, the unusually cold winter during 2007-2008 in parts of South and East Asia is not inconsistent with the global long-term warming trend. It simply reconfirms that at the regional scale, short-term natural climate variability will continue to play an important role, in particular for human health issues, in addition to the underlying warming trend.

\section{Projections of future climate change}

Advances in climate modelling and understanding of climate processes now allow best estimates and likely uncertainty ranges to be given for changes in climate at the end of the Twenty-first century, as shown in Figure 2 (IPCC, 2007).

Future changes in climate necessarily depend on scenarios of future GHG emissions. The lowest scenario that assumes no additional climate policies (B1 in Figure 2) suggests that global GHG emissions could naturally peak by the middle of the century and then decline due to the advance of clean technologies and energy efficiency. Even this optimistic scenario leads to a warming of about $1.8^{\circ} \mathrm{C}$ by the 2090 s relative to the 1980-1999 average (about $2.3^{\circ} \mathrm{C}$ above pre-industrial temperatures). Significant and sustained additional global GHG emission reductions would be required within the next few decades if the increase in global average temperature over the Twenty-first century were to be kept below these warming ranges (IPCC, 2007).

Along with changes in global average temperature, further increases in hot days and heat waves, heavy precipitation and tropical cyclone intensity are expected (IPCC, 2007). For the South and South-East Asia regions, precipitation and run-off are projected to increase in the annual average, but with significant seasonal differences. In many parts of the region, precipitation is projected to decrease during the dry season but increase during the wet season, leading to an increased risk of flooding during heavy monsoon rains but reduced water availability during the dry season. These changing precipitation patterns, along with rising temperatures and increased risk of drought, are expected to negatively affect crop yields particularly in South Asia (Cruz et al., 2007).

The sea level is projected to rise by about 20 to 60 centimetres $(\mathrm{cm})$ by 2100, but additional contributions from melting ice sheets (Greenland and Antarctica) cannot be ruled out. Sea-level rise would especially affect Asian megadeltas, where large populations face high exposure to sea-level rise, storm surges and river flooding. Sealevel rise is expected to continue for many more centuries in a warmer climate and could reach several metres over the scale of a millennium, depending on the level at which GHG concentrations are stabilized (IPCC, 2007). 
Figure 2: Leff Panel: Scenarios of global $\mathrm{GHG}$ emissions (in gigatonne ${ }^{\#}\left(\mathrm{Gt}_{1} \mathrm{CO}_{2}\right.$-eq) in the absence of climate policies; coloured lines indicate the six marker scenarios from the IPCC Special Report on Emissions Scenarios (SRES: IPCC, 2000); the gray shaded area and dashed lines show the $80^{\text {th }}$ percentile and full range of scenarios published since 2000 . Emissions include $\mathrm{CO}_{2}$ methane $\left(\mathrm{CH}_{4}\right)$, nitrous oxide $\left(\mathrm{N}_{2} \mathrm{O}\right)$ and fluorinated gases. Right Panel: Solid lines are multi-model global averages of surface warming for emissions scenarios $A 2, A I B$ and $B I$, shown as continuations of the Twentieth century simulations, also taking into account emissions of shortlived GHGs and aerosols. The bars at the right of the figure indicate best estimates (solid line within each bar) and likely ranges (uncertainty estimates) for each of the six SRES marker scenarios for 2090-2099. All temperatures are relative to 1980-1999 (Adapted from IPCC, 2007)

${ }^{*} 1$ gigatonne $=1000$ tonnes
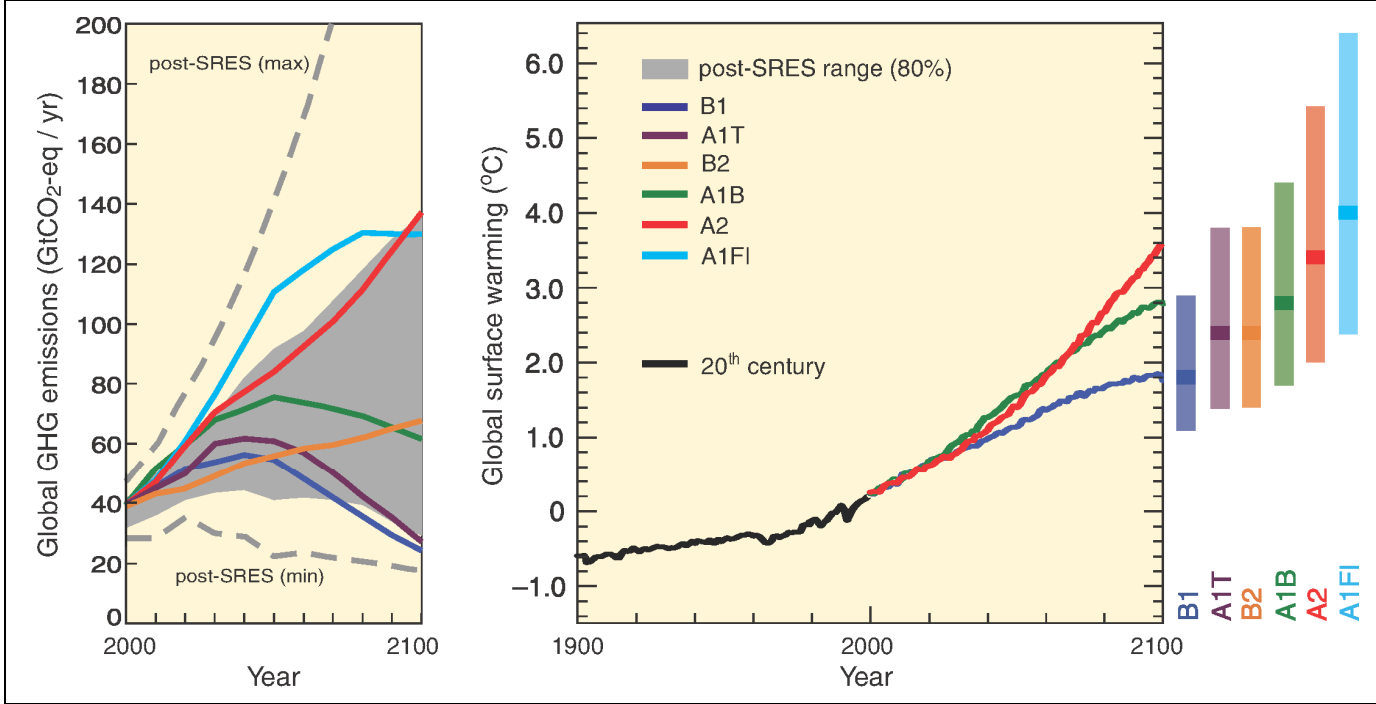

\section{Health impacts of projected climate changes}

The health of millions of people globally is projected to be affected through changes in climate discussed above. In the South and South-East Asia regions, some of the key changes and projected health impacts include (IPCC, 2007; Confalonieri et al., 2007):

- Increase in the number and severity of heat waves contribute to premature deaths from heat stress and exacerbate respiratory diseases and cardiovascular illnesses related to increased ground-level ozone in urban areas; most affected would be children, the elderly and chronically sick persons.
- Change in average temperatures and rainfall patterns affect the distribution of infectious disease vectors such as malaria and dengue; specific outcomes would vary locally since reduced rainfall could also reduce mosquito-breeding ranges.

- Increase in heavy-precipitation events increase the risk of water- and foodborne diseases, diarrhoea and cholera, including through disruption of waste disposal systems; during episodes of severe flooding, there would also be increased direct risk of injuries and death.

- Increased drought risk could lead to more frequent crop failures, increasing the risk of malnutrition especially for poor children, and to 
heightened emotional stress and community tensions in droughtaffected areas.

- Increases in tropical cyclone intensity bring increased risk to human life, property and public infrastructure, and increase post-traumatic stress disorders.

- Sea-level rise, where combined with extreme events such as storms and floods, poses challenges to livelihoods particularly of poorly protected low-lying settlements and farm land; in the longer term, sealevel rise could force significant relocation of populations with attendant stresses on community cohesion and well-being.

The specific impacts and numbers of people affected will depend not only on future climate change but also on socioeconomic development and specific factors that directly shape the health of populations. These include education, health care systems, public health initiatives, infrastructure and economic development, and the ability of these factors to respond to the changing pressures of a changing climate (IPCC, 2007). Figure 3 shows these links schematically.

Figure 3: Schematic diagram of pathways by which climate change affects health, and concurrent direct-acting and modifying (conditioning) influences of environmental, social and health-system factors

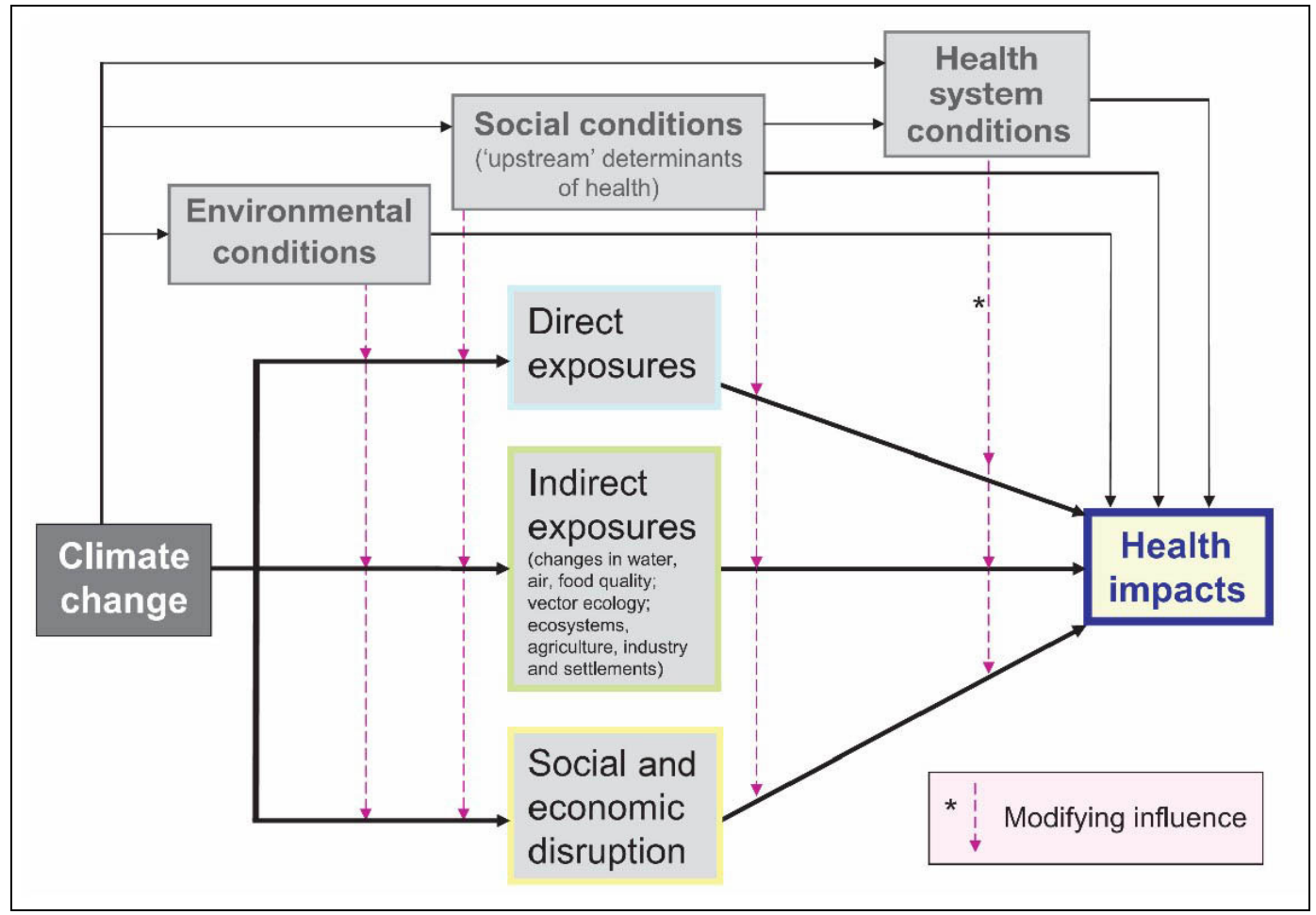

(Source: Confalonieri et al., 2007) 
Globally, not all effects of climate change on human health are projected to be negative. For example, higher winter temperatures are expected to reduce winter illness and mortality in temperate areas. However, negative health effects are on balance expected to outweigh benefits especially in developing countries, including South and South-East Asia (IPCC, 2007).

\section{Protecting human health from climate change - adaptation}

The most direct response to changing health risks arising from climate change consists of adaptation measures that reduce vulnerability and increase resilience of populations that are likely to be the most affected. Such measures are generally most effective if they are embedded in broader development plans, e.g. safe water supplies and waste disposal systems, sustainable food supplies, disease surveillance and response programmes, agricultural diversification and disaster and emergency risk-reduction and response systems. While the primary drivers behind such development plans usually are socioeconomic pressures and expectations, the ability of such programmes to deliver the expected outcomes may well depend on the degree to which they can cope with and are prepared for the additional pressures posed by a changing climate (IPCC, 2007; Confalonieri et al., 2007; Adger et al., 2007; Yohe et al., 2007).

Implementation of effective response measures may require action at a range of scales, from international aid to national policies and local community responses. Early warning systems underpin many adaptation efforts (IPCC, 2007d); these can range from disease and vector surveillance systems to short-term warnings about heat waves or flood risk, and to seasonal forecasts of drought risk under El-Niño conditions. However, such surveillance and warning systems need to be coupled to dissemination of information in a way that is suitable for target populations, and be linked to response programmes (Confalonieri et al., 2007).

Many adaptations to projected climate change would also strengthen the resilience to current climate variability, and reduce suboptimal adaptation to current climate conditions and health risks. For example, improved control of mosquito breeding sites, use of mosquito nets, water purification and supply systems and crop diversification could have vital co-benefits in many regions even in the absence of climate change. On the other hand, efforts to adapt to climate change are unlikely to be successful or even be a priority where governance structures, information and decision-making systems and available resources cannot even cope well with current climate conditions. In these situations, broader sustainable development programmes may be needed to enhance the fundamental capacity to adapt to climate change and multiple other pressures (Yohe et al., 2007).

The recent climatic extremes and their consequences for public health demonstrated that even countries with a high adaptive capacity remain vulnerable to the adverse impacts of climate extremes, and that vulnerability to climate change impacts is highly unevenly distributed even within societies. The European heat wave of 2003 caused several tens of thousands of deaths and affected mainly the elderly population within a generally affluent society. Hurricane Katrina that hit New Orleans, United States of America, in 2005 caused significant damage and loss of life despite excellent early warning systems and technical reports outlining the potential impacts (IPCC, 2007; Confalonieri et al., 2007; Wilbanks et al., 2007). Although these events cannot be attributed to human-induced climate change, they show that effective adaptation requires effective governance and implementation systems, as well as financial and technical capacity. For developing countries, availability of resources 
and building adaptive capacity, which enable the effective integration of climate-change risks into broader development plans and governance systems, appear to be particularly important [IPCC, 2007(b)].

\section{Notes from the field}

The Tata Energy Research Institute (TERI), New Delhi conducted a brief exploratory study in relation to the impact of climate change on diarrhoeal diseases at a site in North 24 Parganas district in West Bengal, eastern India. Several key points emerged from the study which could be relevant when conducting environmental epidemiology studies related to climate change in resource-constrained settings in South-East Asia:

- Adequate resources for judicious site selection along with verification of primary health centre including the register with daily data on cases of diarrhoea;

- Selection of site close to the monitoring station for validity of meteorological data;

- Household survey to focus on socioeconomic status, nutrition, sanitation, breastfeeding practices, household water purification, personal hygiene, household management of diarrhoea and health service access/utilization;

- Microbiological assessment at field site possibly with experimental work;

- River level as well as water quality- and quantity-related data obtained from a water resources authority as well as from the Public Health Engineering department;

- Detailed information of extreme events, land and water use pattern and agriculture data;

- Management methods, such as health facility inventorization, supply chain and logistics;

- Remote sensing and geographic information system (GIS) techniques;

- Extensive "focus group" discussion and "key informant" interview required, such as for inclusion of private health services; and

- Social science research tools and techniques to capture climate resilience, vulnerability and adaptation.

\section{Protecting human health from climate change - mitigation ${ }^{3}$}

It is likely that unmitigated climate change would eventually exceed the capacity of natural and human systems to adapt, both due

\footnotetext{
3 In the context of climate change, the term 'mitigation' generally refers to the reduction of GHG emissions that are the primary cause for human-induced climate change, while adaptation covers efforts to reduce the impact of changes through increasing resilience or specific-response strategies.
}

to increasing costs of adaptation and because adaptation cannot avoid all damages, particularly for the most vulnerable groups [IPCC, 2007(b); Yohe et al., 2007]. Consequently, reducing the rate and amount of climate change itself through reducing global GHG emissions form a vital part of protecting human health from climate change.

The recent IPCC assessment has shown that there is significant economic potential for reduction of GHG emissions. This potential is sufficient to offset the projected further growth 
in global emissions or even to reduce emissions below current levels by 2030. The cost of emission reduction ranges from "net negative" (i.e. where the benefits of increased energy efficiency outweigh costs) up to US\$ 100 per tonne of $\mathrm{CO}_{2}$-equivalent. However, this reduction potential can only be realized if appropriate policies and measures are in place to stimulate the development and uptake of relevant low-carbon technologies and practices, and to overcome market, social and cultural barriers [IPCC, 2007(c)].

The largest potential to reduce GHG emissions at low or even "net negative" costs comes from the building sector. Energy efficiency measures, including efficient lighting, natural cooling functions, thermal insulation and use of solar energy for space and water heating, present opportunities to reduce energy consumption and associated GHG gas emissions, but generally require active government policies and measures to turn them into a reality. Due to the long life of buildings, urban design choices can affect residential energy demand for many decades into the future, including the demand for additional summer cooling in response to rising temperatures (Levine et al., 2007; Wilbanks et al., 2007).

Other mitigation options include lowcarbon energy supply from a range of possible sources (renewables, nuclear, clean-coal technologies, biomass) as well as improved energy efficiency in industrial processes. Relevant energy infrastructure investments will have long-term impacts on GHG emissions due to the long life of energy plants and other infrastructure capital stock [IPCC, 2007(c)].

\section{Synergies of adaptation and mitigation measures with sustainable development}

Responding to climate change has important links with other aspects of sustainable development. The reduction of GHG emissions offers important co-benefits through reduced air pollution, which can offset a substantial fraction of mitigation costs. Fuelswitching for home heating and cooking could in many developing countries also reduce the workload for women and children, who are often at the forefront of fuel wood gathering, and could reduce the depletion of natural resources [IPCC, 2007(c), 2007(d)].

Development of renewable energy resources can also make significant contributions to a country's energy security as well as facilitate energy access in rural areas through the use of solar energy or energy from agricultural waste. Bio-energy can have multiple local co-benefits but requires careful management to avoid negative impacts on biodiversity and food security [IPCC, 2007(c)].

Emission reductions come not only from technological opportunities, but behaviour changes and management practices can also make a difference [IPCC, 2007(c)]. For example, alternatives to individual motorized transport could reduce rapidly-growing GHG emissions while providing important health cobenefits. Walking, cycling or use of public transport could counteract many illnesses linked to increasingly sedentary lifestyles. However, such forms of transport generally have little appeal to increasingly affluent urban populations without clear and sustained government support for safe cycling and walking options in urban areas, and clean, reliable and accessible forms of public transport.

Broader development initiatives can also reduce vulnerability to climate change through, for example, strengthened governance, decision-making and information systems, and through changing development pathways into less carbon-intensive directions [IPCC, 2007(b), 2007(c)]. Until recently few plans for promoting sustainability had explicitly considered climate change impacts or opportunities for emission reductions (Yohe et al., 2007), although some promising initiatives are beginning to emerge. 


\section{Conclusions and directions for future research}

The discussion in this article has shown that linkages between climate change and human health are complex and multi-layered. Rather than being a constraint, this may also be seen as a positive signal that indeed many complementary opportunities and approaches exist to contribute to the protection of human health from the negative impacts of climate change through adaptation, mitigation and broader sustainable development initiatives. On the other hand, failure to address climate change issues in the development of health policies and their implementation could jeopardize the achievement of fundamental development goals due to the increasing pressures generated by a changing climate [Confalonieri et al., 2007; Yohe et al., 2007; IPCC, 2007(d)].

Based on the findings of the recent IPCC assessment and the perspectives offered in this article, some research issues appear to be particularly relevant to allow more effective responses to climate change in the

\section{References}

Adger WN, Agrawala S, Mirza MMQ, Conde C, O'Brien K, Pulhin J, Pulwarty R, Smit B, Takahashi K, 2007. Assessment of adaptation practices, options, constraints and capacity. In: Climate change 2007: impacts, adaptation and vulnerability. Contribution of Working Group II to the Fourth Assessment Report of the Intergovernmental Panel on Climate Change. [ML Parry, OF Canziani, JP Palutikof, PJ van der Linden, CE Hanson. Eds. Cambridge: Cambridge University Press. pp. 717-43.

Confalonieri U, Menne B, Akhtar R, Ebi KL, Hauengue $M$, Kovats RS, Revich B, Woodward A. Human health 2007. In: Climate change 2007: impacts, adaptation and vulnerability. Contribution of Working Group II to the Fourth Assessment Report of the Intergovernmental Panel on Climate Change. ML Parry, OF Canziani, JP Palutikof, PJ van der Linden, CE Hanson. Eds. Cambridge: Cambridge University Press. pp. 391-431.

Cruz RV, Harasawa H, Lal M, Wu S, Anokhin Y, Punsalmaa B, Honda Y, Jafari M, Li C, Huu Ninh N. health sector. These include systematic observations of climate variables and their correlated impacts on public health, in order to generate reliable baselines and to enhance networks on which early warning systems rely. Such observations would also help to further develop our understanding of the statistical linkages between climate and public health and improve health-impact models, and to identify the most effective and highest-priority adaptation interventions. Such work might also help to increase resilience and reduce vulnerability to current climatic conditions.

\section{Acknowledgements}

Most of the material in this article, including some of its wording, is based on the Fourth Assessment Report of the IPCC. Permission to reproduce some of the figures from the IPCC reports is gratefully acknowledged. The authors also thank Chris Galvin and Isabelle Richaud (TERI) for suggestions to improve an earlier draft of this paper. All remaining judgements and responsibility for any mistakes remain those of the authors.

Asia, 2007. In: Climate change 2007: impacts, adaptation and vulnerability. In: Climate change 2007: impacts, adaptation and vulnerability. Contribution of Working Group II to the Fourth Assessment Report of the Intergovernmental Panel on Climate Change. ML Parry, OF Canziani, JP Palutikof, PJ van der Linden, CE Hanson. Eds. Cambridge: Cambridge University Press, pp. 469-506.

IPCC 2000. Special report on emissions scenarios. A Special Report of Working Group III of the Intergovernmental Panel on Climate Change Nakičenovič, N. and R. Swart. Eds. Cambridge: Cambridge University Press.

IPCC 2007. Summary for policymakers. In: Climate change 2007: the physical science basis. Contribution of Working Group I to the Fourth Assessment Report of the Intergovernmental Panel on Climate Change. Solomon S, Qin D, Manning M, Chen Z, Marquis M, Averyt KB, Tignor M, Miller HL. Eds. Cambridge: Cambridge University Press. pp. 1-18 
IPCC 2007. Summary for policymakers. In: Climate change 2007: impacts, adaptation and vulnerability. Contribution of Working Group II to the Fourth

Assessment Report of the Intergovernmental Panel on Climate Change. Parry ML, Canziani OF, Palutikof JP, van der Linden PJ, Hanson CE. Eds. Cambridge: Cambridge University Press. pp. 1-22

IPCC 2007. Summary for policymakers. In: Climate change 2007: mitigation. Contribution of Working Group III to the Fourth Assessment Report of the Intergovernmental Panel on Climate Change Metz B, Davidson OR, Bosch PR, Dave R, Meyer LA. Eds. Cambridge: Cambridge University Press. pp. 1-23.

IPCC 2007. Climate change 2007: synthesis report. Contribution of Working Groups I, II and III to the Fourth Assessment Report of the Intergovernmental Panel on Climate Change. Core Writing Team, Pachauri RK, Reisinger A. Eds. Geneva: Intergovernmental Panel on Climate Change.

Levine M, Ürge-Vorsatz D, Blok K, Geng L, Harvey D, Lang S, G. 2007. Levermore, Mongameli Mehlwana A, Mirasgedis S, Novikova A, Rilling J, Yoshino H.

Residential and commercial buildings. In: Climate change 2007: mitigation. Contribution of Working Group III to the Fourth Assessment Report of the Intergovernmental Panel on Climate Change. Metz B, Davidson OR, Bosch PR, Dave R, Meyer LA. Eds.

Cambridge: Cambridge University Press. pp. 388-445.

Wilbanks TJ, Romero Lankao P, Bao M, Berkhout F, Cairncross S, Ceron JP, Kapshe M, Muir-Wood R, Zapata-Marti R 2007. Industry, settlement and society. In: Climate change 2007: impacts, adaptation and vulnerability. Contribution of Working Group II to the Fourth Assessment Report of the Intergovernmental Panel on Climate Change. Parry ML, Canziani OP, Palutikof JP, van der Linden PJ, Hanson CE. Eds. Cambridge: Cambridge University Press. pp. 357-390.

Yohe GW, Lasco R.D, Ahmad QK, Arnell NW, Cohen SJ, Hope C, Janetos AC, Perez RT, 2007. Perspectives on climate change and sustainability. In: Climate change 2007: impacts, adaptation and vulnerability. Contribution of Working Group II to the Fourth Assessment Report of the Intergovernmental Panel on Climate Change. Parry ML, Canziani OF, Palutikof JP, van der Linden PJ, Hanson CE. Eds. Cambridge: Cambridge University Press. pp. 811-841. 


\title{
How does climate change affect human health in the Hindu Kush-Himalaya region?
}

\author{
Mats Eriksson*, Jing Fang* and Julie Dekens*
}

\section{Introduction}

Poor people in mountain regions have made the least contribution to climate change in terms of carbon emission; however, they will suffer disproportionately from the negative impact of climate change. The temperature increase in the Himalayan region has been greater than the global average of $0.74{ }^{\circ} \mathrm{C}$ over the last 100 years (IPCC 2007; Du et al., 2004). The higher the altitude the more rapid the warming, which also can be noted in temperature records from e.g. Nepal (Shrestha et al., 1999) and China (Liu and Chen, 2000). This ongoing rapid warming has a profound effect on the Himalayan environment, may be most visible in the rapid retreat of Himalayan glaciers and diminishing snow fields (Dyurgerov and Meier 2005). The annual melting of glacial ice provides important water resources for downstream population and ecosystems, particularly in arid areas of the Himalayas and during the critical seasonal dry periods. The supply of water resources, or the snow-and-ice-melt water component, is projected to increase in the coming decades as the perennial covering of snow and ice decreases. However on a longer-term scale, water scarcity, particularly during the dry season is likely to be a future challenge.

* International Centre for Integrated Mountain Development (ICIMOD), Kathmandu, Nepal
Rising temperatures are also affecting the permafrost layer in the Himalayas and in the Tibetan plateau (China). The deterioration of the permafrost layer will have impacts on slope stability, erosion processes, hydrology and the ecology, with subsequent implications for people depending on these areas for their livelihoods. Furthermore, the increased temperature in air masses means that there will be more energy in the meteohydrological system, which in turn will generate impact on precipitation. Some predictions indicate that this will result in rainfall increase, particularly during the wet monsoon, while the dry monsoon might become even drier. It is also anticipated that increased precipitation will result largely in a higher frequency and magnitude of "high intense" rainfall events, with a potential to cause water-induced disasters like flash floods, landslides and debris flows. In the eastern and central Himalayas, retreat of glacier tongues has led to the formation of glacial lakes behind terminal moraines, causing great concern. Many of these highaltitude lakes are potentially dangerous. The moraine dams are often instable and can break suddenly, leading to catastrophic discharge of huge volumes of water and debris. The resulting glacial lake outburst flood (GLOF) can cause damage to life, property, forests, farms and infrastructure. In Nepal alone, 25 GLOF events have been recorded during the last 70 years. 
The above-mentioned indication of ongoing changes in the Himalayan climate and their likely subsequent effect on the environment, particularly on water resources, will have a profound impact on human society, and on its well-being and health. The full impact of these changes is still to be determined, but they definitely call for developing enhanced adaptation and mitigation mechanisms.

\section{Drivers of change that influence human health}

We are living in a world of rapid changes. Many different factors work together and produce an impact on human health. Such an impact will be greater in mountain areas, where people are more vulnerable, more isolated and lack access to many public services that people in lowlands often take for granted. Climate change is only one of the driving forces. There also are other drivers of change that affect human society and health. Many of those drivers are human-induced, such as economic development, population growth, globalization and regionalization. In many cases, the impact caused by multiple drivers is leading to changes in land use, migration, urbanization, and to changes in gender roles and division of labour. An example of the latter is the feminization of the countryside of Nepal. In the Himalayan region, all of these external drivers will have a profound impact on people's well-being and health. We should not look at impact from climate change in isolation, but acknowledge the multiple drivers and employ a multihazard approach. It is now our task to try to understand the subsequent implications of these drivers, and to promote a sound response by developing a strategy of adaptation and mitigation. In most cases, this does not mean invention of new practices and methods, but identification of coping strategies that have been part of people's lives for centuries or longer. The question though is if such traditional strategies are robust enough to cope with the current rapid pace of change, or if people have to develop new adaptive mechanisms.

\section{"Rapid"- and "slow-onset" hazards as effects of climate change}

One of the most profound effects of climate change is the likelihood of an increased magnitude and frequency of weather-related hazards. These are generally of two kinds, "rapid-onset" and "slow-onset" hazards. "Rapid-onset" hazards are mainly waterinduced such as floods, flash floods including glacial lake outburst floods, landslides and debris flows, etc. "Slow-onset" hazards may be droughts, heat waves, cold spells, vectorborne diseases, biodiversity changes and changes in the hydrological cycle, etc. All the above-mentioned hazards are relevant for the Hindu Kush-Himalaya region.

\section{Impact of "rapid-onset" hazards on human health}

During and after a flood or a flash flood, or when any similar "rapid-onset" hazard strikes, there are a number of factors that affect human health. The hazards themselves may cause severe physical injuries and mortalities to people. Vulnerable groups, such as the poorest people, those from a low caste, women and children, and the elderly are often hit the hardest. The poor groups of the society often have their homes in more exposed, less protected areas or are marginalized in other ways. Moreover, in the Himalayas, the majority of the population still lives in rural areas where distances to hospitals may be considerable, thereby aggravating the results of the physical damage to humans during floods or landslides.

Following a disaster, village communities in mountains often have to bear severe damage to their properties. Agricultural 
fields, livestock and houses may get swept away or damaged. This may leave a large proportion of the population in the villages hit by a disaster without any source of income. When their lands are washed away, many people are unable to find the resources to replace them, or they may have to take loans at a very high mortgage. In all these cases it may lead to socioeconomic stress which may impose a series of health problems on those affected, although this negative effect on human health resulting from extreme events seldom gets highlighted.

\section{Impact of "slow-onset" hazards on human health}

Climate change can affect human health through indirect and less visible paths, which can be considered "slow-onset" hazards. These hazards are more pervasive in mountain areas due to their inherent vulnerability to disasters.

Climate change has and will continue to have a profound impact on the availability of water and will increase seasonal or even allyear-round water stress in the Himalayan region. The subsequent effects of a change in the hydrological cycle will put extra pressure on the already inadequate water resources and exacerbate water scarcity, thereby increasing water-related diseases and deaths. In Yuanmou county, Yunnan province of China, the reported waterborne diseases have shown no obvious decline in the last 15 years despite the high economic growth rate and rapid improvement in living standards. In Nepal it is estimated that nearly 30000 people, mostly children under five years, die every year from waterborne diseases as a result of bad water quality, which in turn is the result of lack of adequate sanitation facilities.

Climate change has a crucial impact on ecosystems and their goods and services. Some species may get extinct while invasive species may spread and new species may occur. This will have an impact on biodiversity and affect people's diet and nutritional status and thus cause nutritionrelated health problems. Preliminary findings in Nepal suggest that diminishing of wild food contributes to malnutrition of some indigenous people who rely highly on local ecosystems for their livelihoods.

Infectious diseases, particularly the insect vector-borne diseases such as malaria, dengue fever and Japanese encephalitis are sensitive to the impact of climate change. Rising temperatures shorten the time needed by insect vectors to grow and thus increase the frequency of their feeding on the blood of human beings and animals. This also alters the geographic distribution of vectors: they usually spread to high-altitude areas that previously had no such disease vectors, thereby increasing the probability of their spreading the disease to new populations. In both Yunnan province of China and in Nepal, cases of malaria have been found in villages located at high altitudes.

Agriculture, particularly rain-fed agriculture is highly sensitive to climate change. Increase in temperature may reduce the crop yield, particularly of cereal crops, and therefore cause food shortage, which will cause a number of health issues, including malnutrition, growth retardation in children and low immune system function. Poor people will be affected disproportionately by all this. Globally, a slight downturn of grain yields appears likely but its effect would be greater in the already food-insecure regions in south Asia. It is quite possible that crop yield will decline due to climate change. Rain-fed agriculture will be more severely affected. Decreasing crop yield may aggravate the existing widespread malnutrition, cause hunger and trigger other nutrition-related health problems. Undernutrition is a fundamental cause of stunted growth and low intellectual development in children, low 
productivity in adults, and susceptibility to infectious diseases in everyone (WHO, 2003). Food security is a chronic problem in Nepal, particularly among hill populations and indigenous groups, the latter accounting for $37.2 \%$ of the total population. In 1996, 51\% households in Nepal felt that their consumption of food was less than adequate, $47 \%$ households felt that their food consumption was just adequate and only $2 \%$ households reported that their food consumption was more than adequate. The percentage of households that reported food inadequacy was higher in rural and hill areas than in urban areas and the terai region (Nepal Living Standards Survey Report, 1996). Although there has been some improvement in the last decade, the country still faces the issue of food security. In 2006, undernutrition was still significant in Nepal, with one in two Nepalese children under five years of age being stunted: $50 \%$ - short for their age; $13 \%$ wasted - thin for their age; and 37\% underweight. Moreover, 24\% Nepalese women aged 15-49 years were malnourished with their body mass index (BMI) being lower than the cut-off point of 18.5 (Nepal Demographic and Health Survey, 2006).

However, the impact of climate change on human health is not always entirely negative. The change may have some positive impact on human health as well. For example, a warm winter may reduce coldrelated diseases and deaths. The elderly in high mountains and herders in the Tibetan plateau (China) have felt more comfortable in winters in the last few decades. However, it has been estimated that the negative effects of climate change on human health are greater than its positive effects.

\section{Vulnerability}

Different people adapt differently to changes. The most marginalized (mountain communities and ethnic minorities, etc.) and vulnerable groups (women, the elderly, children and the disabled) will suffer the most from the impacts of climate change because they often have less resources to fall back upon. As such some groups are physically, socially and psychologically more vulnerable to the impacts of climate change. In the context of the Hindu Kush-Himalaya region, this is due to its inherent environmental and socioeconomic characteristics, combined with the changing risks factors (i.e. increasing human activities and the impacts of other global processes). Such characteristics include among others: high exposure to hazards (verticality, slope, altitude and highly dynamic systems, etc.); inaccessibility, isolation and poor infrastructure contributing to a lack of access to many public services; degradation of natural resources on which people's livelihoods depend due to intensification and over-extraction induced by increased demands; cultural diversities and geo-political specificities leading to high cultural and political tensions (many armed conflicts are located in mountain areas); limited livelihood options; widespread poverty; and pre-existing health problems such as widespread malnutrition, etc. In addition, the physical and socioeconomic conditions are changing rapidly in the mountain regions in general, and in the Hindu Kush-Himalaya region in particular: during recent years, population dynamics, new economic growth and climate change have been occurring so rapidly that traditional and balanced adaptation mechanisms are losing their efficiency. Once self-sufficient, people now face dire economic poverty. The impacts of economic globalization, among other global processes including urbanization, poverty and environmental change, are leading to new adaptation strategies in the mountains such as, for example, male migrations - leading thereby to an increasing feminization of agriculture in rural areas. This is creating both new opportunities (e.g. additional cash) and new vulnerabilities (e.g. spreading of new diseases like the human immunodeficiency virus (HIV) and weakening of family structures, etc.). 


\section{Mitigating the effects of climate change}

Climate change is mainly caused by human activities; human beings can also take actions to mitigate the disadvantageous effects and to adapt to the changing climate. In the arena of human health, the following actions should be considered:

- A disease surveillance and moni-toring system should be established/ strengthened to closely monitor the incidence and prevalence of climatesensitive diseases. This will serve as an early warning system to inform the preparedness for preventing and dealing with climate-induced major health disasters. The establishment and operation of such a system depends mainly on the health infrastructure. Thus, the ongoing health reform and development programmes in many countries should take climate change and its health impact into account when designing their development objectives.

- As already mentioned above, research on the links between climate change and health should be promoted and strengthened, particularly regarding the conduct of empirical studies in various settings and communities. Because the impact of climate change on human health is compounded by many other health determinants, it is not identical and evenly distributed. Thus, workable solutions should be drawn from sound and locallyconducted empirical studies. Public and school education should embody climate change and its health impact to raise people's awareness and to stipulate actions for mitigation and adaptation. Climate change has increasingly become a crucial frontier for research, education and policymaking. Thus it needs action by everyone.

\section{References}

Du MY, Kawashima S, Younemura S, Zhang XZ, Chen SB, 2004. Mutual influence between human activities and climate change in the Tibetan plateau during recent years. Global Planetary Change. 41: 241-249.

Dyurgerov MD, Meier MF, 2005. Glaciers and changing earth system: A 2004 snapshot. Boulder (USA): Institute of Arctic and Alpine Research, University of Colorado.

$X_{U}$ J, Sharma R, Fang J, Xu Y. Critical linkages between land-use transition and human health in the Himalayan region. Environ Int. 2008 Feb; 34 (2):239-47.

IPCC (2007). Climate Change 2007: the physical sciences basis. Contribution of Working Group I to the Fourth Assessment Report of the IPCC. Cambridge: Cambridge University Press.

http://www.ipcc.ch/pdf/assessment-report/ar4/wgl/ar4 wgl-frontmatter.pdf - accessed 20 March 2008.

Liu X, Chen B, 2000: Climatic warming in the Tibetan Plateau during recent decades. International Journal of Climatology. 20 (4): 1729-1742.
Nepal living standards survey report 1996. Kathmandu (Nepal): Central Bureau of Statistics, National Planning Commission Secretariat.

http://www.cbs.gov.np/Surveys/NLSS/default.htm accessed 20 March 2008.

Nepal Demographic and Health Survey 2006

Kathmandu (Nepal): Population Division, Ministry of Health and Population, Government of Nepal. http://www.measuredhs.com/pubs/pdf/FR191/FR191.pdf - accessed 20 March 2008

Shrestha AB, Wake CP, Mayewski PA, Dibb JE. 1999. Maximum temperature trends in the Himalaya and its vicinity: an analysis based on the temperature records from Nepal for the period 1971-94. Journal of Climate. 12 (9): 2775-2786

WHO 2003. Climate change and human health: risks and responses: summary. Geneva (Switzerland): World Health Organization, Dept. of Protection of the Human Environment.

http://www.who.int/globalchange/climate/en/ccSCREEN .pdf - accessed 20 March 2008. 


\title{
Climate change and its impact on health in Bangladesh
}

\author{
Atiq Rahman*
}

\section{Introduction}

This background paper was prepared for a workshop on Climate Change and Health in Bangladesh, held on 19-20 November 2007 in Dhaka. The workshop was organized jointly by the World Health Organization (WHO) Country Office, Dhaka and the Bangladesh Centre for Advanced Studies (BCAS). The primary objective of this background paper was to facilitate discussion during workshop by providing latest scientific assessment on: climate change and health; burden and distribution of health impact in Bangladesh related to climate change and extreme weather events; existing response mechanisms; and the way forward.

\section{International science and the global picture}

The recently-published Fourth Assessment Report (AR4) of the Intergovernmental Panel on Climate Change (IPCC) states clearly that climate change is contributing to the global burden of disease and premature deaths. Since health is the primary goal of sustainable development and includes physical, social and psychological well-being, it is crucial that the health impacts of climate change be understood and properly addressed.

*Executive Director, Bangladesh Centre for Advanced Studies, Dhaka, Bangladesh
Climate change affects human health both directly and indirectly. People are exposed directly to changing weather patterns (temperature, precipitation, sea-level rise and more frequent extreme events) and indirectly through changes in the quality of water, air and food, and changes in ecosystems, agriculture, industry, human settlements and the economy. These direct and indirect exposures can cause death, disability and suffering. Health problems increase vulnerability and reduce the capacity of individuals and groups to adapt to climate change. At present the effects of climate change are small but the IPCC has projected a progressive increase in all countries and regions.

The relationship between climate change and human health is multidimensional, as presented schematically in the diagram on page 23.

The emerging evidence of climate change effects on human health (IPCC 2007) shows that climate change has:

- altered the distribution of some infectious disease vectors;

- altered the seasonal distribution of some allergenic pollen species; and

- increased heat wave-related deaths.

Systematic reviews of empirical studies provide the best evidence for the relationship between health and weather or climate factors, but such formal reviews are rare. The evidence published so far indicates that: 
Figure: Relationship between climate change and human health

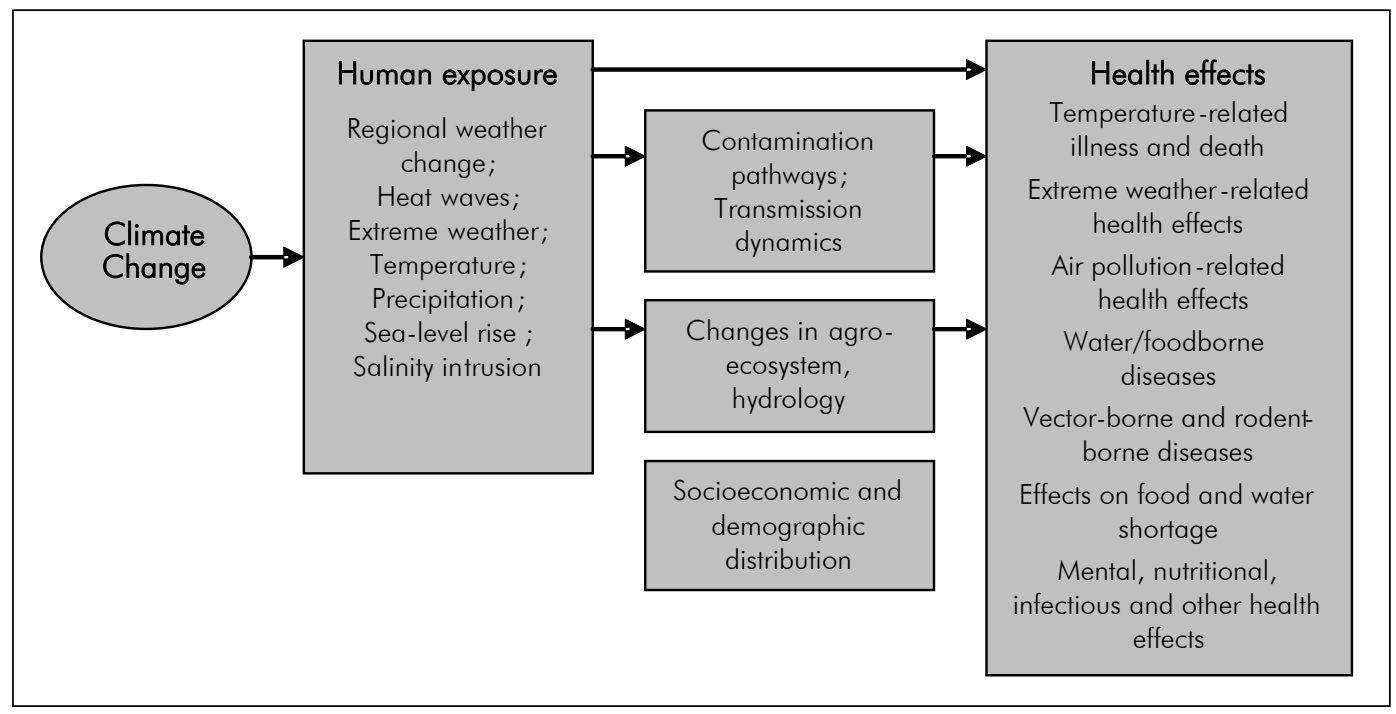

Source: WHO, 2003

- climate change is affecting the seasonality of some allergenic species as well as the seasonal activity and distribution of some disease vectors;

- climate plays an important role in the seasonal pattern or temporal distribution of malaria, dengue, tickborne diseases, cholera and other diarrhoeal diseases; and

- heat waves and flooding can have severe and long-lasting effects.

A comparative risk assessment study at regional and global levels was carried out by WHO to quantify the amount of premature morbidity and mortality due to a range of risk factors, including climate change, and to estimate the benefit of interventions to remove or reduce these risk factors. The study found that in 2000, climate change was estimated to have caused the loss of over 160000 lives annually. (Campbell-Lendrum et al., 2003; Ezzati et al., 2004; McMichael, 2004). The assessment also addressed the level of future burden of climate change that could be avoided by stabilizing greenhouse gas emissions (Campbell-Lendrum et al.,
2003). The health outcomes included in the study were chosen on the basis of their known sensitivity to climate variation, predicted future importance, and availability of quantitative global models (or the feasibility of constructing them). The following health outcomes were included:

- episodes of diarrhoeal disease;

- cases of Plasmodium falciparum malaria,

- fatal accidental injuries caused by coastal floods and inland floods/landslides; and

- nonavailability of the recommended daily calorie intake (as an indicator for the prevalence of malnutrition).

The study indicates that the adverse health impacts will be the greatest in lowincome countries. Those at greater risk include, in all countries, the urban poor, the elderly and children, traditional societies, subsistence farmers and coastal populations.

Climate change is projected to increase the burden of diarrhoeal diseases in lowincome regions by approximately $2 \%$ to $5 \%$ in 2020. Countries with an annual gross 
domestic product per capita of US $\$ 6000$ or more are assumed to have no additional risk of diarrhoea. Endemic morbidity and mortality due to diarrhoeal disease primarily associated with floods and droughts are expected to rise in East, South and South-East Asia due to projected changes in the hydrological cycle associated with global warming. Furthermore, increase in the coastal water temperature would exacerbate the abundance and/or toxicity of cholera in South Asia.

Dengue is the world's most important vector-borne viral disease. Several studies have reported an association between spatial, temporal or spatiotemporal patterns of dengue and climate (Hales et al., 1999; Corwin et al., 2001; Gagnon et al., 2001; Cazelles et al., 2005). The IPCC report also states that approximately one third of the world's population lives in regions where the climate is suitable for dengue transmission.

Malaria is a complex disease to model all published models have limited parameters for some of the key factors that influence the geographical range and intensity of malaria transmission. Given this limitation, models project that, particularly in Africa, climate change will be associated with geographical expansions of areas suitable for stable malaria (Plasmodium falciparum) in some regions and with contractions in other regions (Tanser et al., 2003; Thomas et al., 2004; Ebi et al., 2005). Some projections also suggest that some regions will experience a longer season of transmission. Although an increase in the number of months per year of transmission does not directly translate into an increase in malaria burden (Reiter et al., 2004), it would have important implications for vector control.

According to IPCC, in order to reduce the health impacts of climate change, adaptive capacity needs to be improved everywhere in the world. Recent impacts of hurricanes and heat waves have shown that even high-income countries are not well prepared to cope with extreme weather events. The IPCC also suggests that the following measures be taken to address the health impacts of climate change:

- The planning horizon of public health decision-makers is short, as compared to the projected impacts of climate change. Therefore, the current risk-management approaches that focus only on short-term risks will need to be modified.

- A two-tiered approach may be needed, with modifications to incorporate current climate change concerns into ongoing programmes and measures, along with regular evaluations to determine a programme's likely effectiveness to cope with projected climate risks. For example, epidemic malaria is a public-health problem in most areas in Africa, with programmes in place to reduce the morbidity and mortality associated with these epidemics.

- Proactive adaptation strategies, policies and measures need to be implemented by national governments, including ministries of health, and by international organizations such as $\mathrm{WHO}$, and by individuals. Because the range of possible health impacts of climate change is broad and the local situations diverse, the examples that follow are illustrative and not comprehensive.

The IPCC states that future trends in health are relevant to climate change because the health of populations is an important element of adaptive capacity. Infectious diseases could become more prominent if public health systems are not efficient or if new pathogens arise that are resistant to our current methods of disease control, leading to falling life expectancies 
and reduced economic productivity. The total number of people at risk, the age structure of the population and the density of settlements are important variables in any projection of the effects of climate change.

\section{Burden and distribution of disease: Bangladesh scenario}

Bangladesh is vulnerable to outbreaks of infectious, waterborne and other types of diseases (World Bank, 2000). Records show that the incidence of malaria increased from 1556 cases in 1971 to 15375 in 1981, and from 30282 cases in 1991 to 42012 in 2004 (WHO, 2006). Other diseases such as diarrhoea and dysentery, etc. are also on the rise especially during the summer months. It has been predicted that the combination of higher temperatures and potential increase in summer precipitation may cause the spread of many infectious diseases [Ministry of Environment and Forests (MoEF), Bangladesh]. Climate change also brings about additional stresses like dehydration, malnutrition and heat-related morbidity especially among children and the elderly. These problems are thought to be closely interlinked with water supply, sanitation and food production. Climate change has already been linked to land degradation, freshwater decline, biodiversity loss and ecosystem decline, and stratospheric ozone depletion. Changes in the above factors may have a direct or indirect impact on human health as well.

Bangladesh also carries the burden of high population, natural disasters and diminishing and polluted natural resources. The added burden of increased health problems, possibly due to climate change and climate variability, will push back its developmental achievements.

Public health depends on safe drinking water, sufficient food, secure shelter and good social conditions. A changing climate is likely to affect all of these conditions. The health effects of a rapidly-changing climate are likely to be overwhelmingly negative, particularly in the poorest communities.

Some of the health effects of climate change include:

- Increasing frequency of heat waves: Recent analyses show that humaninduced climate change contributed significantly to the occurrence of the European summer heat wave of 2003 and of 2007. This has implications for Bangladesh since the elderly and children suffer the most from increased temperatures. Even though no formal study on increase of heat waves in Bangladesh has been undertaken, we are already observing yearly trends in rise in temperatures. The health impacts associated with heat waves are heat stroke, dehydration and aggravation of cardiovascular diseases in elderly people. It is also to be noted that Bangladesh does not have records on illnesses and deaths related to heat waves. However, it was generally observed that prevalence of diarrhoeal diseases increased during extreme temperatures and heat waves, particularly in children.

- Variable precipitation patterns: Changes in precipitation patterns are likely to compromise the supply of fresh water, thus increasing the risk of waterborne diseases. They are also associated with floods and waterlogging that increase the incidence of diarrhoea, cholera and skin and eye diseases. Agricultural production and food security are also linked directly to precipitation patterns - this impacts the nutritional status of the population.

- Malnutrition: Rising temperatures and variable precipitation are likely to 
decrease agricultural production, thereby increasing the risk of malnutrition. Malnutrition will further increase the vulnerability of those affected to infectious and water- and vector-borne diseases.

- Vector-borne diseases: Changes in climate are likely to lengthen the transmission seasons of important vector-borne diseases, and alter their geographic range. Already, dengue is a regular disease in the major cities of Dhaka and Chittagong.

- Rising sea levels: These increase the risk of coastal flooding, and may necessitate population displacement, and cause many other health-related problems such as cholera, diarrhoea, malnutrition and skin diseases, etc. More than half of the world's population now lives within $60 \mathrm{~km}$ of the sea. Some of the most vulnerable regions are the Nile delta in Egypt, the Ganges-Brahmaputra delta in Bangladesh, and many small islands, such as Maldives, and the Marshall Islands and Tuvalu in the Pacific Ocean.

In Bangladesh, millions of people suffer from diarrhoea, skin diseases, malaria, mental disorders and dengue, etc. A recent study carried out jointly by the BCAS and the National Institute of Preventive and Social Medicine (NIPSOM) in 2007 indicated that the annual incidence of diarrhoea was 2841273 cases during the period 19882005 and that of skin diseases was 2623092 cases during 1998-1996. Other health problems such as malnutrition, hypertension and kala-azar also affect people of different regions of the country. The following table shows the incidence of some of the major climate-sensitive diseases and their trend during the last few decades.
Table: Incidence of some of the major climate-sensitive diseases occurring during the last few decades in Bangladesh

\begin{tabular}{|l|c|l|c|}
\hline \multicolumn{1}{|c|}{ Diseases } & $\begin{array}{c}\text { Total cases } \\
\text { per period }\end{array}$ & Period & $\begin{array}{c}\text { Average } \\
\text { annual cases }\end{array}$ \\
\hline Diarrhoea & 48302636 & $\begin{array}{l}1988- \\
2005\end{array}$ & 2842273 \\
\hline $\begin{array}{l}\text { Skin } \\
\text { diseases }\end{array}$ & 23697833 & $\begin{array}{l}1988- \\
1996\end{array}$ & 2623092 \\
\hline Malaria & 1018671 & $\begin{array}{l}1974- \\
2004\end{array}$ & 33956 \\
\hline $\begin{array}{l}\text { Mental } \\
\text { disorders }\end{array}$ & 201881 & $\begin{array}{l}1988- \\
1996\end{array}$ & 22431 \\
\hline Dengue & 19830 & $\begin{array}{l}1999- \\
2005\end{array}$ & 3305 \\
\hline
\end{tabular}

Source: Data modified from WHO, 2006; DirectorGeneral, Health (Bangladesh); 1996, 1997; MoEF, 2005

\section{Overall assessment of the disease burden in Bangladesh}

Since the country's independence more than 30 years ago, the Government of Bangladesh has invested substantially in the institutionalization and strengthening of health and family planning services, with special attention to rural areas, and is committed to the key health-for-all (HFA) and primary health care (PHC) approaches. Over the last 30 years there has been substantial improvement in the health status of the people. However, despite these improvements, much still remains to be done. Mortality rates, especially infant and maternal, continue to be unacceptably high. The quality of life of the general population is still very low. Low calorie intake continues to result in malnutrition, particularly in women and children. Diarrhoeal disease continues to be the major killer. Communicable and poverty-related diseases that are preventable still dominate the top ten causes of morbidity.

The government is aware of the situation, as well as of the major shortcomings that need to be addressed, such as development of an efficient project management mechanism 
across the health system; improvement in the logistics of drug supplies and equipment to health facilities at district and lower levels; improvement in the production and quality of human resources; a system to ensure regular maintenance and upkeep of existing health facilities; and development of a comprehensive plan to improve and ensure the quality of health resources.

\section{Bangladesh's response to its existing disease burden}

\section{Health policies and strategies}

The cornerstone of Bangladesh's national health policy is the Health and Population Sector Strategy (HPSS) which was introduced in 1998. The priority of the strategy is to ensure universal accessibility to and equity in health care, with particular attention to the rural population. The Maternal and Child Health $(\mathrm{MCH})$ programme receives priority in the public sector while "reproductive health" has recently become a priority concern. Moreover, government's financial allocation for health has also improved. Efforts are being made to develop a package of essential services based on the priority needs of clients, to be delivered from a static service point, rather than through door-to-door visits by community health workers. This will be a major shift in strategy that will require complete reorganization of the existing service structure. Such reorganization is expected to reduce costs and increase efficiency as well as meet peoples' demands. Privatization of medical care at the tertiary level, on a selective basis, is also being considered. The progress being made towards achievement of the health-related Millennium Development Goals (MDGs) is given below:

Intersectoral cooperation: Intersectoral committees have been formed at different levels ranging from the national level to the periphery, depending on the need for cooperation. At national level, for example, the nutrition and population councils are chaired by the Prime Minister. At district and thana levels, intersectoral coordination committees have been organized, while at the lowest administrative level (union), intersectoral committees have been formed, e.g. for water and sanitation projects.

Organization of the health system: Committees have been formed, including an inter-ministerial committee, to integrate/merge the health and family planning departments. Functionally, health and family planning personnel work closely at thana, union and outreach levels, but a dichotomy exists at district and national levels. As a result, greater decentralization of management is being considered.

Managerial process: The government decided to formulate a national health policy in 1997, for which a health policy committee and five subcommittees were formed. This resulted in a change from a "top-down" planning process for health to a participatory approach involving the stakeholders in the health sector. The first product that was formulated utilizing this approach was the health sector perspective plan. A new approach to programme implementation, which is product-oriented and emphasizes on "outputs" rather than "inputs" is being tried out with WHO's assistance. Decentralization of the management process is also being considered.

Health information system: Weekly epidemiological surveillance and outbreak control reporting system for selected communicable diseases have been initiated throughout the country. The routine Health Management Information System (HMIS) is functioning with some limitation, though activities have been undertaken to strengthen it. Information support is not yet adequate. The use of data remains limited. Strengthening of the HMIS through training, use of existing data collection tools, and establishment of information networks with computer support has been planned. 
Community action: The roles of the individual, family and community are emphasized in the intensified action programme for PHC implementation, which involves decentralized planning at thana and union levels. A total of 12 districts (86 thanas) are now covered under the intensified PHC programme. Through intersectoral collaboration and community participation, a joint action plan has been implemented involving 60000 village health volunteers (one each for 50 households). The participation of teachers and religious leaders is encouraged. The information department and mass media inputs are also utilized to support information, education and communication (IEC) activities.

Emergency preparedness: Currently, there is no legislation in the country that underpins the management of natural disasters at national and sub-national levels. In the absence of any legislation, the Ministry of Disaster Management and Relief in 1997 issued revised "standing orders for disasters." These "orders" provide guidelines and instructions to various line departments and ministries. There are separate "standing orders" for different hierarchical levels of the health sector, which include coordination committees; contingency plans for manpower deployment, essential medical relief supplies and maintaining a database; training in emergency preparedness and response; a communication network; and budgetary allocation for emergency management. A draft "Disaster Management Act" is currently under review.

Health research and technology: Three organizations, namely the Bangladesh Medical Research Council (BMRC), the Institute for Cholera and Diarrhoeal Disease Research, Bangladesh (ICDDRB), and Essential National Health Research (ENHR) carry out biomedical and operational research. They undertake training and provide research grants. Many of their research findings are helpful in making policy decisions. Research units have also been opened by BMRC in medical colleges. Field study stations have been established by BMRC and ICDDRB. The BMRC has reorganized itself internally to cope with the growing demands of young researchers. Literature search systems in BMRC and ICDDRB have been modernized.

Health systems research (HSR) is not handled as a separate, independent entity. Individual faculty members and other relevant people have been trained in HSR, but there is no coordination among researchers. Health training institutions are yet to include HSR in their curricula. Research culture is just developing in Bangladesh, hence there is no effective critical mass of researchers to form a strong advocacy group. Coordination and networking among researchers and funding agencies are yet to be developed.

\section{Health services}

Health education and promotion: Educational support to national health programmes has been provided by the Health Education Bureau (HEB). In recent years emphasis has been on school health education, hospital health education and coordination with nongovernmental organizations (NGOs). Constraints include the lack of a national IEC strategy, the low priority given to health education by health services, underutilization of health education officers, and lack of opportunities for professional advancement of those working in health education. Some issues under consideration are the inclusion of a health education component in the new national health policy and strengthening of coordination among HEB, ongoing government health programmes and NGOs.

\section{Prevention and control of locally endemic diseases}

Dengue: Dengue was an unfamiliar disease in Bangladesh till its outbreak in the summer of 2000. It started as an acute febrile illness in three major cities of Bangladesh (Dhaka, 
Chittagong and Khulna) with the highest incidence being in the Dhaka district. People of all ages and both sexes are susceptible to dengue. The infection can lead to the fatal dengue shock syndrome (DSS). This vectorborne disease is transmitted by certain species of Aedes mosquito. Aedes aegypti and Aedes albopictus are peri-domestic mosquitoes that lay eggs in small collections of clean water such as in flower vases and pots. Usually dengue transmission occurs during the rainy season. Bangladesh never experienced a serious epidemic of dengue until 2000. However, scattered studies did indicate sporadic cases over the last few years preceding 2000 .

Since July 2000 onwards, dengue and DHF cases have been reported in Dhaka and other major cities in the country. As of 2004, a total of 16388 dengue cases were reported of which 210 were fatal. The case fatality rate (CFR) was $1.28 \%$. The DirectorGeneral, Health Services has taken initiatives to develop national guidelines by adapting the WHO guidelines according to local needs. The objective of the guidelines is to control transmission of dengue fever and DHF, reduce morbidity and prevent deaths.

Malaria: In 1992 an epidemiological follow-up found that the resistance of Plasmodium falciparum to a number of antimalarial drugs was increasing and that in relation to 1982 the number of malaria cases had doubled. The government introduced a National Guideline for Treatment of Malaria in 1994, which was revised in 2004. Statistics from 2001 to 2005 show a marked increase in the proportion of Plasmodium falciparum cases every year. WHO declared that malaria could not be eradicated and subsequently a new strategy for malaria control was launched. The new strategy is being implemented gradually. It emphasizes disease control aspects and endorses the four technical elements (early diagnosis, prompt treatment, recognition of treatment failures and management of severe and complicated cases in hospitals). Emphasis is also placed on malaria surveillance, preparedness for control of malaria outbreaks/epidemics and introduction of insecticide-impregnated bednets. The main constraint is the reduced capacity of the core technical unit for control of vector-borne diseases to take on activities countrywide (MIS, DG-Health, 2007).

Other diseases: Kala-azar has reemerged since the cessation of dichlorodiphenyl-trichloroethane (DDT) spraying operations. At least 20 million people in more than 27 districts are at risk. The estimated cumulative disease-specific burden is 35000 cases. Under the project for integrated control of vector-borne diseases, an emergency plan for the control of kala-azar was initiated in 1994-1995 in 22 thanas of 11 districts (population five million). The plan was successful and further expansion is now being planned. At least 8000 kala-azar patients have been successfully treated to date. The major constraint is similar to that faced in the control of malaria.

Eighteen million people in 12 districts are considered to be at risk of filariasis. A revised strategy for the elimination of filariasis is being pilot-tested in one district. This strategy involves administering a single dose of ivermectin with albendazole yearly for a period of three years to the total population in the district.

\section{Prevention, control and management of common diseases and injuries}

Acute respiratory infection (ARI) accounts for about 145000 (33\%) deaths annually among children less than five years of age (ICDDRB 1994). Forty to sixty per cent of outdoor visits and $30-40 \%$ of indoor admissions are attributed to ARI. The programme for the control of ARI continues to be implemented on a phased basis according to the recommended WHO strategies. 
Though diarrhoeal diseases continue to be responsible for significant morbidity and mortality, the current strategies have reduced mortality considerably. Multi-sectoral partners are involved in mobilizing the community regarding correct home-based care and timely referral. The availability of oral rehydration solution (ORS) has increased through the formation of ORS depots in the community. Constraints include inappropriate use of anthelmintics and anti-diarrhoeals, especially in the private sector and underutilization of health facilities.

\section{Policy and institutional strategy}

The HPSS (introduced in 1998), which forms the basis for the future national health policy, is based on several key principles: greater orientation to client needs, especially women; improved quality, efficiency and equity of government health services; provision of a package of essential health services; expanded private sector role in providing health and population services; and a onestop shopping via co-location of services.

Some of the main objectives of the new strategy are to:

- allocate more resources to support services for the poor, and for vulnerable groups (women and children);

- unify the bifurcated health and family planning service delivery system;

- achieve an appropriate balance between the public and private sector in the financing and provision of services; and

- decentralize management through devolution of authority.

The following activities have been identified to achieve the above-mentioned objectives:

- Deliver an "essential services package" to the whole population with the aim of maximizing health benefits, relative to per capita expenditures.

- The service delivery mechanism should be unified, restructured and decentralized at both thana and hospital levels. Other services, particularly at the hospital level, are proposed to be provided through partnerships with or by commissioning the services of NGOs and private, not-for-profit hospitals. The public sector hospital services delivery will be improved through greater autonomy of management, local-level accountability, "cost-recovery", fee retention and utilization, as well as a "drug-revolving" fund. Integrated support systems should be strengthened. A sector-wide approach to manage the health sector be introduced, rather than having a series of projects with their own funding, management, implementation and reporting arrangements. In view of the potential resource gap between sectoral resources and projected sectoral expenditures, increased reliance on "cost recovery" for public sector services will be considered.

- Health insurance coverage in urban Bangladesh is proposed to be increased through development of a health insurance scheme for government employees and for employees of state-owned enterprises. At the Centre, health services will be more integrated, while at lower levels, they will be decentralized. Hospital-level services will be improved.

- The policy and regulatory framework will be strengthened. Existing policies will be reviewed and revised for improving accessibility, affordability and quality of services and for further improving affordability, quality and 
safety of drugs, as well as the rational use of drugs.

- New policies on public and private sectoral mix and financing of services will be developed.

\section{The way forward}

The following are some of the possible measures that Bangladesh should take to reduce the health impacts from climate change:

- Waterborne diseases are a major public health problem in Bangladesh. Therefore, changes in climate will increase their incidence. To address such problems and to reduce the possibility of incidences of climatesensitive diseases, initiatives such as taking policy decisions; undertaking scientific research to confirm earlier findings; and building institutional capacity to handle adverse consequences of climate change, need to be considered.

- Government agencies (e.g. DirectorGeneral, Health) should initiate surveillance measures for climatesensitive diseases separately or include a separate component for such measures in the existing national disease surveillance programme.

- The government should develop a dataset for climate-sensitive diseases,

\section{References}

Bangladesh Bureau of Statistics (BBS) 2005.

Compendium of Environment Statistics of Bangladesh 2005. Dhaka (Bangladesh): BBS.

Bangladesh Health System Profile 2005 [Internet]. New Delhi (India): WHO, Regional Office for South-East Asia. http://www.searo.who.int/LinkFiles/Bangladesh Country HealthSystemProfile-Bangladesh-Jan2005.pdf.

BCAS and NIPSOM 2007. Climate Change and Health Impacts. Report prepared for Climate Change Cell.

as well as vector data based on geographical distribution to facilitate further research and prediction.

- Health professionals need to be trained on climate change and its impacts on human health to deal with future adversity.

- The government in association with $\mathrm{NGOs/research} \mathrm{organizations} \mathrm{working}$ on climate change and health issues may initiate training programmes for health professionals.

- Awareness programmes on climate change impacts on human health would build the community's resilience.

- Considering all the relevant climate and non-climate factors, appropriate adaptation strategies to deal with climate change should be developed. A Climate Change Cell (CCC) can initiate developing such strategies in association with relevant partners and governmental/ nongovernmental organizations.

- Improve water supply and sanitation management.

- Protect water resources.

- Improve hygienic practices at individual and community levels.

Dhaka (Bangladesh): Ministry of Environment and Forests, Department of Environment.

Confalonieri UB, Menne R, Akhtar KL, Ebi M, Hauengue

RS, Kovats B, Woodward A, 2007. Human health. In:

Climate Change 2007: Impacts, adaptation and vulnerability. Contribution of Working Group II to the Fourth Assessment Report of the Intergovernmental Panel on Climate Change. M.L. Parry, O.F. Canziani, J.P. Palutikof, P.J. van der Linden and C.E. Hanson, Eds. Cambridge (U.K): Cambridge University Press. p. 391-431. 
Director General of Health Services (DG-Health) 1999

Bangladesh Health Bulletin 1997. Ministry of Health and

Welfare, Government of Bangladesh.

Director General of Health Services (DG-Health) 1998.

Bangladesh Health Bulletin 1996. Ministry of Health and

Welfare, Government of Bangladesh.
Ministry of Environment and Forests (MOEF) 2005

National Adaptation Programmes of Action (NAPA) Study

Note. Dhaka (Bangladesh): MOEF. 


\title{
Climate change and malaria in India: Interplay between temperatures and mosquitoes
}

\author{
Ramesh C. Dhiman*t, Sharmila Pahwa* and Aditya P. Dash*
}

\begin{abstract}
Malaria is still a major public health problem in India. The epidemiology of malaria constitutes man as host, four species of protozoan parasite, plasmodia (Plasmodium vivax, Plasmodium falciparum, Plasmodium malariae and Plasmodium ovale) and anopheline mosquitoes as vectors. Environmental conditions play an important role in the transmission dynamics of malaria, as the parasite has to pass its developmental cycle in the mosquito. The three main climatic factors that affect malaria transmission and distribution are temperature, precipitation and relative humidity. ${ }^{1}$ Climate predicts, to a large degree, the natural distribution of malaria. ${ }^{2}$
\end{abstract}

Climate change is a new emerging threat to health, particularly in the context of vectorborne diseases. The Third Assessment Report of the Intergovernmental Panel on Climate Change (IPCC) ${ }^{3}$ has highlighted that by 2100 the global temperature would increase by $1.8^{\circ} \mathrm{C}-4^{\circ} \mathrm{C}$. The Fourth Assessment Report of IPCC (2007) has clearly highlighted the possible increase in vector-borne diseases spatially and temporally. The Government of India has also taken initiatives for studying the vulnerability assessment and adaptation measures to address the threat of climate change in the field of vector-borne diseases. The logic behind the possible increase/decrease in malaria transmission in view of climate

*National Institute of Malaria Research (NIMR), Delhi, India

tE-mail: dhimanrc@icmr.org.in change is based on the interplay between temperatures and developmental cycles in anopheline mosquitoes. This is discussed in this article with emphasis on India.

To assess the impact of climate change on malaria, it is imperative to understand the intricacies of the biology of anopheline mosquitoes and the lifecycle of the malaria parasite. When an infected mosquito bites a healthy person, it transfers sporozoites to him/her, which after entering the hepatic cells and the red blood cells develop into male and female gametes within two weeks $\{$ the average incubation period of Plasmodium vivax and Plasmodium falciparum, the major parasites in India is $15(12-17)$ and 12 (914) days respectively\}. The parasite cannot develop further in human beings. The gametes are taken up by female anopheline mosquitoes along with blood meal, which develop into sporozoites. The development of a parasite in a mosquito is called extrinsic incubation period or sporogony, the duration of which depends on environmental temperatures.

There are primarily six major species of malaria vectors; Anopheles culicifacies, a rural vector; Anopheles stephensi, an urban vector; Anopheles fluviatilis, prevalent in the foothills; Anopheles sundaicus in the Andaman and Nicobar Islands; and Anopheles minimus and Anopheles dirus in north-east India (see figure). ${ }^{4}$ 


\section{Figure: Distribution of malaria vectors in India}

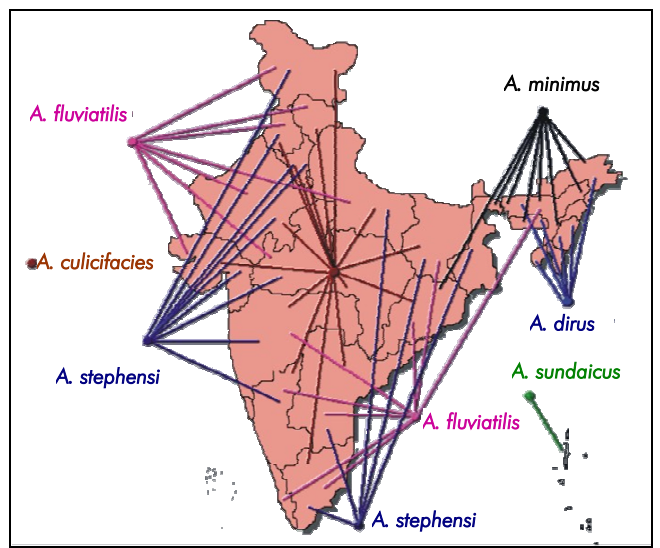

Source: NIMR, India; $A=$ Anopheles

The distribution of different malaria vectors, diversity in geography and environmental conditions result in variable endemicity of malaria.

Temperature affects the developmental period related to different stages of a mosquito's lifecycle: blood feeding rate; gonotrophic cycle (physiological process consisting of digestion of blood-meal and development of ovaries); and longevity. At increased temperatures, the rate of digestion of blood-meal increases, which in turn accelerates ovarian development, egg laying, reduction in gonotrophic cycle and a greater frequency of feeding on hosts, thereby increasing the probability of transmission. A reduction in the duration of the gonotrophic cycle would make the vectors bite more frequently, thereby increasing the probability of malaria transmission.

It takes about 10 days for an egg to reach the adult stage of an anopheline mosquito at an optimum temperature of $28^{\circ} \mathrm{C}$. At lower temperature, the duration gets prolonged while at increased temperature the duration is reduced. However, at more than $40^{\circ} \mathrm{C}$, mortality occurs in adult mosquitoes.

Reduction in the duration of gonotrophic cycle and in the extrinsic incubation period of malaria parasite is related with increased rate of transmission. ${ }^{5-8} \quad$ These two entomological variables are especially sensitive to changes in environmental temperature, ${ }^{9-11}$ being reduced with increments in temperature.

The minimum temperature required for development of Plasmodium vivax parasite in anopheline mosquitoes ranges from 14.5$16.5^{\circ} \mathrm{C}$, while for Plasmodium falciparum it ranges from $16.5-19^{\circ} \mathrm{C} . .^{5,12}$ However, the best conditions for development of the malaria parasite are $20-30{ }^{\circ} \mathrm{C}$ temperature and $60 \%$ relative humidity $(\mathrm{RH}){ }^{7}$

Based on the minimum temperature needed for completion of sporogony of the malaria parasite in anopheles vectors, Detinova (1962) by following the OrganovRayevsky method expressed the relation between temperature and duration of sporogony of Plasmodium vivax as a mathematical expression. At $16^{\circ} \mathrm{C}$ it will take 55 days for completion of sporogony of Plasmodium vivax while at $28^{\circ} \mathrm{C}$, the process can be completed in seven days. ${ }^{13}$ At $18^{\circ} \mathrm{C}$ it will take 29 days. At $40^{\circ} \mathrm{C}$, Anopheles culicifacies which is a malaria vector in rural areas of India, does not survive for more than 24 hours under laboratory conditions. ${ }^{14}$ At $35^{\circ} \mathrm{C}$ temperature and humidity ranging from $20 \%$ to $100 \%$, it survives for $4-10$ days. The average longevity of Anopheles culicifacies under field conditions was found to be 8.5 to 14 days from August to November. ${ }^{15}$ The average duration of sporogony of human plasmodia is given in the table, which reveals the significance of increased temperature in the reduction of sporogony.

Reductions in oocyte development time and in the duration of the gonotrophic cycle associated with increments in temperature have also been recorded for Anopheles culicifacies, Anopheles stephensi ${ }^{16,17}$ and Anopheles maculipennis. ${ }^{6}$ 
Table: Average duration of sporogony of human plasmodia

\begin{tabular}{|l|c|c|}
\hline \multirow{2}{*}{ Parasite species } & \multicolumn{2}{|c|}{$\begin{array}{c}\text { Number of days } \\
\text { required for sporogony } \\
\text { at different } \\
\text { temperatures }\end{array}$} \\
\cline { 2 - 3 } & $20^{\circ} \mathrm{C}$ & $25^{\circ} \mathrm{C}$ \\
\hline Plasmodium falciparum & $\begin{array}{c}22-23 \\
\text { days }\end{array}$ & $\begin{array}{c}12-14 \\
\text { days }\end{array}$ \\
\hline Plasmodium vivax & $\begin{array}{c}16-17 \\
\text { days }\end{array}$ & $\begin{array}{c}9-10 \\
\text { days }\end{array}$ \\
\hline Plasmodium malariae & $30-35$ & $23-24$ \\
& days & days \\
\hline Plasmodium ovale & - & $\begin{array}{c}15-16 \\
\text { days }\end{array}$ \\
\hline
\end{tabular}

Adapted from WHO Manual on Practical Entomology in Malaria, Part II, 1975

The duration of the larvae stage of Anopheles minimus was shorter at higher temperature than at lower temperature. For larvae, $25^{\circ} \mathrm{C}$ was found to be the optimum temperature with $38 \%$ larvae developing into adults.

The effect of increasing temperature on the maturation of ovaries and duration of the gonotrophic cycle of Anopheles albimanus (vector of malaria) was studied in the Colombian Pacific coast. ${ }^{19}$ With an increase of $3{ }^{\circ} \mathrm{C}$ (from $24^{\circ} \mathrm{C}$ to $27^{\circ} \mathrm{C}$ ) a 13-hour reduction in the gonotrophic cycle was observed, although no significant difference was recorded for the duration of the cycle when temperatures ranged from $27^{\circ}$ to $30^{\circ} \mathrm{C}$.

Studies on vulnerability assessment and possible impacts of climate change on malaria in India were initiated under the National Communication Project of the Ministry of Environment and Forests, Government of India. Keeping in view the minimum required temperature and $\mathrm{RH}\left(18^{\circ} \mathrm{C}\right.$ and $55 \% \mathrm{RH}$ ) for ensuing transmission of malaria, it was found that northern states like Jammu and Kashmir, Himachal Pradesh, Punjab, Haryana, Uttarakhand and Uttar Pradesh, and the north-eastern states were more vulnerable to climate change..$^{20,21}$
The transmission windows of malaria are likely to extend by one-three months. It is basically due to the fact that low temperatures (below $18^{\circ} \mathrm{C}$ ) are not suitable for transmission and during winter months, i.e. from November to February, the density of malaria vectors i.e. Anopheles culicifacies in rural areas and Anopheles stephensi in urban areas is also very low. On the other hand, the southern states of India, i.e. Andhra Pradesh, Karnataka, Tamil Nadu and Orissa and some parts of Gujarat are less vulnerable to climate change. Rather, these states may experience a reduction in temporal limits of transmission.

Since the dynamics of malaria transmission also depend on agricultural practices, socioeconomic conditions, pre-existing health status of the population, developmental activities and the type of intervention measures undertaken, the projections in increase/ decrease in transmission windows of malaria are simplistic.

If we examine the projection of rise in temperature vis-a-vis the distribution of malaria vectors, we will find that increased temperature would affect the biology of Anopheles culicifacies, Anopheles fluviatilis and Anopheles minimus to a major extent. It is also possible that the adult anopheline mosquito species may find a micro niche for their survival e.g. Anopheles stephensi rests in tanks in Rajasthan to overcome high temperatures. Vector species like Anopheles minimus and Anopheles fluviatilis may also seek outdoor resting places in thick vegetation under a changed climatic scenario.

The studies cited here reveal the impact of temperatures on the life stages, gonotrophic cycle and sporogony of the malaria parasite and on the projection of increase/decrease in transmission windows of malaria in view of climate change. In addition to malaria, other vector-borne 
diseases like dengue, chikungunya, filariasis, Japanese encephalitis and leishmaniasis are also prevalent in India. The biology of anopheline mosquitoes, particularly malaria vectors has been studied to some extent in India and its neighbouring countries ${ }^{4}$. In recent years studies have been undertaken in different parts of the word on climate-related modelling of vector-borne diseases. ${ }^{19,22-24}$ In

\section{References}

1. Pampana E. Textbook of malaria eradication. $2^{\text {nd }}$ edition. London: Oxford University Press, 1969.

2. Bouma MJ, van der Kaay HJ. The El Niño Southern Oscillation and the historic malaria epidemics on the Indian subcontinent and Sri Lanka: an early warning system for future epidemics? Tropical Medicine and International Health. 1996 Feb; 1(1): 86-96.

3. McCarthy J J et al. Climate change 2001: impacts, adaptation and vulnerability. London: Cambridge University Press, 2001. http://www.grida.no/climate/ipcc tar/wg2/index.htm - accessed on 05 March 2008

4. Rao TR. The anophelines of India. New Delhi: Indian Council of Medical Research, 1981. 594 pp.

5. Macdonald $\mathrm{G}$. The epidemiology and control of malaria. London: Oxford University Press, 1957. 201 pp.

6. Detinova TS. Age-grouping methods in diptera of medical importance, with special reference to some vectors of malaria. Monograph series 47. Geneva: World Health Organization, 1962.

7. Bruce-Chwatt LJ. Epidemiology of malaria. In Essential Malariology. London: William Heinemann Medical Books Ltd, 1980. pp. 129-168.

8. Molineaux L. The epidemiology of human malaria as an explanation of its distribution, including some implications for its control. In WH Wernsdorfer, SI McGregor, eds. Malaria, principles and practice of malariology. London: Churchill Livingstone, 1988. pp. 913-998.

9. Lindsay SW, Birley MH. Climate change and malaria transmission. Annals of Tropical Medicine \& Parasitology. 1996 Dec; 90(6): 573-88.

10. Martens P. Health impacts of climate change and ozone depletion: an ecoepidemiological modeling approach. Environmental Health Perspectives Supplements. 1998; 106: 241-251. view of the threat of climate change to the possible spatial and temporal increase/decrease in vector-borne diseases, it is imperative to undertake basic, in-depth studies on different vectors of aforementioned diseases under laboratory as well as field conditions so as to model a realistic future scenario of malaria and other vector-borne diseases in India.

11. Martens P, Kovats RS, Nijhof S, de Vries P, Livermore MTJ, Bradley DJ, Cox J, McMichael AJ. Climate change and future populations at risk of malaria - a review of recent outbreaks. Global Environmental Change. 1999; 9(Suppl 1): S89S107

12 Martens WJ, Niessen LW, Rotmans J, Jetten TH, McMichael AJ. Potential impact of global climate change on malaria risk. Environmental Health Perspectives. 1995 May; 103(5):458-64.

13. World Health Organization. Manual on practical entomology in malaria. Part II. Geneva: WHO, 1995. WHO Offset Publication No. 13.

14. Pal R. On the bionomics of Anopheles culicifacies Giles, Part I. Longevity under controlled conditions of temperature and humidity. Journal of Malaria Institute of India 1943, 5:77-85.

15. Afridi M K, Majid S A, Sha IA. Studies on the behaviour of adult An culicifacies Part II. Journal of Malaria Institute of India 1940, 3:23-51.

16. Mahmood F, Reisen W. Duration of the gonotrophic cycle of Anopheles culicifacies Giles and Anopheles stephensi Liston, with relation to observations on reproductive activity and survivorship during winter in Punjab Province, Pakistan. Mosquito News 1981, 41: 41-50.

17. Reisen WK, Mahmood F. Anopheles culicifacies Giles: some relationships among oviposition, refeeding and survivorship. Mosquito News 1979, 39: 374-81.

18. Chử Vũ Đình Effects of temperature and source of blood on development of Anopheles minimus in laboratory. TC Phòng chông bệh sốt rét và các bệhh ký sinh trùng. 2005. 5: 58-63

19. Rúa GL et al. Laboratory estimation of the effects of increasing temperatures on the duration of gonotrophic cycle of Anopheles albimanus (Diptera: Culicidae). Mem. Inst. Oswaldo Cruz. 2005 Aug 100(5): 515-20. 
20. Dhiman, RC, Sharmila Bhattachariee, Tridibesh Adak, Sarala K, Subbarao. Impact of Climate Change on Malaria in India with Emphasis on Selected Sites. In: Proceedings of the NATCOM V\&A Workshop on Water Resources, Coastal Zones and Human Health. New Delhi, 27-28 June, 2003. pp 127-131.

21. Bhattacharya S, Sharma C, Dhiman RC, Mitra AP. Climate change and Malaria in India. Current Science. 2006 Feb, 90 (3): 369-375. http://www.ias.ac.in/currsci/feb102006/369.pdf accessed on 07 March 2008.
22 Craig MH, Snow RW, le Sueur D. Climate based distribution model of malaria transmission in subSaharan Africa. Parasitol Today. 1999 Mar; 15 (3): 105-11.

23. Bayoh MN, Lindsay SW. Temperature-related duration of aquatic stages of the Afrotropical malaria vector mosquito Anopheles gambiae in the laboratory. Medical and Veterinary Entomology. 2004 Jun, 18 (2): 174-179

24. Moshe B Hoshen and Morse AP A weather-driven model of malaria transmission. Malar J. 2004 Sep $6 ; 3: 32$. 


\title{
Climatic determinants of malaria and kala-azar in Nepal
}

\author{
Sagar Dahal*
}

\begin{abstract}
Vector-borne diseases have been a national public health problem in terms of their mortality, morbidity and the subsequent overall impact on the national economy of Nepal. Important vector-borne diseases of national public health importance include malaria, kala-azar, lymphatic filariasis, Japanese encephalitis and dengue. Nepal is striving to control or eliminate these diseases through adoption of a multiple set of strategies.
\end{abstract}

Malaria is now distributed in almost 67 districts of the country. Kala-azar has re-emerged and is present in 12 districts of the eastern and central terai regions.

The distribution of these two diseases has been analysed against several conditions but the analysis did not cover the climatic changes or variations taking place. This paper attempts to assess the effects of climatic factors like temperature, precipitation and humidity on the occurrence of these diseases in a few specific locations.

Data do not support association of temperature and humidity with eruption of malaria and kalaazar cases. However, the annual mean temperature and total kala-azar cases show a linked trend since 1980. With increase in the mean precipitation, both malaria and kala-azar cases have been found to be on the rise. In the case of malaria, increased disease frequency has been observed following a certain time lag after precipitation. There are still too many uncertainties to link changes in distribution or prevalence of the two diseases due to an absence of adequate surveillance data. Serious work therefore needs to be done to establish any link between climatic variability and vector-borne diseases.

\section{Introduction}

Vector-borne diseases have been a public health problem in terms of their mortality, morbidity and the subsequent overall impact on the national economy of Nepal. Vectorborne diseases that have important public health implications in the national context include malaria, kala-azar, lymphatic filariasis, Japanese encephalitis and - more recently — dengue.

*Epidemiology and Disease Control Division, Department of Health Services, Kathmandu, Nepal
Malaria, once believed to be confined to the forest and forest-fringe areas of the terai and inner terai regions is now distributed over almost 67 districts of the country. Japanese encephalitis, first identified in 1978, is now present in 24 districts. Kala-azar was not a problem up to 1980 but is now present in 12 districts of eastern and central terai regions. Lymphatic filariasis is endemic in 60 districts, while in 2006 dengue and its vector were identified in some border districts.

Nepal is striving to control or eliminate these diseases. The key strategies that have been adopted to address these diseases 
include enhanced surveillance, early diagnosis and treatment, mass treatment (e.g. for eliminating lymphatic filariasis), integrated vector control and community-based environmental modifications, and protecting those susceptible with inoculations in the case of Japanese encephalitis.

The Department of Health Services, Nepal, has institutionalized the process of annual review of all priority programmes: starting first, at the district level, then at the regional level and finally, at the central level. Besides, programme divisions like the Epidemiology and Disease Control Division have also been evaluating vector-borne diseases like malaria, kala-azar and Japanese encephalitis periodically. The analysis in such reviews and evaluations usually covers performance indicators like incidence, prevalence and the associated mortality, and factors that affect the integrated vector control initiatives like vectoral distributions and behaviour, change in the habitat, urbanization, migration, developmental changes affecting the breeding sites of vectors, and host population characteristics. Until now, the analysis has not covered the climatic changes or variations taking place and the distribution of vector-borne diseases throughout the country. This paper attempts to analyse the effects of climatic factors like temperature, precipitation and humidity on the occurrence of malaria and kala-azar in a few specific locations of the country.

\section{Malaria situation}

Malaria in its various forms has been the cause of mortality in Nepal through the ages. It also constitutes one of the most important causes of economic misfortune.

There is no documented record of the prevalence of malaria in Nepal during the Nineteenth century apart from a few historical descriptions. The first documented epidemiological survey dates back to 1925. It was undertaken by Major Phillips of the Indian Military Service in the Makwanpur and Chitwan valley. Out of 889 children examined, 712 or $80 \%$ had enlarged spleen. In 1954, with the objective of controlling malaria mainly in the southern terai belt of central Nepal, a large-scale malaria control project: Insect Borne Disease Control (IBDC), supported by the United States Agency for International Development (USAID), was started in Nepal. Another planned malaria control project was taken up in the Rapti Valley by His Majesty's Government (HMG)/WHO and USAID during 1956-1958 to obtain baseline data and to recommend an appropriate strategy for a malaria eradication programme. The National Malaria Eradication Programme (NMEP) was launched as a vertical programme in 1958 with the objective of eradicating the disease from the country. A major event in the 1960s was the incrimination of $A n$. minimus and $A n$. fluviatilis as being responsible for transmission of malaria in the terai belt and An. willmori as the vector responsible for transmission of malaria at an altitude of 6500 feet above the mean sea level (MSL) in Mugu district of the mid-western region. The virtual disappearance of An. minimus as the primary vector with high anthropophilic index (>90\%) and high sporozoite rate (up to $16 \%$ ) was a magnificent achievement.

In 1978 the "eradication" programme was converted into "control" of malaria programme according to WHO's Global Strategy of Malaria Control. Evidence of malaria, which was previously believed to confine itself with regard to its endemicity and epidemicity to the forest and forest-fringe areas of the terai and inner terai regions, was observed even at an altitude of almost 2000 metres above MSL (Figure 1). However, so far there is no entomological evidence to explain the distribution of malaria in terms of altitude. 
Figure 1: Topographical distribution of malaria

Transect of Nepal (schematic) showing the main topographical features

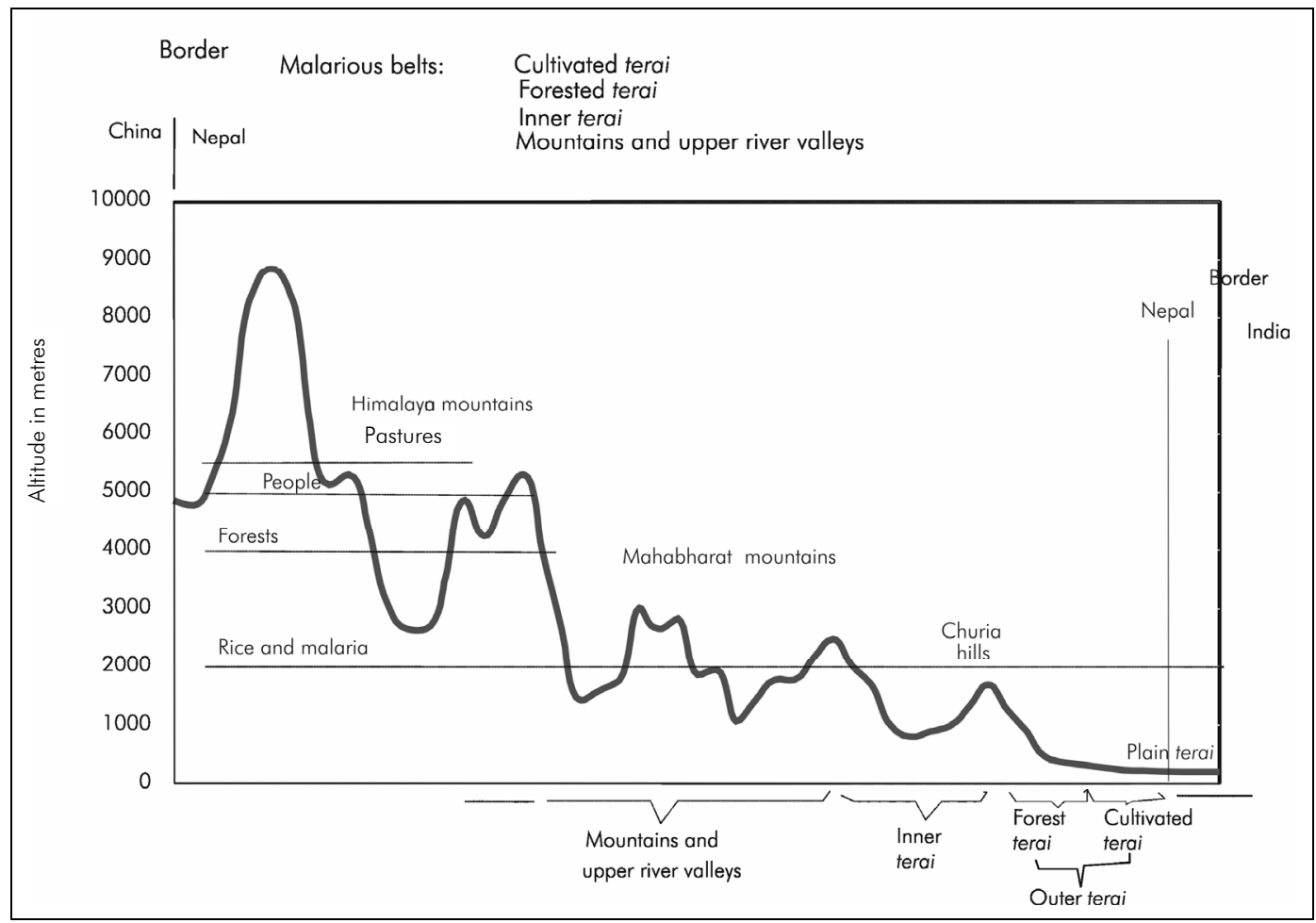

Figure 2: Temperature and malaria cases (1975 to 2005)

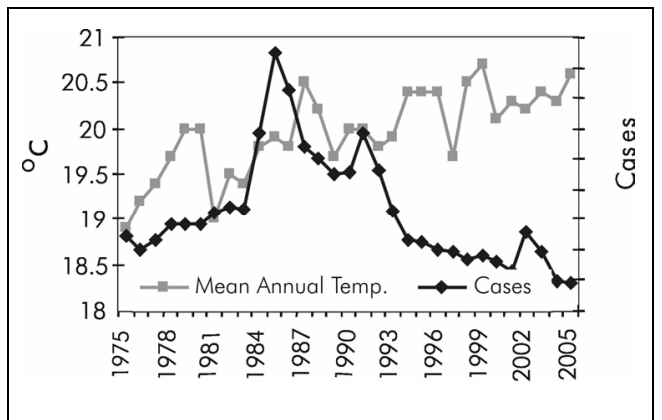

Malaria is now prevalent in 67 districts of the country with high endemicity in 12 districts. Since 1970, the country has overcome a number of outbreaks in 1974, 1985, 1991, 2002, 2005 and 2006. The highest number of cases was observed in the 1985 and 1991 epidemics (Figure 2). The programme has however made remarkable progress in controlling malaria in terms of its incidence, which has been curtailed to a figure between 5000 and 7000 cases annually. Knowledge about the effect of climate change on the epidemiology of malaria has remained elusive in the absence of specific studies. However, the existing body of knowledge suggests that the disease in terms of its vectors and parasites is very much sensitive to changes in climatic factors such as temperature, humidity and rainfall.

\section{Climatic factors and malaria}

It is well known that malaria is influenced by climatic factors such as temperature, precipitation and relative humidity. While there is increasing evidence of temperature rise in Nepal, more research needs to be 
carried out on the correlation between rainfall, humidity and outbreaks of malaria.

\section{Figure 3: Mean malaria cases and average monsoon} precipitation in 11 highly-endemic districts

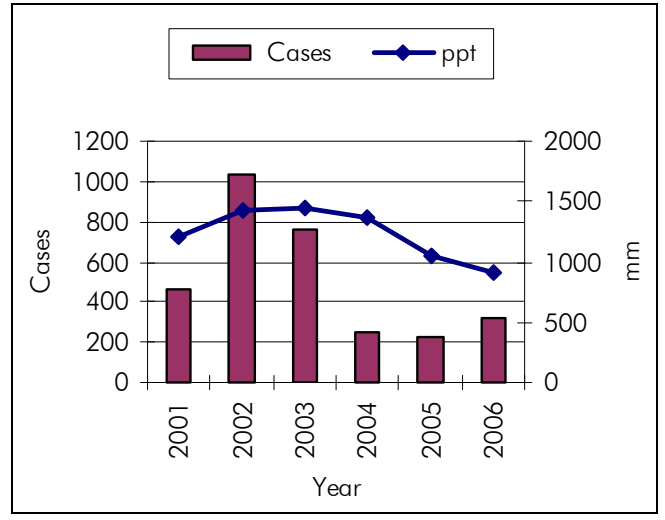

Figure 4: Malaria cases and precipitation in Jhapa, 2005

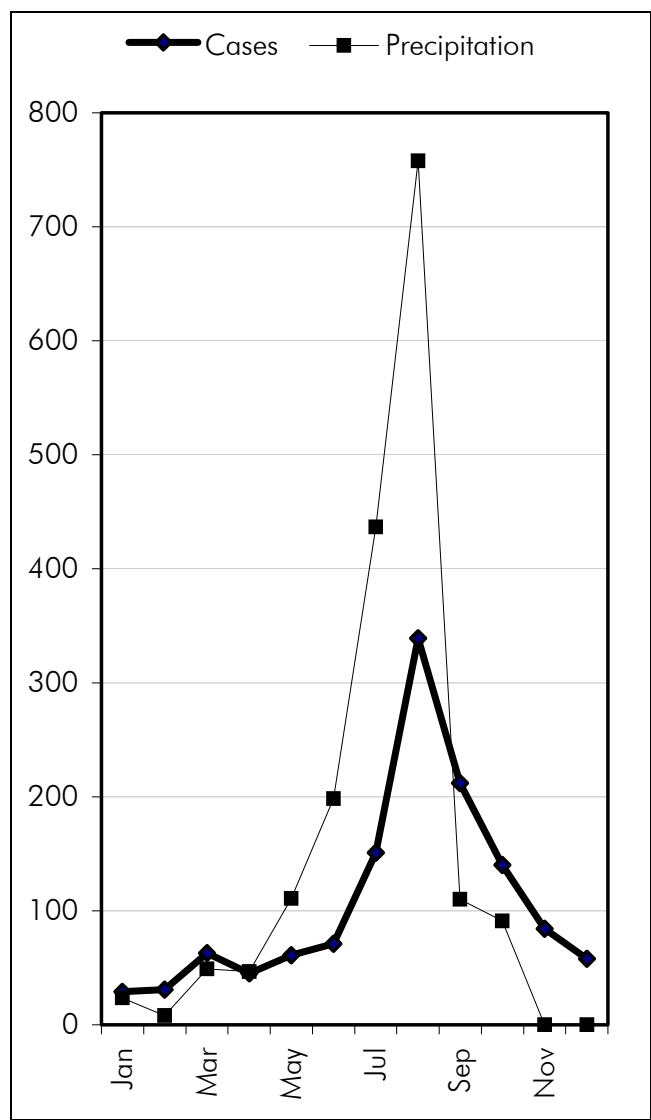

Figure 3 shows how malaria cases in highly endemic districts could be related to rainfall patterns. Figures 4 and 5 indicate that precipitation in the months of June, July and August does influence the number of malaria cases which occur (after a certain time lag) during September, October and November (also see table on next page). Figure 6 however does not show a positive correlation between relative humidity and malaria cases. There is an evident need to further explore these associations so as to better understand the link between climate change and malaria, and institute relevant adaptation measures.

\section{Figure 5: Malaria cases and precipitation, Jhapa, 2006}

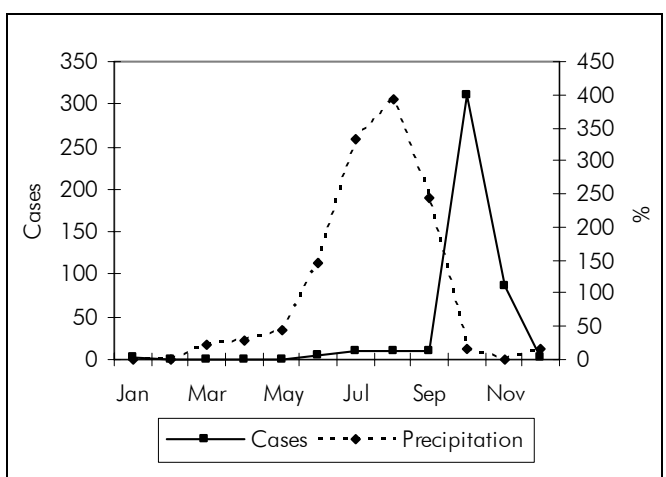

Figure 6: Relative humidity and malaria cases, Banke, 2006

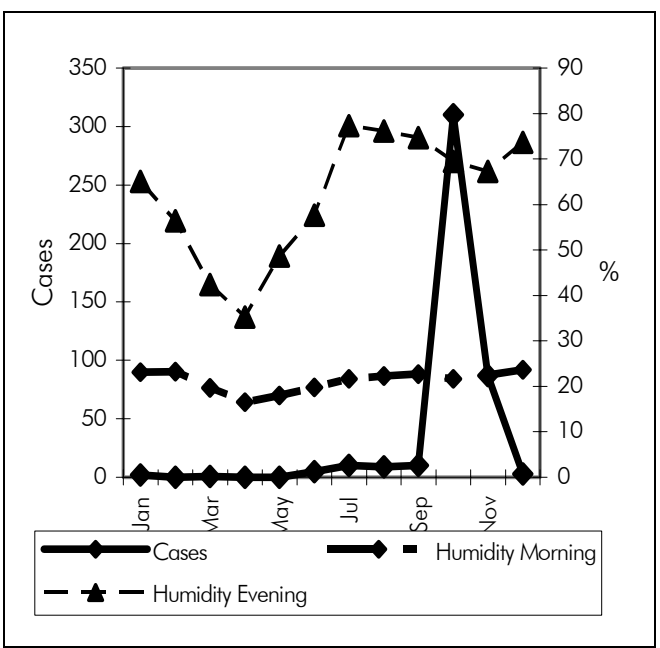


Table: Month-wise malaria cases and precipitation and humidity

\begin{tabular}{|l|r|r|r|r|r|r|}
\hline \multirow{3}{*}{ Months } & \multicolumn{2}{|c|}{ Jhapa } & \multicolumn{5}{c|}{ Banke } \\
\cline { 2 - 7 } & \multicolumn{2}{|c|}{2005} & \multicolumn{4}{c|}{2006} \\
\cline { 2 - 7 } & Cases & Precipitation & Cases & Precipitation & $\begin{array}{r}\text { Morning } \\
\text { humidity }\end{array}$ & $\begin{array}{c}\text { Evening } \\
\text { humidity }\end{array}$ \\
\hline Jan & 29 & 23.4 & 2 & 0 & 89.9 & 65.1 \\
\hline Feb & 31 & 8 & 0 & 0 & 90.5 & 56.4 \\
\hline Mar & 63 & 49 & 1 & 21 & 76.6 & 42.4 \\
\hline Apr & 45 & 46.6 & 0 & 29 & 64.2 & 35.3 \\
\hline May & 61 & 110.9 & 0 & 45.2 & 69.9 & 48.7 \\
\hline Jun & 71 & 198.6 & 5 & 146.7 & 76.9 & 57.7 \\
\hline Jul & 151 & 436.8 & 10 & 332 & 84.1 & 77.3 \\
\hline Aug & 339 & 757.8 & 9 & 393 & 86.6 & 76.2 \\
\hline Sep & 212 & 110.2 & 10 & 243 & 88.5 & 74.7 \\
\hline Oct & 140 & 91.1 & 310 & 15.5 & 84.3 & 69.5 \\
\hline Nov & 84 & 0 & 87 & 0 & 87.3 & 67.3 \\
\hline Dec & 58 & 0 & 3 & 17 & 92.1 & 73.7 \\
\hline
\end{tabular}

\section{Climatic factors and kala-azar}

Visceral leishmaniasis, also termed kala-azar, has been known to be endemic in the southern terai area of Nepal. During the 1960s and 1970s, visceral leishmaniasis ceased to be a public health problem. This development was attributed mainly to the countrywide malaria eradication activities involving spraying of dichloro-diphenyl-trichloroethane (DDT). With progress in malaria eradication activities and improvement of the malaria situation, insecticide spraying was reduced. After more than a decade of curtailment of insecticide

Figure 7: Trend of kala-azar cases with regard to mean annual temperature (1980-2005)

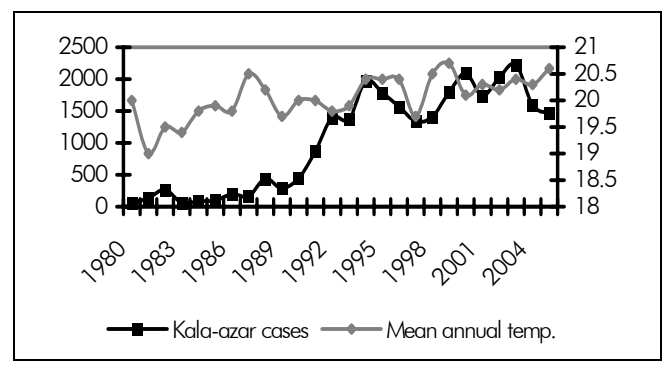

spraying particularly in the southern terai areas, cases of visceral leishmaniasis again began to be detected: they were first recorded in 1980 with an incidence rate of 1.5 per 100000 population and a case fatality rate of $5.88 \%$. Since then cases of visceral leishmaniasis have been rising steadily (Figure 7).

Figure 8 indicates an association between precipitation and kala-azar cases during

Figure 8: Kala-azar cases and precipitation in Sarlahi (2003-2006)

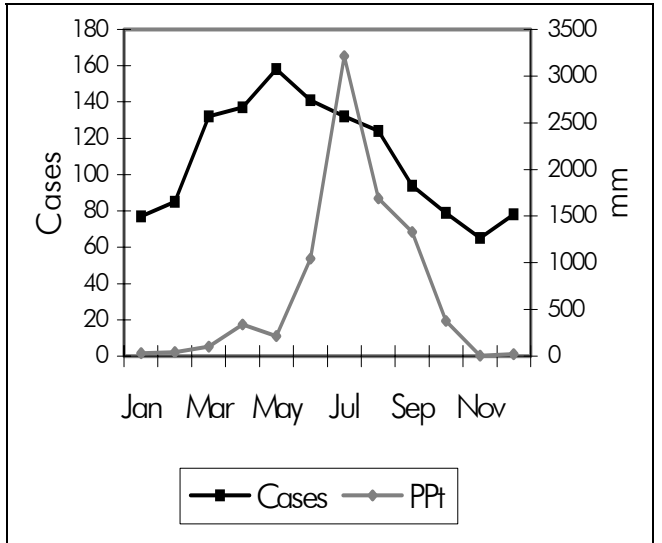

Regional Health Forum - Volume 12, Number 1, 2008 
2003-2006. The outbreaks tend to occur one to two months after heavy rainfall. The interdependency of these and other climatic factors needs to be studied further to evaluate the relative significance of each factor. This will allow us to focus on the priority areas which need to be addressed in the context of global climate change.

\section{Conclusion and recommendation}

Scientific knowledge suggests strongly that there should be some linkage between vector-borne diseases such as malaria and kala-azar with climatic variations. But in order to relate climatic factors with the incidence of malaria and kala-azar, merely an analysis of climatic factors like rainfall, humidity and temperature is not sufficient.

\section{References}

1. Department of Health Services, Epidemiology and Disease Control Division. Annual report 2002. Teku (Nepal): Ministry of Health and Population, 2002.
Several non-climatic factors such as host, environment, agent and vector influence the epidemiology of vector-borne diseases. Without nullifying the effect of these nonclimatic factors, any attempt to understand the effect of climate change in vector-borne disease epidemiology will always remain incomplete. However, this is the best time in Nepal to clarify the effect of climate change in vector-borne disease epidemiology at large with the help of a robust scientific study that will establish a strong linkage, and thereby help the Department of Health Services, Nepal to address the problem through improved adaptation measures and preparedness strategy. The policy implications of such studies will add new impetus to the national effort to control and eliminate these diseases.

2. Department of Health Services, Epidemiology and Disease Control Division. Annual report 2003. Teku (Nepal): Ministry of Health and Population, 2003.

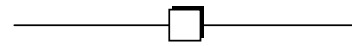




\title{
Economic impact of climate change on Mumbai, India
}

\author{
Rakesh Kumar*t, Parag Jawale* and Shalini Tandon*
}

\begin{abstract}
Climate change impacts will lead to economic losses for various sectors. In this paper the impacts of climate change on the financial capital of India, Mumbai, have been delineated. These include the impact of temperature rise on rains and floods, and their consequent effects on health. The other consequences such as rise in deaths from vector-borne diseases, dislocation due to floods and sea-level rise have been shown as projected economic losses for the years 2025 and 2050. The economic costs of sea-level rise in terms of loss of property along the coastline have also been projected for a 25- and 50 -year timescale respectively. The costs arising due to increase in malaria, diarrhoea and leptospirosis outbreaks have been projected till 2050. The conservative estimate of total costs of all these impacts, including the impact of climate change on tourism, are found to be enormous.
\end{abstract}

\section{Introduction}

According to the National Climatic Data Center (NCDC), ${ }^{1}$ the United States of America, the 13 warmest years of the last century occurred within the last 15 years, with the years 2001 , 2002 and 2003 being the hottest years ever recorded.

Mega coastal cities like Mumbai could face profound consequences from climate changes. Mumbai has a high exposure level to such changes due to population density, and its major industrial and financial installations. Furthermore, the major proportion of its reclaimed land is in low-lying areas and the high population of its urban poor has limited coping capacity to face the consequences of climate change.

According to an earlier estimate of a study conducted 10 years ago, the economic damage to Mumbai, the country's financial capital, as a result of climate change could

*National Environmental Engineering Research Institute, Mumbai, India

tE-mail:r_kumar@neeri.res.in amount to over Rs 2 lakh crore ${ }^{2}$." However, since then, urbanization and investments have only gone up in Mumbai.

According to the Intergovernmental Panel on Climate Change (IPCC), the sea level is expected to rise at the rate of 2.4 millimetres $(\mathrm{mm})$ per year in India. By the middle of the century the rise will be 38 centimetres $(\mathrm{cm})$. This would inundate lowlying areas, drown coastal marshes and wetlands, erode beaches, exacerbate flooding and increase the salinity of rivers, bays and groundwater.

\section{Economic impact}

Increase in temperature will lead to an increase in rainfall intensity and frequency. Extreme precipitation is likely to increase substantially over the western coast and westcentral India. Overall, the summer monsoon rainfall will show a $20 \%$ increase over the

\#Rs 10 lakh = Rs 1 million

Rs 10 million $=$ Rs 1 crore 
present rate; the increase will be seen in all the states except Punjab, Rajasthan and Tamil Nadu. Simulations with climate models and observations indicate that rainfall extremes such as the Mumbai deluge of 2005 could become more frequent in India under the impact of climate change ${ }^{4}$. Both 2005 and 2006 had spells of excessive rainfall that normally would have occurred once in about 100 years. It has been observed that till 1989 the average rainfall of Mumbai was 2129 $\mathrm{mm}^{5}$. However, in 2005-2006 the average annual rainfall was found to be of $3214 \mathrm{~mm}$, an increase of $50 \%$. Besides the rainfallrelated issue, energy consumption will also be a major issue.

Increase in rainfall and rise in the mean sea level (MSL), in addition to the poor drainage of the city will increase the frequency of floods. Almost one fourth of Mumbai comprises low-lying areas (below or at MSL). Therefore low-income groups and poor residents living in vulnerable locations (accounting for nearly $50 \%$ of Mumbai's population) will be affected more.

A conservative estimate shows that about $40 \%$ population will be affected in the city of Mumbai as shown in Figure 1. Frequent floods and salt-water intrusion will affect the structural stability of high-rise buildings, which are mushrooming at an increasing rate. Floods, especially in the low-lying areas of the city, will result in dislocation of people and also deaths.

Figure 1: Low-lying areas in South Mumbai

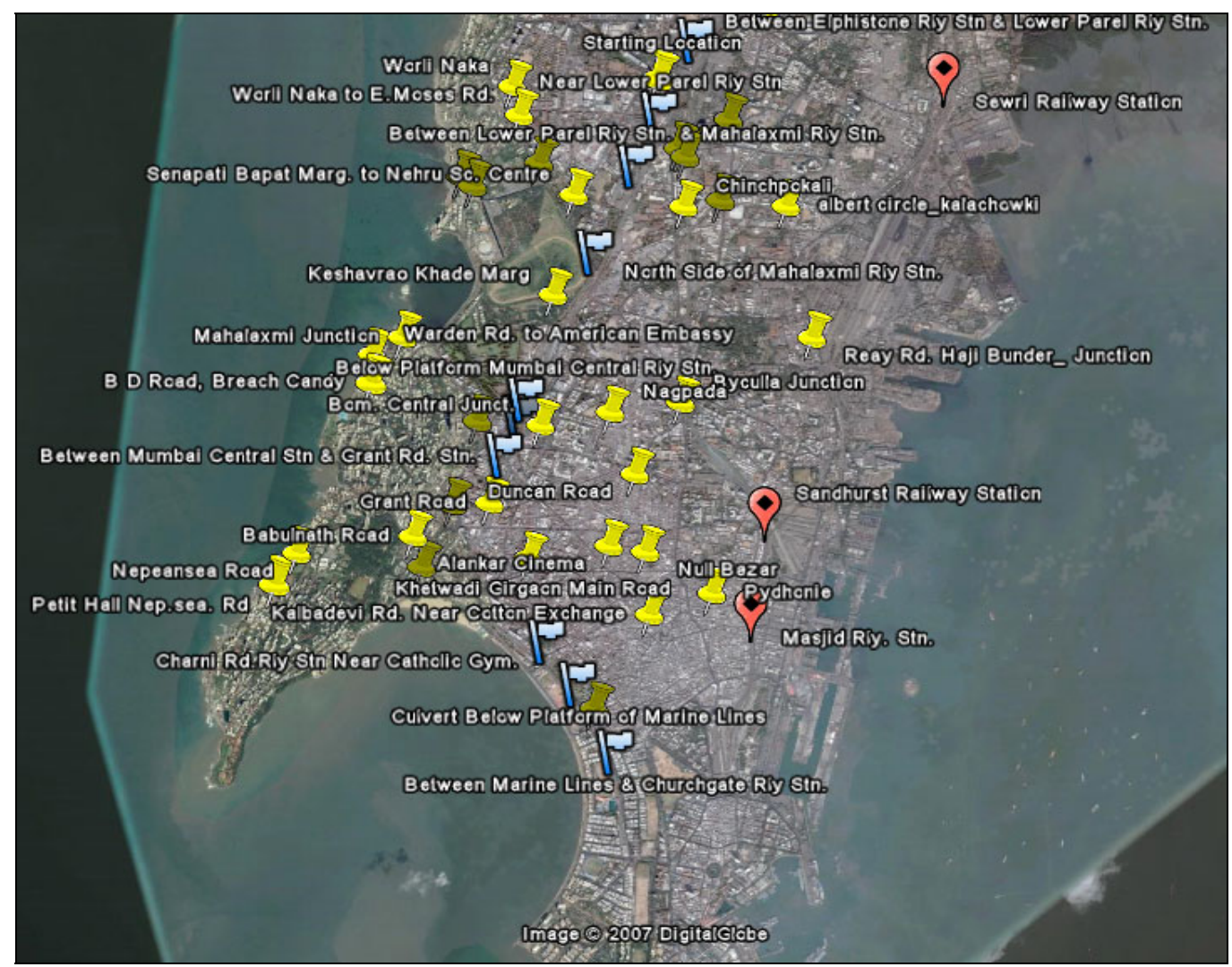


Human health is another major area where the impact of climate change could be very severe. Such an impact would translate mainly into three major illnesses - diarrhoea, malaria and leptospirosis.

The tourism sector will also be hit by climate change. It is likely to suffer a loss of Rs 1963500 crores by the year 2050 .
An economic analysis has been performed to understand these impacts with a view to plan out adaptability strategies for the city for the period up to $2050^{3}$. These cost considerations take into account the most conservative figures with regard to the period of impact, population affected, loss of earnings and material damage.

Table: Estimated economic losses due to the impact of climate change in Mumbai

\begin{tabular}{|l|l|c|}
\hline \multicolumn{1}{|c|}{ Type of impact } & \multicolumn{1}{|c|}{$\begin{array}{c}\text { Type of costs and } \\
\text { period of impact }\end{array}$} & $\begin{array}{c}\text { Cost in rupees } \\
\text { (crores) }\end{array}$ \\
\hline $\begin{array}{l}\text { Dislocation due to extreme events of flooding of low-lying } \\
\text { areas - every five years till 2050* }\end{array}$ & $\begin{array}{l}\text { Cumulative costs over the } \\
\text { period 2005-2050 }\end{array}$ & 407.6 \\
\hline $\begin{array}{l}\text { Material damage to low-lying areas due to extreme } \\
\text { events - every five years till 2050* }\end{array}$ & $\begin{array}{l}\text { Cumulative costs over the } \\
\text { period 2005-2050 }\end{array}$ & 6413 \\
\hline $\begin{array}{l}\text { Mortality costs due to extreme events of flooding - every } \\
\text { five years till 2050* }\end{array}$ & $\begin{array}{l}\text { Cumulative costs over the } \\
\text { period 2005-2050 }\end{array}$ & 3050 \\
\hline $\begin{array}{l}\text { Disability-adjusted life years (DALYs) lost due to diseases } \\
\text { like malaria, diarrhoea and leptospirosis** }\end{array}$ & $\begin{array}{l}\text { Cumulative costs over the } \\
\text { period 2005-2050 }\end{array}$ & 3153 \\
\hline $\begin{array}{l}\text { Building-foundation damages for the period till 2050 due } \\
\text { to sea-level rise*** }\end{array}$ & $\begin{array}{l}\text { Single-cost estimate for } \\
\text { the year 2050 }\end{array}$ & 1501725 \\
\hline Tourism loss: less number of tourists visiting Mumbai**** & $\begin{array}{l}\text { Single-cost estimate for } \\
\text { the year 2050, as } \\
\text { compared with the base } \\
\text { year 2005 }\end{array}$ & 19600 \\
\hline
\end{tabular}

*The costs of work disruption and material damage, as well as mortality costs (loss of earnings) have been computed on the basis of a conservative approach wherein it has been assumed that flooding would be limited to five days in an year and also that the frequency of such extreme occurrences shall be once every five years. The computation has been limited to the year 2050. It also conservatively assumes that the population in these areas will not change, though it would change depending upon the local government policy of development relevant to the timeframe up to 2050. Population figures have been taken from the census for locations shown in Figure 1 based on the area and density of population.

**Increase in the incidence of malaria, diarrhoea and leptospirosis would result in loss of income due to non-working days and deaths. Losses have been computed using Disability-adjusted life years (DALYS) for all the major illnesses likely to impact the population. Incidence of all these illnessses will increase steadily with increase in income loss; a sharp increase is likely from 2045 to 2055. By 2050 the cumulative income loss due to malaria, diarrhoea and leptospirosis, calculated on the basis of DALYS will be 155597 and 2401 crores, respectively. The calculation of DALYs is based on the World Health Organization (WHO) guidelines ${ }^{8,9}$ and income levels prevalent for Mumbai.

${ }^{* * *}$ Due to sea-level rise there will be loss of coastal area and ingress of sea water. Assuming that sea water penetrates $200 \mathrm{~m}$ inland, calculations have been made showing the monetary loss due to buildings getting affected in the region near the shore. The current loss has been computed on the basis of the present value of buildings. This is based on the assumption that buildings along the coastline located within $200 \mathrm{~m}$ from the shore will get affected due to rise in the sea level and ingress of sea water.

${ }^{* * * *}$ Calculations are based on Tourism Statistics of India ${ }^{10}$. Future costs have been calculated using the average gross domestic product (GDP) growth rate of India. It also takes the current rates of $6 \%$ and $13 \%$ increase respectively in domestic and foreign tourism per year into account. 
Computations for economic losses due to climate change have been summarized in the table below. The first four types of costs indicated are for likely impacts of extreme events. The other two costs are for losses likely to be witnessed by the year 2050 . The latter could turn out to be much higher if the frequency of occurrences of extreme events and their duration increase over the period considered in this analysis.

Besides the frequent disease outbreaks, heat stress caused by the rising mercury would also affect the workforce of the city. Episodes of heat cramps, heat exhaustion and heat stroke would affect the population, primarily the large poor section of the society. As the immune system weakens due to heat stress, susceptibility to diseases would further increase. The resulting increase in expenses on health care by individuals would escalate leading to greater stress. Hence, this vicious cycle would lead to depreciation of human resources. Besides human beings, heat stress would not even spare the cattle sheds. It has been found that cattle are more sensitive to heat stress; this could impact milk production from cattle sheds in Mumbai. The effect of raised body temperature is an adaptive depression of the metabolic rate associated with reduced appetite. Factors such as water deprivation, nutritional imbalance and nutritional deficiency may exacerbate the impact of heat stress.

\section{Responses needed}

Though there are indications of the impacts of climate change that could possibly be felt, their micro detailing has not been attempted as yet. Therefore, there is a need for such detailing for Mumbai to understand the economic implications of these impacts and to deal with them effectively. The following could be some of the responses based on anticipated climate changes:

- Micro-level planning for developing on effective drainage system is needed.

- Building experts and other related experts will need to detail the steps to be taken for new building construction practices in order to reduce the salt content of building materials. For older buildings, an assessment and remedial plan will need to be prepared. Buildings very close to the sea shore also need to be examined from the point of view of stability of the land due to erosion (near Dadar and Juhu).

- Greater investment in health sector will be needed for treating people affected by climate change. More health care facilities and health infrastructure will be needed.

- Anti-erosion measures will need to be put in place at beaches and seafronts.

- The protection plan for mangroves and other wetland areas needs to be implemented.

- Energy conservation measures at all levels (appliances, building design, energy use pattern and alternative sources of energy, etc.) need to be instituted.

- An urban ecosystem enhancement (creation of more open spaces, greenery, parks and tree-lined roads, etc) needs to be undertaken. 


\section{References}

1. National Climatic Data Center (NCDC) [Internet]. Asheville (North Carolina): U.S. Department of Commerce.

http://www.ncdc.noaa.gov/oa/ncdc.html accessed on 20 March 2008.

2. Tata Energy Research Institute [Internet]. New Delhi (India): TERI, c2008.

http://www.teriin.org/teri_news.php?num=11 accessed on 20 March 2008).

3. Kumar KR, Sahai AK, Kumar KK, Patwardhan SK Mishra PK, Revadekar JV, Kamala K, Pant GB. High-resolution climate change scenarios for India for the 21 st century. Curent Science 2006 Feb; 90 (3): 334-345

http://www.ias.ac.in/currsci/feb102006/334.pdf accessed 20 March 2008.

4. Frontline: India's National Magazine [Internet]. Chennai (India): The Hindu, c2008.

http://www.hinduonnet.com/fline/ - accessed 19 March 2008.

5. WorldClimate .com [Internet]. Isle of Man: Buttle and Tuttle, c1996-2008.

http://www.worldclimate.com/ - accessed 19 March 2008.

6. Glisters International [Internet]. Mumbai (India): Glisters Internationals. http://www.glisters.com/rates.html - accessed 10 March 2008.

7. Kshirsagar NA, Shinde RR, Mehta S. Floods in Mumbai: impact of public health service by hospital staff and medical students. J Postgrad Med. 2006 Oct-Dec; 52(4):3 12-4.

8. Prüss-Üstün, Annette; Campbell-Lendrum, Diarmid; Corvalán, Carlos; Woodward, Alistair. Assessing the environmental burden of disease at national and local levels: introduction and methods.

Environmental Burden of Disease Series, Nol .

Geneva: World Health Organization, 2003.

http://whalibdoc.who.int/publications/2003/9241 546204.pdf - accessed on 5 March 2008.

9. World Health Organization. National burden of disease studies: a practical guide. 2nd edition. Geneva: WHO, 2001

10. Federation of Hotel and restaurants Association of India [Internet]. New Delhi (India): FHRAI. http://www.fhrai.com. - accessed 20 March 2008.

11. Fung WY, Lam KS, Hung WT, Pang SW, Lee YL. Impact of urban temperature on energy consumption of Hong Kong. Energy. $2006 \mathrm{Nov}$; $31(14): 2623-37$. 


\title{
Climate change and mental health
}

\author{
Prabhat Kumar Chand* and Pratima Murthy**
}

\section{Introduction}

The physical health impacts of climate change, especially infections, allergies and respiratory and cardiovascular diseases are now well recognized. However, the mental health impact of such change, especially in Asian countries became topical after the Asian tsunami. In this article, we attempt to look at the diverse aspects of climate and mental health: seasonal climate variation and its effect on mental health, extreme weather conditions and their psychological impact and specific climatic disasters and their consequences.

\section{Mood and climate}

Seasonal variation of mood, characterized by onset of depression in winter/autumn and its remission or appearance of mania or hypomania in spring is a well-known entity described in the Diagnostic and Statistical Manual (DSM IV) as seasonal affective disorder (SAD). The etiology of cyclical changes of mood is believed to be the fluctuation in daylight hours throughout the year. This is supported by the use of light therapy in the treatment of these conditions. ${ }^{1,2}$ The prevalence of this disorder varies with the

\footnotetext{
*Assistant Professor, Department of Psychiatry, National Institute of Mental Health and Neuro Sciences, Bangalore, India

**Professor, Department of Psychiatry, National Institute of Mental Health and Neuro Sciences, Bangalore, India
}

geographical distance from the equator. Hospital admission studies have shown that apart from seasonality, various climatic parameters including daily ambient temperature, relative humidity, atmospheric pressure, rainfall and hours of sunshine contribute to seasonal variations in bipolar disorder admissions. ${ }^{3-5}$ Carney et al., 6 reported that admission rates for mania were higher in the sunnier months with a longer average day length. They found that the current month's mean daily hours of sunshine and the mean day length correlated with admission rates.

\section{Suicide}

It has been postulated that climate can influence rates of suicide. A study from Italy showed higher rates of suicidal behaviours in the country's northern towns where there was significant climatic variation. Northern towns, as indicated by their latitude, are less exposed to the sun and have lower mean temperatures (both minimum and maximum) than southern towns. Rainfall levels are higher in the north than in the south. This influence was more marked in the case of females. One can only speculate on the link between climates that are dry, little exposed to the sun, and therefore presumably cold and a higher incidence of suicides as seen in the case of SAD. It is possible that living in a place with low exposure to the sun might determine an abnormally persistent stimulation of circuits which use serotonin as a neurotransmitter, leading to adaptations of 
these circuits. This would result in their becoming less responsive to sudden variations in the discharge of serotoninergic neurons. In a person who is vulnerable, climate contributes to this biological risk by modifying the responsiveness of the circuits that control mood and behaviour, and also the frequency and intensity of social interactions. ${ }^{7}$ A total of 71227 male suicides and 26466 female suicides occurring in Italy from 1974 to 2003 were investigated and a significant peak was found in spring. ${ }^{8}$ Of different climatic variables, temperature was found to be positively correlated with suicide rates. Some researchers have suggested that deviations of monthly mean temperatures from the expected mean temperature for that time of the year, rather than absolute ambient temperature, might be much more important for suicidal death.' Extrapolating from such preliminary findings, it is likely that global climatic changes may have a significant impact on various dimensions of mental health and well-being.

\section{Climate and psychosis}

The association between acute psychosis and climatic variation is known, especially in tropical countries. One of the hypotheses of acute psychosis is an increased association with post-viral infections. Borna virus infection outbreaks have been associated with schizophrenia and mood disorders, obsessive compulsive disorders with streptococcal infections and algal toxins with cognitive impairment. ${ }^{10}$ Studies from tropical countries like India suggest an increased prevalence of acute psychosis following viral fever, especially in winter. ${ }^{11}$

Studies undertaken in the Northern Hemisphere have shown a small but relatively consistent excess of winter and spring births of individuals who later develop schizophrenia compared with the general population. ${ }^{12}$ Jablensky $^{13}$ noted that the season-of-birth effect was one of the most robust findings in the epidemiology of schizophrenia. However, later comparisons from the Southern Hemisphere have not supported this relationship. ${ }^{14}$ One of the speculations is that climatic factors other than seasonality need to be studied to support the season-of-birth effect.

The hospital admission rates for schizophrenia and "schizoaffective" patients are clearly increased in summer and fall respectively, as reported in an 11 -year study from Israel. Schizophrenia patients' mean monthly admission rates correlated with the mean maximal monthly environmental temperature, indicating that a persistently high environmental temperature may be a contributing factor for psychotic exacerbation in schizophrenia patients and their consequent admission to mental hospitals. ${ }^{15}$

\section{Extreme weather events and psychological sequelae}

Extreme weather events include periods of very high temperature, torrential rains and flooding, droughts and storms. Hyperthermia, or heat stroke can present with neuropsychiatric symptoms including confusion, delirium and persisting neuropsychological deficits. ${ }^{16}$ Persons with mental illness are more prone to heat stroke, ${ }^{17}$ especially those on antipsychotic and anticholinergic medication. Extreme environments, both hot and cold, can affect human sleep and central stress pathways. ${ }^{18}$ Extreme physical environments, combined with isolation and confinement, can additionally alter cognitive ability and create interpersonal tension and conflict. ${ }^{19}$

\section{Flooding}

It is anticipated that severe flooding may become more frequent due to global warning. A study in southern England following severe flooding in the town of Lewes reported a fourtime higher risk of psychological distress on 
the 12-item General Health Questionnaire. ${ }^{20}$ Despite the tremendous loss to life and property, displacement and other far-reaching adversities, the mental health impact of flooding has not been examined in most parts of the world. Around half the children and adolescents exposed to the 'supercyclone' in the state of Orissa in India reported symptoms of the post-traumatic stress disorder (PTSD) syndrome of different severity even after one year. $^{21}$

\section{Drought}

Another understudied area is the mental health impact of drought, a likely sequel of climate change. Drought affects farmers and can contribute to severe mental agony due to financial hardship from increased debt. It is difficult for farmers to plan for crops, stocking, improvements, breeding and succession. This affects other businesses, limiting their ability to expand and employ staff. Drought affects family relationships. Stress, worry and the rate of suicide increase. Drought can lead to isolation and increased workload as fewer workers take on more work, partners move off the farm for additional income or for school needs, and families can no longer afford social support. ${ }^{22}$ The phenomenon of farmers' suicides in India ${ }^{23}$ is a typical example of the consequences of climatic vagaries in poor, predominantly agrarian economies.

While floods and droughts are regularlyoccurring disasters, the mental health implications of which have not been fully recognized, recent disasters, particularly the tsunami and hurricane Katrina have thrust mental health issues into the foreground.

\section{Disaster}

In general populations, the 12-month prevalence rate of mild and moderate common mental disorders (e.g. mild and moderate depression and anxiety disorders, including PTSD) is on average about $10 \%$ in countries across the world (World Mental Health Survey 2000 data). However, this rate is likely to rise possibly to $20 \%$ after exposure to severe trauma and resource loss. In case of severe mental disorders like psychosis, the $2-3 \%$ rate in general population may be expected to go up (e.g. to approximately 3$4 \%)$ after exposure to severe disaster. Trauma and loss (i) may exacerbate previous mental illness (e.g. may turn moderate depression into severe depression); and (ii) may cause a severe form of trauma-induced common mental disorder in some people. ${ }^{24}$

Following the Asian tsunami of 2005, the World Health Organization estimated that $20-40 \%$ of affected people suffered from short-lasting mild psychological distress and another 30-50\% experienced moderate-tosevere psychological distress. ${ }^{24}$

In Indonesia there was a reported 15$20 \%$ increase in outpatients with anxiety and depression and a corresponding increase in the number of psychotropic prescriptions. Other consequences of disasters include an increase in alcohol and drug abuse. ${ }^{25}$

Disasters result in loss of life with its associated grief, loss of property and most of all, loss of homes. A home however poor and substandard, can symbolize years of personal and familial investment and memories.

An important outcome of the tsunami has been the development of national responses in many Asian countries through emphasis on mental health and psychosocial services and integrating emergency mental health services into disaster emergency services. ${ }^{26}$

Hurricane Katrina has been associated with a high prevalence of psychiatric morbidity. In a telephonic survey of a probability sample of 1043 affected residents, the 30-day prevalence of anxiety-mood disorders was found to be $49.1 \%$ and that of PTSD $26.4 \% .^{27}$ In a longer-term evaluation of the mental health impact of Katrina in a representative 
sample of 815 pre-hurricane residents, the prevalence of PTSD was found to have actually increased over time, as had attempts at selfharm. High prevalence of mental morbidity thus continued even two years after the hurricane. ${ }^{28}$ Such calamities also disrupt the existing mental health services for persons with pre-existing mental disorders and limit treatment for new-onset cases. This illustrates the lack of disaster preparedness even in countries with relatively better developed mental health services. ${ }^{29}$

Several factors appear to determine mental health responses to natural disasters. Most of the literature in this area is from studies of post-disaster impact. One of the core issues that appears to determine psychological response is disaster preparedness. If an individual has come through prior disasters, having coped reasonably well, this prior experience confers knowledge, realistic expectations and a measure of self-efficacy and confidence. If an individual is generally prone to anxiety, or had a prior traumatic experience of a disaster situation, it is probable that in a future disaster situation this anticipatory anxiety or dread will erode both psychological and practical preparedness. Social support, group support, easily accessible network of services are also critical in ensuring better adjustment to an adversity.

Collectivist reactions and shared community beliefs are also critical. A study from Australia shows that residents of the coastal north have developed both a stoicism and elaborated mythology about how the weather affects behaviour during the onset of the wet season. Individual perceptions of their environments include regional beliefs that have both a stereotypic and normative character to them, which can subtly but powerfully influence the perceived reasonableness and/or legitimacy of expressing concerns or distress. ${ }^{30,31}$ Research on "place" meaning, attachment and identity over the past several decades and on the cultural contexts of risk perceptions and responses suggests that communities are deeply affected by such powerful and often devastating 'acts of nature' and engage a spectrum of sense-making, protective strategies and beliefs to make their world and their lives more secure and less unpredictable, threatening and unjust.

\section{Summary and conclusion}

Climate is known to affect human health in different ways. The health impacts of climate change can occur through a number of direct and indirect causal pathways, and the severity is in part determined by the adaptive capacity of the population. ${ }^{32}$ People living in poverty, those geographically vulnerable to extreme weather events, those highly dependent on agriculture for their livelihood and those vulnerable to develop mental illness are at high risk. The principal and direct concerns include injuries and fatalities related to severe weather events and heat waves; infectious diseases related to changes in vector biology, water and food contamination; allergic symptoms related to increased allergen production; respiratory and cardiovascular diseases related to worsening air pollution; and nutritional shortages related to changes in food production. Major concerns, for which data to support projections are less robust, more complex and have multiple determinants are the mental health consequences, population dislocation and civil conflict following the above-mentioned direct sequels. ${ }^{33}$ Mental health consequences need to be studied from several dimensions: psychological distress per se; consequences of psychological distress including proneness to physical diseases as well as suicide; and psychological resilience and its role in dealing effectively with the aftermath of disasters. 


\section{References}

1. Rosenthal NE, Sack DA, Gillin JC, Lewy AJ, Goodwin FK, Davenport Y, et al. Seasonal affective disorder: a description of the syndrome and preliminary findings with light therapy. Arch Gen Psychiatry. 1984 Jan; 41 (1): 72-80.

2. Boyce P, Parker G. Seasonal affective disorder in the southern hemisphere. Am J Psychiatry. 1988 Jan; 145(1): 96-9.

3. Mawson D, Smith A. Relative humidity and manic admissions in the London area. Br J Psychiatry. 1981 Feb;138:134-8.

4. Abdul-Rahim FA, Al-Sabai A, Al-Hamad AR, Bamgboye $E$. The seasonality of mania: preliminary findings. Ann Saudi Med. 1992 Sep; 12(5):472-5.

5. Salib E and Sharp N. Relative humidity and affective disorders. Int. J. Psychiatry Clin. Pract. 2002; 6: 147- 53

6. Carney PA, Fitzgerald CT and Monaghan CE. Influence of climate on the prevalence of mania. $\mathrm{Br}$. J. Psychiatry. 1988 Jun; 152: 820-823.

7. Preti A, Miotto P. Seasonality in suicides: the influence of suicide method, gender and age on suicide distribution in Italy. Psychiatry Res. 1998 Nov; 81 (2): 219-231.

8. Rocchi MB, Sisti D, Cascia MT, Preti A. Seasonality and suicide in Italy: amplitude is positively related to suicide rates. J Affective Disorders . 2007 Jun; 100 (1-3): 129-36.

9. Marion SA, Agbayewa MO, Wiggins S. The effect of season and weather on suicide rates in the elderly in British Columbia. Can. J. Public Health. 1999 Nov-Dec; 90 (6): 418-22.

10. Jain S, Murthy P, Shankar SK. Neuropsychiatric perspectives from nineteenth-century India: the diaries of $\operatorname{Dr}$ Charles I Smith. History of Psychiatry. 2001 Dec; 12 (48 Pt 4): 459-66.

11. Collins PY, Varma VK, Wig NN, Moitabai R, Day R, Susser E. Fever and acute brief psychosis in urban and rural settings in north India. Br J Psychiatry. 1999 Jun; 174:520-4.

12. Torrey EF, Miller J, Rawlings R, Yolken RH. Seasonality of births in schizophrenia and bipolar disorder: a review of the literature. Schizophr Res. 1997 Nov; 28(1): 1-38.

13. Jablensky A. Schizophrenia: the epidemiological horizon. In: Hirsch SR, Weinberger DR.EEds. Schizophrenia. Oxford: Blackwell Science, 1995: pp. 206-52.
14. McGrath JJ, Welham JL. Season of birth and schizophrenia: a systematic review and metanalysis of data from the Southern Hemisphere. Schizophrenia Research. 1999; 35: 237-242.

15. Shiloh R, Shapira A, Potchter $O$, Hermesh $H$, Popper M, Weizman A. Effects of climate on admission rates of schizophrenia patients to psychiatric hospitals. European Psychiatry. 2005 Jan; 20(1): 61-4.

16. Romero JJ, Clement PF, Belden C. Neuropsychological sequelae of heat stroke: report of three cases and discussion. Mil Med. 2000 Jun; 165(6): 500-3.

17. Naughton MP, Henderson A, Mirabelli MC, Kaiser R, Wilhelm JL, Kieszak SM, Rubin CH, McGeehin MA. Heat related mortality during a 1999 heat wave in Chicago. Am J Prev Med. 2002 May;22(4): 221-7.

18. Buguet A. Sleep under extreme environments: effects of heat and cold exposure, altitude, hyperbaric pressure and microgravity in space. $J$ Neurol Sci. 2007 Nov; 262(1-2): 145-52.

19. Palinkas LA, Suedfeld P. Psychological effects of polar expeditions. Lancet. 2008 Jan 12; 371 (9607): 153-63.

20. Reacher M, McKenzie K, Lane C, Nichols T, Kedge I, Iversen A, Hepple P, Walter T, Laxton C, Simpson J; Lewes Flood Action Recovery Team. Health impacts of flooding in Lewes: a comparison of reported gastrointestinal and other illness and mental health in flooded and non-flooded households. Commun Dis Public Health. 2004 Mar; 7(1): 39-46.

21. Kar N, Mohapatra PK, Nayak KC, Pattanaik P, Swain SP, Kar HC. Post-traumatic stress disorder in children and adolescents one year after a supercyclone in Orissa, India: exploring cross-cultural validity and vulnerability factors. BMC Psychiatry. 2007 Feb 14; 7: 8.

22. Sartore GM, Kelly B, Stain HJ. Drought and its effect on mental health - How GPs can help. Aust Fam Physician. 2007 Dec; 36(12): 990-3.

23. Tata Institute of Social Sciences. Causes of farmer suicides in Maharashtra: an enquiry. Osmanabad: Tata Institute of Social Sciences, 2005. http://www.tiss.edu/Causes\%20of\%20Farmer\%20S vicides\%20in\%20Maharashtra.pdf - accessed on 11 March 2008

24. World Health Organization. Mental health assistance to population affected by the Tsunami in Asia [Internet]. Geneva: WHO, c2008. (www.who.int/mental health/resources/tsunami accessed on 11 March 208). 
25. Math SB, Girimaji SC, Benegal V, Uday Kumar GS, Hamza A, Nagaraja D. Tsunami: psychosocial aspects of Andaman and Nicobar islands. Assessments and intervention in the early phase. Int Rev Psychiatry. 2006 Jun; 18(3): 233-9.

26. Ruzek Jl, Young BH, Cordova MJ, Flynn BW. Integration of disaster mental health services with emergency medicine. Prehosp Disaster Med. 2004 Jan-Mar; 19(1): 46-53.

27. Galea S, Brewin CR, Gruber M, Jones RT, King DW, King LA, McNally RJ, Ursano RJ, Petukhova M, Kessler RC. Exposure to hurricane-related stressors and mental illness after Hurricane Katrina. Arch Gen Psychiatry. 2007 Dec; 64(12): 1427-34.

28. Kessler RC, Galea S, Gruber MJ, Sampson NA, Ursano RJ, Wessely S. Trends in mental illness and suicidality after Hurricane Katrina. Mol Psychiatry. 2008, Jan 8 Epub ahead of print.

29. Wang PS, Gruber MJ, Powers RE, Schoenbaum M, Speier AH, Wells KB, Kessler RC. Disruption of existing mental health treatments and failure to initiate new treatment after Hurricane Katrina. Am J Psychiatry. 2008; 165 (1): 34-41.
30. Jull P. The politics of northern frontiers in Australia, Canada and other 'first world' countries: a discussion paper. Darwin: North Australian Research Unit, Australian National University, 1991.

31. Morrissey SA. Seasonal affective disorder: characteristicsand prevalence in North Queensland. PhD Thesis. Townsville: James Cook University of North Queensland, 1995.

32. Confalonieri $U$, Menne B, Akhtar R, Ebi KL, Hauengue M, Kovats RS, Revich B, Woodward A. Human health. In: Climate change 2007: impacts, adaptation and vulnerability. Contribution of Working Group II to the Fourth Assessment Report of the Intergovernmental Panel on Climate Change. ML Parry, OF Canziani, JP Palutikof, PJ van der Linden, CE Hanson. Eds. Cambridge: Cambridge University Press, 2007. pp. 391-431.

33. Frumkin $\mathrm{H}$, Hess J, Luber G, Malilay J, McGeehin M. Climate change: the public health response. Am J Public Health. 2008 Mar; 98(3): 435-45. 


\title{
Adaptation measures for human health in response to climate change in Maldives
}

\author{
Dr Sheena Moosa*
}

\section{Impact of climate change on human health}

The impacts of climate change on human health in Maldives can be grouped into three categories (Corvalàn et al., 2005) used in the Millenium Ecosystem Assessment (www.millenniumassessment.org). These are:

(1) Direct health impacts due to disasters causing injury and death, such as tidal waves causing water shortage and increased exposure to ultraviolet radiation (UVR) causing diseases of the skin and subcutaneous tissue like cold sores and pterygium of the eye.

(2) Ecosystem-mediated health impacts resulting in altered infectious disease risk and pattern as seen in the epidemiology of dengue and emergence of scrub typhus.

(3) Indirect and deferred health impacts such as diverse health consequences of livelihood loss and population displacement following extreme weather events such as tidal waves and swells resulting in mental and psychosocial health issues.

The actual health impacts are influenced by local environmental conditions and socioeconomic circumstances and the adaptation measures taken to reduce these effects on health (McMichael et al., 2003). It is estimated that environmental risk factors

*Ministry of Health, Maldives contribute to $24 \%$ of the global burden of disease from all causes and to $23 \%$ of all deaths worldwide (Corvalàn et al., 2005).

In Maldives the population today enjoys a considerably improved health status. However, despite the achievements in communicable disease control and epidemiological transition of disease burden, the country is continuously burdened with emerging communicable diseases and chronic conditions which are linked to environmental issues. These include disease conditions that arise due to unsafe water and food, poor environmental sanitation and hygiene, pollution and global warming.

Although mortality due to diarrhoea and acute respiratory infections has been reduced to zero, both diseases continue to cause significant morbidity among children $(<5$ years of age) and adults ( $>5$ years of age). This is depicted in Figure 1. Disease trends over the past four years show continued high levels of morbidity due to acute gastroenteritis. In the years 2002-2004, about 15000 cases were reported, while this figure increased by almost $50 \%$ in 2005 .

It is estimated that $2.4 \%$ of global diarrhoea is due to climate change and that rainfall patterns and storms influence the transport and distribution of infectious agents while temperature affects their growth (Patz et al., 2003). A time series analysis conducted in island nations such as Fiji showed a $3 \%$ 
increase in reported cases of diarrhoea per $1{ }^{\circ} \mathrm{C}$ increase in temperature (Hales et al., 2003). The diseases of the rainy season include giardiasis, E.coli, cryptosporidiosis, typhoid shigella and hepatitis $A$ and $E$. These diseases can create problems during flooding and sewage contamination of surface water, including contamination of recreational water sources.

\section{Figure 1: Incidence of acute gastroenteritis in Maldives (2002-2005)}

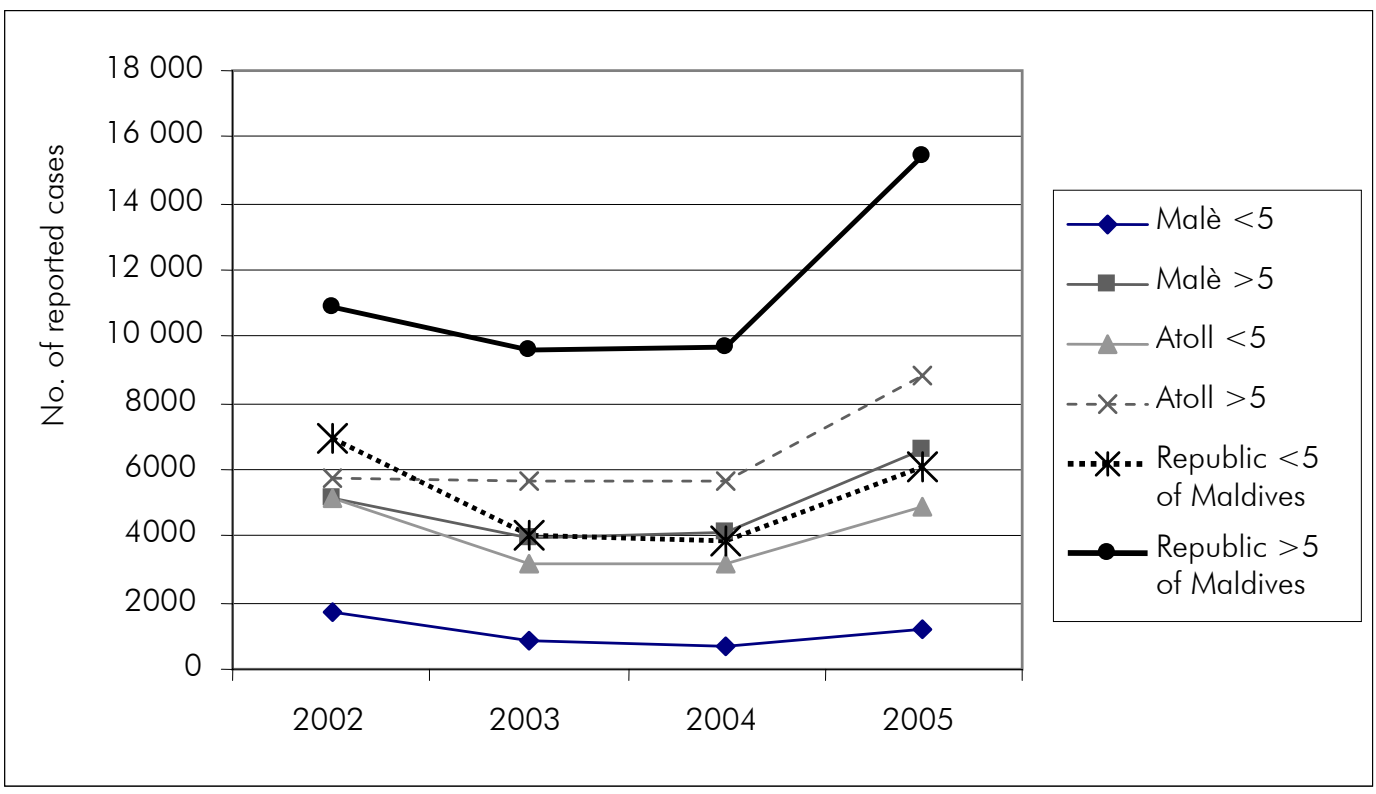

(Source: Epidemiological Surveillance Records, Directorate of Public Health (DPH), Ministry of Health, Maldives, 2006)

Studies of marine surface water also indicate an increase in vibrio cholerae in areas of increased surface temperatures (Patz et al., 2003). The World Health Organization (WHO) reports that climate-sensitive marine biotoxins cause poisoning of scromboid fish, paralytic shellfish and ciguatera, thereby affecting human health too. (WHO, 2005).

Although etiological data of gastroenteritis cases is not available, the trend closely follows climatic events such as altered rainfall pattern in 2004 and 2005 in Maldives. It is important to note from the above data that people living in the atolls are more vulnerable to diarrhoeal diseases compared to the population living in Malè and that this disparity is more pronounced in children under five years of age.
Vector-borne diseases such as dengue and scrub typhus have emerged as major communicable diseases of public health concern. Although there is significant morbidity due to dengue, with appropriate case management, the dengue case fatality rate remains quite low at $0.4 \%$ [Directorate of Public Health (DPH), 2006]. The disease trends show that dengue is now endemic in the country with seasonal outbreaks. Epidemiological data show changes in the seasonal nature of dengue, with its continued high prevalence from mid-2005, spreading to the atolls, and leading finally to epidemic proportions (Figure 2), thereby causing disruption of economic and social activities. This trend is linked to increased rainfall in the latter half of 2005 as indicated by the national meteorological data. 
Figure 2: Incidence of dengue in Maldives (2000-2005)

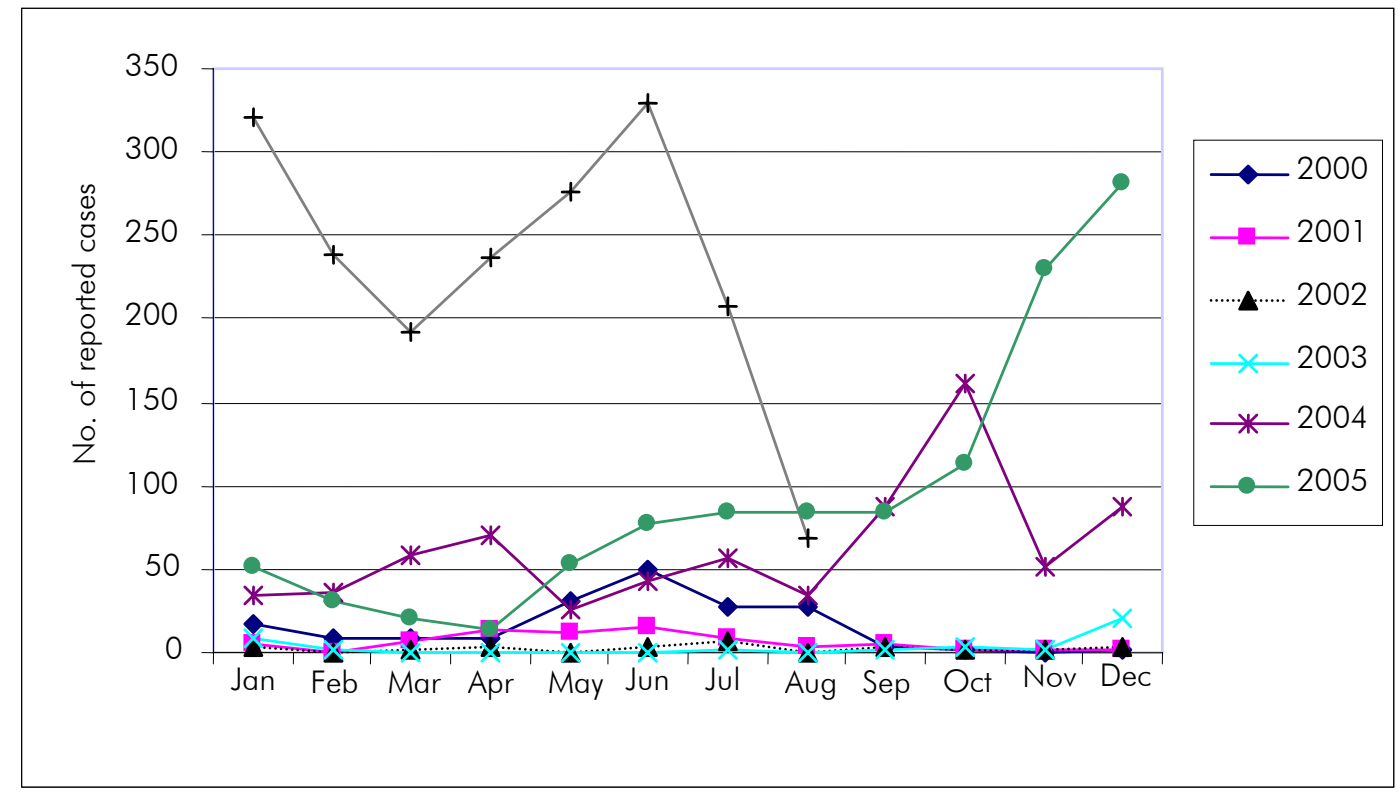

(Source: Epidemiological Surveillance Records, DPH, Ministry of Health, Maldives, 2006)

It is estimated that $95 \%$ of the global dengue burden is attributable to environmental factors (Prüss-Üstün et al., 2006). Since a number of infectious diseases show seasonality, with implied association with climatic factors, climatic conditions in a particular region affect the infectious disease pattern globally. When changes in the ecosystem occur, the pattern and extent of an infectious disease depends on the ecosystem affected, the type of land use, disease transmission dynamics and socio-cultural practices (Corvalàn et al., 2005). The important environmental factors include temperature, precipitation and humidity (Hales et al., 2003; Patz et al., 2003). In Maldives, an increase in dengue incidence leading to epidemic proportions was observed for about nine months following the tsunami (DPH, 2006). However indirect factors also were involved, such as changes in the pattern of rainfall, poor waste management, increased rebuilding activities and increased island-toisland transport (DPH, 2006).

Factors such as sea-level elevation, wind, flooding or drought and duration of daylight are important in the context of vector- and rodent-borne diseases. These factors lead to changes in the growth, distribution and survival of vectors and in their transmission seasons by altering their feeding rates and host contacts. At the same time, these factors also alter habitats, thereby leading to increase in vector breeding sites or in "reservoir host" distribution; human-induced genetic changes such as resistance to pesticides; and environmental contamination by infectious disease agents (WHO, 2005).

Scrub typhus which was endemic in the country in the early Twentieth century, reemerged in 2002 resulting in mortality rates as high as $10 \%$. Although the mortality rate has declined to $1 \%$ with appropriate case management, scrub typhus continues to be prevalent causing significant morbidity (Figure 3).

In addition to infectious diseases, Maldives is witnessing an increase in the negative conditions of the skin, subcutaneous tissue and of the eyes. This increase is linked closely to climate change that is resulting in 
increased exposure to ultraviolet radiation (UVR). Medical records at the main referral hospital in the country indicate rapid increase in radiation-related disorders of the skin and subcutaneous tissue, as well as in cases of herpes viral vesicular dermatitis (cold sores). They also show an increasing trend of pterygium, a condition of the eye related to exposure to UVR (Figure 4).

\section{Figure 3: Incidence of scrub typhus in Maldives (2000-2005)}

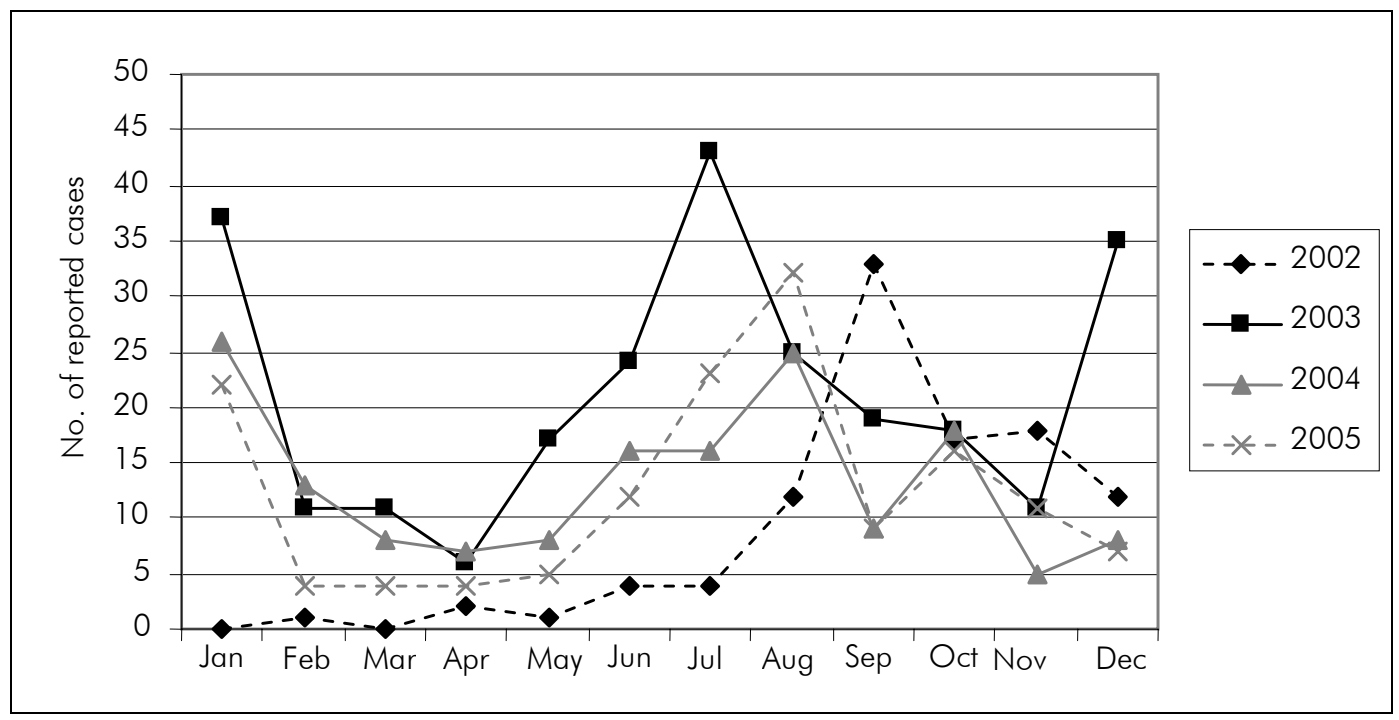

(Source: Epidemiological Surveillance Records, DPH, Ministry of Health, Maldives, 2006)

Figure 4: Morbidity due to the condition of the skin and eyes (2002-2005)

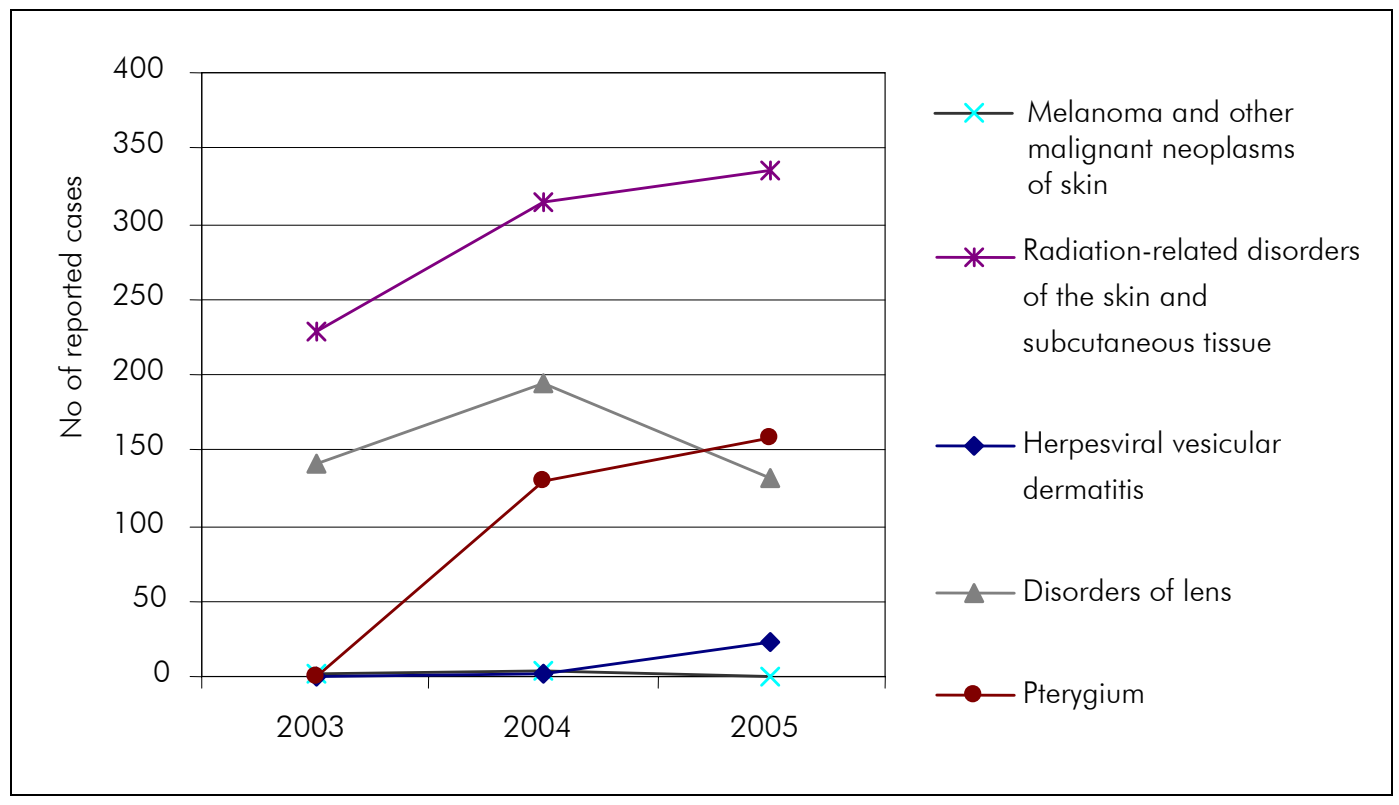

(Source: Medical records, Indira Gandhi Medical Hospital, Malè) 
It is estimated that globally up to 60000 deaths occur per year due to too much exposure to UVR (Prüss-Üstün et al., 2006). Of these, about 48000 are caused by malignant melanomas and 12000 by skin carcinomas. This amounts to a loss of 1.5 million disability-adjusted life years (DALYs) due to UVR exposure. Of all malignant melanomas, $50-90 \%$ are estimated to be due to UVR exposure, while $50-70 \%$ of skin cancers are attributable to UVR exposure. In addition to these, UVR causes sunburns, skin photoageing, reactivation of herpes of the lip (cold sores) and conditions of the eye such as cataracts and pterygium. The UVR exposures cause $100 \%$ of all photoageing and sunburns and $25-50 \%$ of cold sores of the lip. Of the eye conditions, $5 \%$ of all cataracts and 40 $70 \%$ of pterygium are attributable to UVR exposure (WHO, 2006).

Table: Health effects attributable to climate change and environmental conditions

\begin{tabular}{|c|c|c|}
\hline Health outcomes & $\begin{array}{l}\text { Environmental factors leading to health } \\
\text { outcomes }\end{array}$ & $\begin{array}{l}\text { Attributable proportion } \\
\text { of environmental } \\
\text { factors* }\end{array}$ \\
\hline Diarrhoeal diseases & $\begin{array}{l}\text { Unsafe water (rain, ground and recreational } \\
\text { water); flooding; increased temperature; } \\
\text { contaminated food; malnutrition; personal } \\
\text { hygiene }\end{array}$ & $84-98 \%$ \\
\hline Upper respiratory infections & $\begin{array}{l}\text { Overcrowding; indoor air pollution; } \\
\text { malnutrition }\end{array}$ & $14-38 \%$ \\
\hline Dengue & $\begin{array}{l}\text { Deforestation; variations in climate - rainfall } \\
\text { and temperature; urbanization; waste } \\
\text { management; water resources management; } \\
\text { environmental hygiene }\end{array}$ & $90-99 \%$ \\
\hline $\begin{array}{l}\text { Lower respiratory infections } \\
\text { and chronic obstructive } \\
\text { lung diseases }\end{array}$ & $\begin{array}{l}\text { Indoor and outdoor air pollutants and } \\
\text { chemicals; tobacco smoke; smoke from solid } \\
\text { fuels }\end{array}$ & $32-47 \%$ \\
\hline Malnutrition & $\begin{array}{l}\text { Macro and micronutrient shortage; } \\
\text { contaminated food and water; hygiene } \\
\text { practices }\end{array}$ & $39-61 \%$ \\
\hline $\begin{array}{l}\text { Cancers of the skin and } \\
\text { subcutaneous tissue }\end{array}$ & $\begin{array}{l}\text { UVR exposure; chemical exposure; outdoor } \\
\text { occupations }\end{array}$ & $50-70 \%$ \\
\hline Cataracts & UVR exposure; outdoor occupations & $5-10 \%$ \\
\hline Pterygium & UVR exposure; outdoor occupations & $40-70 \%$ \\
\hline $\begin{array}{l}\text { Rodent- and tick-borne } \\
\text { diseases (leptospirosis and } \\
\text { scrub typhus) }\end{array}$ & $\begin{array}{l}\text { Deforestation; outdoor occupations; waste } \\
\text { management; environmental hygiene; personal } \\
\text { hygiene }\end{array}$ & $\begin{array}{l}\text { Moderate association } \\
\text { (percentage data NA) }\end{array}$ \\
\hline Injuries & $\begin{array}{l}\text { Disasters; recreational environment; built-up } \\
\text { environment }\end{array}$ & $16-60 \%$ \\
\hline Drowning & Flooding; disasters; recreational environments & $46-91 \%$ \\
\hline Poisonings & Chemicals & $52-86 \%$ \\
\hline
\end{tabular}

* Reproduced from Prüss-Üstün et al., 2006

NA - not available 
An examination of the disease burden in Maldives shows that at present a number of disease conditions of public health importance are linked to environmental factors. These include those related to unsafe water, food and nutrients including fish; air pollution; weather changes with resulting emergence of vector- and rodent-borne diseases; and UVR exposure. The table shows diseases which are linked to environmental factors in Maldives. Following a global pattern, the less-developed communities (as those in the atolls) and children are more vulnerable, as observed earlier in this article.

\section{Adaptation measures for human health}

The health impact of climate change is dependent on the vulnerability of the population and the ability of the population and health systems to respond and adapt to climate change (McMichael et al., 2003).

The vulnerability of the population to climate change and its ability to adapt depends on factors such as population density and the level of economic development of a country (Corvalàn et al., 2005). In addition, local environmental conditions, food availability, income levels, pre-existing health status and quality and accessibility of public health care are factors that affect the vulnerability of the population (McMichael et al., 2003).

Assessments of environmental disease burden indicate that populations living in developing countries are more vulnerable to environmental health hazards than those living in developed countries (Corvalàn et al., 2005). Prüss-Üstün et al., estimate that the total number of healthy years of life lost per capita due to environmental burden is 15 times higher in developing countries. And globally, healthy years of life lost due to environmental factors are five times greater in children under five years than in the total population, with $36 \%$ deaths among children between 0-14 years attributable to environmental factors. This number increases eight times for children living in developing countries, as compared to those living in developed countries. Similarly, populations of small island states are more vulnerable (Ebi et al., 2006). In case of extreme weather conditions, children and the elderly are seen to be more vulnerable. Age, socioeconomic status, housing conditions and behaviour are indicators of vulnerability to temperaturerelated mortality (Hales et al., 2003).

For Maldives, the following adaptation measures could be taken to reduce the human health impact of climate change:

- Strengthening of public health infrastructure and services is identified as the most cost-effective, core adaptation strategy globally (Patz et al., 2003). In the context of Maldives, this includes public health-trained personnel, effective surveillance systems for monitoring disease patterns, epidemiological investigations, strategically planned public health emergency response systems and sustainable prevention and control programmes.

- Developing community capacity to protect people and help them adapt to climate changes as a social response to extreme weather conditions and disasters is another important strategy to minimize the health impacts of climate change (Hales et al., 2003). In Maldives this includes awareness-raising and skill development in response to disease outbreaks, public health hazards and disasters, as well as utilizing appropriate technology.

- National assessments of the impact on human health as an integral part of environmental impact assessments are also essential (McMichael et al., 2003). In Maldives, this includes 
identifying data gaps and undertaking and documenting entomological and epidemiological research with development of appropriate models and methodology for climate change, adaptation and mitigation in small island states.

- Developing capacity for knowledge management through networking of the academia, research institutions and technical and expert groups, both within the country as well as in other small island states $(\mathrm{WHO}$,

\section{References}

Corvalàn et al., 2005. Ecosystems and human wellbeing: health synthesis. Geneva: World Health Organization.

http://www.who.int/globalchange/ecosystems/ecosys.pdf - accessed on 19 March 2008.

Department of Public Health, 2006. National strategic plan for prevention of dengue and dengue hemorrhagic fever. Male: Government of the Republic of Maldives, Ministry of Health.

Ebi et al., 2006. Climate variability and change and their effects in small island state: Information for adaptation planning in the health sector. Environmental Health Perspectives 114 (12):1957-1963.

http://www.ehponline.org/members/2006/8429/8429.pdf - accessed 19 March 2008.

Hales et al., 2003. Health impacts of climate extremes. In: McMichael, eds. Climate change and human health: risks and responses. Geneva: World Health

Organization.

http://www.who.int/globalchange/climate/en/chapter5.p df - accessed 19 March 2008

Lewis et al., 2003. Scrub Typhus re-emergence in the Maldives, Emerging Infectious Diseases. Dec; 9

(12): 1638-41.

http://www.cdc.gov/ncidod/EID/vol9no12/pdfs/030212.pdf - accessed 19 March 2008

McMichael et al., 2003. Climate change and human health-risks and responses. Geneva: World Health Organization.

http://whalibdoc.who.int/publications/2003/92415624

8X eng.pdf - accessed 19 March 2008.
2005). Seminars and other forums including Internet-based forums should be explored to enable continuous exchange of information, building up of a knowledge base and timely access to relevant information and data.

- Protection and preservation of natural environmental resources, especially water sources and wetlands with the use of appropriate technology that promotes human health (Grambsch et al., 2003).

McCarthy et al., 2001. Climate change 2001: impacts, adaptation and vulnerability; Cambridge: Cambridge University Press.

http://www.grida.no/climate/ipcc tar/wg2/pdf/wg2TARfr ontmatter.pdf accessed 01.03.2008

Patz et al., 2003; Climate change and infectious diseases. In: McMichael, eds. Climate change and human health - risks and responses. Geneva: World Health Organization.

http://www.who.int/globalchange/publications/climatech angechap6.pdf - accessed 19 March 2008.

Prüss-Üstün et al., 2006. Preventing disease through healthy environments: towards an estimate of the environmental burden of disease. Geneva: World Health Organization.

www.who.int/quantifying_ehimpacts/publications/prevent ingdisease.pdf - accessed on 19 March 2008.

WHO 2005. Climate and Health - Fact Sheet, July 2005. Geneva: World Health Organization.

http://www.who.int/globalchange/news/fsclimandhealth/ en/index.html - accessed 19 March 2008.

WHO 2005. Moving Beyond the Tsunami: the WHO story. New Delhi: World Health Organization, Regional Office for South-East Asia.

http://whqlibdoc.who.int/searo/2005/9290222425 eng .pdf accessed 19 March 2008.

WHO 2006. Health consequences of excessive solar UV radiation; Fact Sheet No 227 August 1999. Geneva: WHO Press Office. www.who.int/entity/uv/resources/fact/en/fs227toomuchs un.pdf - accessed 19 March 2008. 


\title{
Opinion
}

\section{Indonesia's vulnerability to climate change: An increasing trend}

\author{
Tom Staringa*
}

Disaster occurrences and losses associated with them have increased dramatically in recent years in Indonesia. While their association still needs to be documented, there is no doubt that human activities and their impacts on the environment are generating conditions favouring global warming and climate change. The report by the Intergovernmental Panel on Climate Change (IPCC), presented at a meeting held in Bali in December 2007, stated that there was unequivocal evidence of disasters caused by flooding, landslides, droughts, forest fires and coastal erosions having become more frequent in Indonesia. At the same time, however, the vulnerability of population to such disasters has not been reduced due to many reasons, including economic and political. One could in fact argue that losses from recent disasters outweigh development gains, thereby increasing the challenge to achieve the Millennium Development Goals.

Events related to unevenly distributed rainfall are and have been a major concern in Indonesia. The country's rainfall patterns are dependent on the location and movement of the atmospheric pressure cyclones in the eastern South Indian Ocean (January to April) and the eastern Pacific Ocean (May to December). Strong winds

* WHO Country Office, Indonesia often occur during the transition between the north-east and the south-west monsoons. In recent years, these extreme climatic events have become more frequent and their impact more severe. While between 1844 and 1960, droughts occurred on an average every four years, between 1961 and 2006, they occurred every three years. The El Niño event of 1997-1998 was the most severe in the last 50 years. The El Niño refers to changes in ocean currents in the Pacific Ocean, making them unusually warm. The opposite case, when the currents are unusually cold, is called La Niña. Linked with these events is the "Southern Oscillation" which refers to changes in atmospheric pressure in the Southern Hemisphere. Taken together, they are called the El Niño-Southern Oscillation (ENSO). El Niño events bring more droughts, La Niña, more floods. Over the period 1844-2006, out of 43 droughts, 37 were associated with an El Niño. The ENSO is also one of the main factors in the frequency of major forest fires, which in turn trigger atmospheric haze.

The islands of Java, Madura, Bali, West Nusa Tenggara and East Nusa Tenggara suffer from a water deficit during the dry season. These islands host about $65 \%$ of Indonesia's population and $60 \%$ of its irrigated agricultural areas, as well as about $70 \%$ of its industry. Decreased rainfall during critical times of the year would translate into 
reduced agricultural production and drastic increases in the number of malnourished people, thereby hindering progress against poverty and causing food insecurity (Wang et al., 2006).

During the rainy season, many of Indonesia's rivers swell with large discharges causing floods, while the upper watersheds of many major rivers suffer from land degradation. The number of people living in flood- and landslide-prone areas is increasing with urbanization. During the Jakarta flood of 2 February 2007, 70000 houses were inundated, 420440 people were displaced and losses were estimated at the equivalent of US\$ 450 million (WHO, 2007). Heavy rainfalls and flooding overwhelm rudimentary systems of sanitation in slum areas of towns and cities, thereby exposing people to waterborne diseases such as diarrhoea and cholera. Prolonged, intense heat waves coupled with high humidity lead to heat exhaustion particularly among the urban poor and the elderly.

Stronger, more frequent El Niño events will exacerbate drying and/or flooding trends and could lead to decreased food production and increased hunger. Delayed wet season (monsoon) and a temperature increase beyond $2.5^{\circ} \mathrm{C}$ are projected to cause a substantial drop in rice yields and a loss in farm-level net revenue of 9 to $25 \%$ (Lal, 2007).

Changing rainfall patterns will reduce the availability of water for irrigation and for drinking. In coastal areas, the loss of groundwater combined with rising sea levels will also allow more sea water to intrude into water sources.

Indonesia is acutely aware that global temperature change will result in a rise in the sea level. This will have serious consequences for the country, which is an archipelago comprising 17500 islands and a coastline of more than 81000 kilometres. The industrial infrastructure, urban populations and the most fertile agricultural lands are concentrated in low-lying coastal areas. Of a total of about 180 million Indonesians, approximately 110 million live in coastal areas. Indonesia will therefore suffer significant physical and socioeconomic impacts from even very small rises in the sea level.

The sea level has been increasing at 1-3 millimetres $(\mathrm{mm}) /$ year, but is projected to accelerate to a rate of about $5 \mathrm{~mm}$ per year over this century (Cruz et al., 2007), thereby increasing the number of people in South Asia affected by floods annually, from 13 million to 94 million [under a very conservative sea-level rise scenario - $40 \mathrm{~cm}$ by 2100 (Wassmann et al., 2004)]. Millions will be at risk from flooding and sea-water intrusion due to sea-level rise and declining dry-season precipitation, negatively impacting the aquaculture industry (e.g. fish and prawn industries) and infrastructure along the coasts of South and South-East Asia, (Cruz et al., 2007). A rise in the sea level also threatens Indonesia's coastal mangroves (Tran et al., 2005).

Deforestation and forest fires in Indonesia have made the country the thirdlargest contributor of greenhouse gases behind the United States of America and China. Logging (legal and illegal) and land use change - mainly to plant palm trees for biofuel - release enormous amounts of carbon stored in plant matter and in the soil peat. More frequent forest fires will have significant impacts on forest losses, wildlife habitat and biodiversity and would translate into serious domestic and trans-boundary pollution with grave economic consequences: the economic costs of droughts and fires in 1997-1998 were estimated at about US\$ 9 billion (Applegate et al., 2002).

Global warming and climate change in Indonesia present a high risk to its unique biodiversity. Fisheries will be directly affected due to the projected loss of $88 \%$ coral reefs in Asia in the next 30 years due to warming seasurface temperatures, sea-level rise and other 
added stresses (Wilkinson, 2004). Significant declines in fish larvae abundance and largescale changes in fish habitat, such as tuna, are projected in the equatorial Pacific (Cruz et al., 2007; Loukos et al., 2003).

Climate change threatens to undermine Indonesia's efforts to combat poverty. Its projected impacts will intensify the risks and vulnerabilities that poor people are facing already, placing further stress on the overstretched coping mechanisms. Climate change impacts may lead to forced migration, thereby resulting in a rise and/or exacerbation of social tensions.

As climate changes become increasingly known at the global level, it still remains difficult at the local level to raise awareness for the need to integrate the issue of climate change into everyday life and planning for the future. A bit "too much rain" during the rainy season or "too little" in the dry months are not yet associated with the first signs of a permanent change.

There is an urgent need to create awareness among all concerned, especially the decision-makers on how climate change is evolving, its impacts in general and effects on human health in particular. Thus, the health sector has a key role to play in initiating adaptation and/mitigation efforts to protect health from the adverse effects of climate change. 


\section{Comment}

\section{Notes and news}

\section{Biregional programme managers' meeting on dengue}

A biregional programme managers' meeting on dengue was held in Phuket, Thailand from 19 to 21 September 2007. In his message, (delivered by Dr Myint Htwe, Director, Programme Management, WHO/SEARO) the Regional Director, Dr Samlee Plianbangchang said, "Over the last two or three decades, dengue and dengue haemorrhagic fever have emerged as serious public health problems. These problems are acutely serious in the AsiaPacific region, where the population "at risk" of dengue is huge. Effective tools and interventions to prevent and control dengue have been available for more than two decades, and there have been several success stories in countries of the Asia-Pacific region. These success stories need to be critically reviewed so that the lessons learnt can be applied, modified as appropriate, and practical and cost-effective national operational plans designed to prevent and control dengue. We are all aware that an optimal mix of different tools and interventions play an important role in containing any disease or condition. We need to work out and identify the best combination of interventions depending on the epidemiological scenario of an area or country."

The Regional Director concluded, "I hope that this meeting will serve as a landmark to launch an all-out war against dengue through strong collaboration between the two $\mathrm{WHO}$ regions and with full support from WHO headquarters and all the experts present at this meeting."

\section{The South-East Asia Public Health Education Institutions' Network (SEAPHEIN)}

The Third Annual Meeting of the South-East Asia Public Health Education Institutions' Network (SEAPHEIN) was held in Jaipur, Rajasthan, India from 25 to 28 September 2007.

Delivering his inaugural address on the occasion, the Regional Director, Dr Samlee Plianbangchang, said, "The theme of the meeting, "Moving SEAPHEIN to Influence Public Health Policy and Action" is indeed encouraging and timely. For many reasons, it is time for us to revisit public health of countries in this part of the world. This is with the view to strengthen our public health systems and public health infrastructures. While the basic philosophy and principle of public health may still be valid today, its concept and approach may need reorientation in order to catch up with today's changing health scenario. The framework for health development has expanded significantly during the last three decades. Governments worldwide have been striving for their citizens to live longer and healthier lives. They would like to see that all their people lead a socially and economically productive life."

Dr Samlee concluded, "We all are here with the same objective. That objective is to find 
the best ways and means to strengthen public health systems and public health infrastructures in our countries. This is in order to ensure the most effective way to develop health of all our people; to ensure that our people will live longer, be healthier and wealthier. It is really a noble task to develop human resources because the development of human potential can serve countries more productively in both social and economic terms."

\section{Nippon Foundation/Sasakawa Memorial Health Foundation Advisory Board}

The annual meeting of the Nippon Foundation/Sasakawa Memorial Health Foundation Advisory Board was held in the Regional Office on 28-29 September 2007. Delivering his opening remarks on the occasion, the Regional Director, Dr Samlee Plianbangchang said, "On behalf of $\mathrm{WHO}, \mathrm{I}$ wish to convey our deep appreciation and thanks to The Nippon Foundation (TNF), and the Sasakawa Memorial Health Foundation (SMHF) for their strong and sustained support, for more than 30 years, to the $\mathrm{WHO}$ Global Leprosy Elimination programme."

Underscoring the important role of the regional focal persons, the Regional Director said that they "need to get actively involved in this exercise in close coordination and cooperation with the Goodwill Ambassador, Mr Sasakawa. Supporting the involvement of leprosy-affected people from the planning stage of development is essential indeed. We will review and examine together the issues and challenges involved in leprosy elimination, both regionally and globally. Here, we will learn from our strengths and weaknesses and we will jointly chalk out our plans for the future, along with our main partners - TNF and SMHF. We earnestly urge TNF/SMHF to continue their generous support so that together we can tackle the "unfinished agenda" more effectively, and move forward towards a "leprosy-free" world. I repeat that we will have to ensure sustained high-quality leprosy services through general health care systems; sustained and efficient surveillance systems; and further reduction in the burden of leprosy in all countries."

In conclusion, Dr Samlee said, "In the process, we have to adequately take into account the socioeconomic dimensions of the disease. And we have to devote all efforts to ensure that we are able to reach the unreached."

\section{Regional Conference of Parliamentarians on legislative and policy actions for promoting health}

The Regional Director, Dr Samlee Plianbangchang, addressed the inaugural session of the Regional Conference of Parliamentarians on "Legislative and Policy Actions for Promoting Health" held at Bali, Indonesia, on 8-9 October 2007.

In his inaugural speech, the Regional Director said, "All aspects of health development being multisectoral, the Parliamentarians' Forum is an appropriate place to discuss the multisectorality of health issues in various areas of concern. It is an important forum to reach consensus on the issues of priority public health problems. In this context, the WHO Regional Office for SouthEast Asia has been convening the Regional Parliamentarians' Conference on topical subjects from time to time, to discuss multisectoral actions in specific areas of health concern".

The Regional Director concluded, "In providing health-care services to their populations, governments have to ensure universal coverage by reaching the unreached. The unreached are usually the poor, underserved, underprivileged, marginalized and vulnerable people. In this context, we have to work towards social control of health technology - technology that is socially and culturally appropriate and acceptable to all people in the community, and which is economically affordable by everyone. 


\section{Country Cooperation Strategy - Bangladesh}

The WHO Country Cooperation Strategy (CCS) for Bangladesh was launched in Dhaka on 31 October 2007.

Speaking on the occasion, the Regional Director, Dr Samlee Plianbangchang, said, "The WHO country cooperation strategy is an important technical tool for facilitating collaboration between individual Member States and WHO. It is a tool which helps ensure effective WHO "country focus" and WHO country-specific approach. Such an approach ensures that WHO's work is really responsive to the needs and requirements of health development in the country concerned - the needs and requirements that are determined within the country's sociocultural, economic and political contexts. The WHO CCS is country specific; it is developed to guide the implementation of WHO collaborative activities in individual Member countries. This technical tool is implemented through the use of WHO resources knowledge, know-how, information and expertise, with necessary catalytic financial support. The priority concerns in the development of WHO CCS are the local health problems, issues and needs. At the same time, the WHO CCS is developed taking into account the global health policies and strategies, as mutually agreed to by all Member States at meetings of WHO's governing bodies. These are particularly those policies and strategies which are reflected in the WHO General Programme of Work and the Medium-term Strategic Plan," Dr Samlee clarified.

The Regional Director concluded, "I would also like to mention that, without the CCS, WHO collaboration with the country may not be adequately focused to ensure the required impact on the country's health problems and health situation. If implemented properly, this WHO CCS with its seven strategic directions, can take us a long way forward in strengthening the capacity of the country's health systems - capacity that is a prerequisite for sustainable health development and selfreliance that are required for the long-term health improvement for all people."

\section{Regional consultation on reducing workplace exposure through risk management toolkit}

The Regional Consultation on Reducing Workplace Exposure through Risk Management Toolkit was held from 19 to 22 November 2007 in Chennai, India.

In his message, the Regional Director, Dr Samlee Plianbangchang said, "One of the greatest challenges in occupational health is to develop programmes for the informal sector of industry where resources and technical expertise are usually scarce. The World Health Report 2002 found that during 2000, workrelated risk factors were responsible for the loss of about 30 million disability-adjusted life years (DALYs) globally. Countries of the SouthEast Asia Region lost over eight million DALYs (about $27 \%$ of the global total) and had the highest burden of disease attributable to occupational factors. Traditional risk assessment is undertaken through the measurement of hazardous substances in the work environment, followed by identification of appropriate control techniques. This is a very resource-intensive approach, which is often beyond the reach of the informal sector of industry."

Dr Samlee concluded, "While this is a new strategy for controlling occupational hazards, implementation challenges exist. No matter how impressive the information, it is only valuable when it can be made practically useful at the local level. Therefore, implementation systems must be established at every level. I am sure the toolkit approach will provide a powerful instrument for solving the occupational health problems of workers in the informal sector in this Region." 


\section{Emergency health actions}

The first meeting of the Regional Technical Advisory Group for Emergency Health Actions was held in New Delhi, India from 20-22 December 2007. Delivering his closing remarks at the concluding session of the meeting, Regional Director $\mathrm{Dr}$ Samlee Plianbangchang said, "First of all, let me thank all participants of the Advisory Group for their contributions to the success of this meeting. All the recommendations derived from the meeting will certainly take us a long way forward in strengthening the capacity of countries in the South-East Asia Region in the area of Emergency Preparedness and Response (EPR). As all of us are aware, countries in this Region are more prone to natural disasters, especially cyclones, floods and earthquakes. We have observed that during the recent past, there has been an increase both in the number and severity of floods and cyclones. This may have been contributed to by climate change, which is an important international concern. Therefore, the EPR programme will continue to be crucial in the foreseeable future", Dr Samlee stressed.

The Regional Director concluded, "This was the first meeting of the Advisory Group. A number of important technical issues were discussed and recommendations made. I now look forward to future meetings when new areas of our concern will be picked up for deliberations. To be perfect in EPR is indeed utopian. However, we can become effective and helpful to countries during emergencies. Country focus and a countryspecific approach will be important strategies for us regarding EPR work."

\section{Primary health care towards health for all}

The Regional Director, Dr Samlee Plianbangchang, delivered a keynote address at the International Conference on Primary Health Care, held on 4 February 2008 at
Chiang Mai University, Thailand. Speaking on the topic: "Primary Health Care towards Health for All", Dr Samlee said, "All of us must be aware that this year is the Thirtieth anniversary of the Alma Ata Declaration on Primary Health Care (PHC). This declaration was the outcome of the International Conference on Primary Health Care held in September 1978. The conference defined how "Health for All" could be achieved. A year prior to the Alma Ata conference, the Thirtieth World Health Assembly in 1977 decided, among other things, that the social target of governments and $\mathrm{WHO}$ in the coming decades should be the attainment by all citizens of the world by the year 2000 of a level of health that will permit them to lead a socially and economically productive life. As far as health is concerned, this decision of the World Health Assembly was really historic. The decision was popularly known as "Health for All by the year 2000". The overriding consideration underlying this decision was the increasing magnitude and severity of the world health problems, and the global concern with the unjust and unbalanced distribution of health resources throughout the world. The decision was based also on the consideration that health is a basic human right and a worldwide social goal. And that health is essential to the satisfaction of basic human needs, and to the quality of life of all people."

Dr Samlee concluded, "At this important international conference on $\mathrm{PHC}$, let us once again reaffirm our unwavering determination and commitment to the attainment of the social goal of health for all through the PHC approach. Let us continue our untiring efforts to advocate for more political will, and for decisive political commitment to the development of national public health systems based on primary health care. We all must ensure that PHC will continue to be firmly embedded as an indispensable element of all public health interventions to promote and support equity and social justice in health care around the world." 


\section{Publications corner}

Global surveillance, prevention and control of chronic respiratory diseases:

\section{a comprehensive approach}

Nonserial Publication

ISBN-13 9789241563468

ISBN-10 924156346X

Order Number 11500708

Price CHF 40.00 / US\$36.00

Developing countries: CHF 28.00

Chronic respiratory diseases, such as asthma and chronic obstructive pulmonary disease, kill more than four million people every year and affect hundreds of millions more. These diseases erode the health and well-being of the patients and have a negative impact on families and societies. This report raises awareness about the huge impact of chronic respiratory diseases worldwide, and highlights the risk factors as well as ways to prevent and treat these diseases.

\section{Prevention of cardiovascular disease: Guidelines for assessment and management of cardiovascular risk (with CD-ROM) \\ Nonserial Publication}

ISBN-13 9789241547178

ISBN-10 9241547170

Order Number 11500703

Price CHF 30.00 / US\$ 27.00

Developing countries: CHF 21.00

This publication provides guidance on reducing disability and premature deaths from coronary heart disease, cerebrovascular disease and peripheral vascular disease in people at high risk, who have not yet experienced a cardiovascular event. People with established cardiovascular disease are at very high risk of recurrent events and are not the subject of these guidelines. They have been addressed in previous $\mathrm{WHO}$ guidelines. The risk prediction charts that accompany these guidelines allow treatment to be targeted according to simple predictions of absolute cardiovascular risk.

\section{WHO Expert Committee on Problems Related to Alcohol Consumption}

Second Report; Technical Report Series, No 944

ISBN-13 9789241209441

ISBN-10 9241209445

Order Number 11000944

Price CHF 30.00 / US\$ 27.00

Developing countries: CHF 21.00

Since the last meeting of the $\mathrm{WHO}$ Expert Committee on Problems Related to Alcohol Consumption, $\mathrm{WHO}$ has undertaken a range of major initiatives to support Member States and reinforce the evidence on which policies work, to develop global and regional information systems, and to promote effective policies in health-care settings. These initiatives provide the background for the continuing role of $\mathrm{WHO}$ in supporting Member States to reduce the harm done by alcohol.

\section{Chemical safety of drinking-water:}

Assessing priorities for risk management

Nonserial Publication

Thompson, T., Fawell, J., Kunikane, S., 
Jackson, D., et al.

ISBN-13 9789241546768;

ISBN-10 924154676X;

Order Number 11500630

Price CHF 40.00 / US\$36.00;

Developing countries: CHF 28.00

This book provides guidance on the chemical safety of drinking water. Chemical contaminants of drinking water are often considered a lower priority than microbial contaminants, because adverse health effects from chemical contaminants are generally associated with long-term exposures, whereas the effects from microbial contaminants are usually immediate. Nonetheless, chemicals in water supplies can cause very serious problems. The objective of this publication is to help users at national or local level to establish which chemicals in a particular setting should be given priority in developing strategies for risk management and monitoring of chemicals in drinking water. The document will be useful to public health authorities, those responsible for setting standards and for surveillance of drinking-water quality, and to water supply agencies responsible for water quality management. In particular, this publication will be applicable in settings where information on actual drinking-water quality is limited, which is the case in many developing countries and in rural areas of some developed countries.

\section{Monitoring and evaluation of mental health policies and plans; mental health policy and service guidance package WHO Nonserial Publication \\ ISBN-13 9789241547154 \\ ISBN-10 9241547154 \\ Order Number 11500700 \\ Price CHF 20.00 / US\$ 18.00 \\ Developing countries: CHF 14.00}

This module examines key aspects of monitoring and evaluation as they relate to a mental health policy and plan, including how to monitor a plan and the different ways to evaluate a policy and plan. It presents a fivestep process for conducting evaluations and explains how results of an evaluation can be utilized to improve policies and plans. The module then provides a detailed case study of a policy and plan of a hypothetical country. It describes various ways that evaluation can be used over a period of time to assess and influence policy and the plan that arises from it, including the practical steps involved in policy evaluation and the policy decisions that can be made on the basis of monitoring and evaluations.

\section{Selection and use of essential medicines}

(The)

Report of the WHO Expert Committee, 2007 (including the 15th Model List of

Essential Medicines)

WHO Technical Report Series, № 946

ISBN-13 9789241209465

ISBN-10 9241209461

Order Number 11000946

Price CHF 25.00 / US\$25.00

Developing countries: CHF 17.50

This report presents the recommendations of the WHO Expert Committee responsible for updating the WHO List of Essential Medicines. The first part contains a summary of the Committee's considerations and justifications for additions and changes to the Model List, including its recommendations. Annexes to the main report include the revised version $\left(15^{\text {th }}\right)$ of the WHO Model List of Essential Medicines and a list of all items on the Model List sorted according to their five-level Anatomical Therapeutic Chemical (ATC) classification codes. Other annexes cover the proposed procedure for updating and disseminating the WHO Model List of Essential Medicines, and the revised procedure for updating the content of the Interagency Emergency Health Kit. 


\section{Assessing the financing, education, management and policy context for strategic planning of human resources for health}

ISBN-13 9789241547314

ISBN-10 9241547316

\section{Order Number 11500715}

Price: CHF 30.00/US\$30.00

Developing countries: CHF 21.00

This book contains a method for assessing the financial, educational and management systems and policy context, essential for strategic planning and policy development for human resources for health. This tool has been developed as an evidence-based comprehensive diagnostic aid to inform policymaking in low- and middle-income countries with regard to human resources for health. It does so in three stages by assessing the current status of the health workforce and capacities for health workforce policy implementation with a particular focus on four aspects - finance, education, management and policy-making, by identifying priority requirements and actions based on the current status of the health workforce and by showing how to sequence policies and draw up a prioritized action plan for human resources for health.

This tool is designed as an initial diagnostic instrument to be used in the process of developing a national strategic plan on human resources for health. It helps to provide a rapid initial assessment and a preliminary strategic plan as part of a longer-term and sustained process of human resources planning. It is not intended to assess the appropriateness of a workforce's skills-mix or the technical quality of pre-service curricula, which are the subjects of several other assessment tools. Rather, it focuses on determining system capacities to increase the effectiveness of the health workforce. 


\section{Guidelines for contributors}

THE Regional Health Forum seeks to inform and to act as a platform for debate by health personnel including policy-makers, health administrators, health educators and health communicators.

Contributions on current events, issues, theories and activities in all aspects of health development are welcome. Contributions should be original and contain something of interest to those engaged in health policy and practice, some lesson to be learned, some idea, something that worked, something that didn't work, in fact anything that needs to be communicated and discussed on a broader scale. Articles, essays, notes, news and views across the spectrum of health development will be published.

Every year, the April issue of the Forum is dedicated to the World Health Day theme of the year. Readers may send contributions relating to the theme for inclusion in the special issue.

Papers for submission should be forwarded to the Editor, Regional Health Forum, World Health Organization, Regional Office for South-East Asia, World Health House, Indraprastha Estate, Mahatma Gandhi Road, New Delhi 1 10002, India (E-mail address: editor@searo.who.int).

Contributions should:

- be in English;

- be written in an anecdotal, informal, lively and readable style (so that sophisticated technologies, for example, may be easily understood);

- be in MS Word and sent on-line to editor@searo.who.int

- not normally exceed 3000 words with an abstract (approx. 250 words) and a maximum of 30 references.

Letters to the editor should normally be between 500-1000 words with a maximum of six references.

\section{Responsibility of authors}

Authors are responsible for:

- ensuring that their contributions contain accurate data and references (and are requested to check the accuracy of both before submission);

- obtaining permission to use copyrighted material (if used). The letter granting such permission should be attached to the manuscript when submitted;

- obtaining permission from appropriate governmental authorities if the contribution pertains to a government programme/project and contains material/statistics/data derived from government sources;

- ensuring that all abbreviations (if used) are explained; 
- giving their full names, the name and address of their institutions, and an exact description of their posts;

- declaring sources of funding for the work undertaken, and

- disclosing at the time of submission, information on financial conflict of interest that may influence the manuscript. They may also choose to declare other interests that could influence the results of the study or the conclusions of the manuscript. Such information will be held in confidence while the paper is under review, and if the article is accepted for publication the editors will usually discuss with the authors the manner in which such information is to be communicated to the reader.

\section{Tables and illustrations}

- The use of tables and illustrations should be restricted to those that clarify points in the text.

- All illustrations and tables should be numbered consecutively and should be lightly marked on the back with the figure number, and the author's name indicated.

- Graphs and figures should be clearly drawn and all data identified.

- Photographs should be on glossy paper, preferably in black and white.

- Each table should be submitted on a separate sheet of paper.

\section{References}

- References should be numbered consecutively as they occur in the text.

- Journal titles should be written out in full (i.e. not abbreviated).

- A reference to a contribution in a book should include the chapter title and page range.

\section{Reprints}

Reprints of contributions are not produced but five printed copies of the issue will be supplied to the respective authors. An electronic version of the article in PDF format may also be made available to authors if they provide their e-mail addresses. 


\section{How to order WHO Publications}

New WHO publications are issued frequently. Requests for information about WHO publications and orders should be addressed to the nearest sales agent (listed below) or to WHO, New Delhi. Orders sent to New Delhi must be accompanied by payment in the form of a demand draft/Indian postal order/money order (prices include handling and postage charges). Orders from countries other than India can be addressed to the sales agent or WHO Representative in that country and are payable in local currency:

\section{INDIA}

\section{Southern India}

M/s New Century Book House (P) Ltd. 136 Anna Salai

Chennai 600 002, TAMIL NADU

\section{Western India}

$\mathrm{M} / \mathrm{s}$ Consumer Communications

52, Shafi Estate, Amar Mahal

Chembur

Mumbai 400 089, MAHARASHTRA

M/s K.M. Varghese \& Company Medical Book Distributors \& Publishers 104 Hind Rajasthan Building Dadasaheb Phalke Road, Dadar Mumbai 400 014, MAHARASHTRA

\section{Eastern India}

$\mathrm{M} / \mathrm{s}$ Insales India (P) Ltd.

1C/1\&2, Camac Court

25-B, Camac Street

Calcutta 700 016, WEST BENGAL

\section{BANGLADESH}

Ahsania Mission Book Distribution House House No. 1/A, Road No. 13,

Dhanmondi R.A. (Mirpur Road) 1st Floor, Dhaka-1209

Email:dam@drik.bgd.toolnet.org

\section{INDONESIA}

M/s C.V. Sagung Seto

Jalan Pramuka No. 27

P.O. Box 4661

Jakarta 10001

\section{NEPAL}

Everest Media International Services (P) Ltd.

Shanti Nagar-34

Block No. Kha-1-248

New Baneswar, Kathmandu

\section{THAILAND}

Suksit Siam Co. Ltd

113, 115 Fung Nakhon Road

Opp. Wat Rajbopith

Bangkok 10200

World Health Organization

Regional Office for South-East Asia

Indraprastha Estate

New Delhi 110 002, India

Attn: Publications (Sales)

Telephone: 2337-0804

Telefax: 2337-9395 / 2337-9507

Email:publications@searo.who.int 
